\title{
Progress in sacral neuromodulation of the lower urinary tract
}

Citation for published version (APA):

Scheepens, W. A. (2003). Progress in sacral neuromodulation of the lower urinary tract. [Doctoral Thesis, Maastricht University]. Universiteit Maastricht. https://doi.org/10.26481/dis.20031205ws

Document status and date:

Published: 01/01/2003

DOI:

10.26481/dis.20031205ws

Document Version:

Publisher's PDF, also known as Version of record

\section{Please check the document version of this publication:}

- A submitted manuscript is the version of the article upon submission and before peer-review. There can be important differences between the submitted version and the official published version of record.

People interested in the research are advised to contact the author for the final version of the publication, or visit the DOI to the publisher's website.

- The final author version and the galley proof are versions of the publication after peer review.

- The final published version features the final layout of the paper including the volume, issue and page numbers.

Link to publication

\footnotetext{
General rights rights.

- You may freely distribute the URL identifying the publication in the public portal. please follow below link for the End User Agreement:

www.umlib.nl/taverne-license

Take down policy

If you believe that this document breaches copyright please contact us at:

repository@maastrichtuniversity.nl

providing details and we will investigate your claim.
}

Copyright and moral rights for the publications made accessible in the public portal are retained by the authors and/or other copyright owners and it is a condition of accessing publications that users recognise and abide by the legal requirements associated with these

- Users may download and print one copy of any publication from the public portal for the purpose of private study or research.

- You may not further distribute the material or use it for any profit-making activity or commercial gain

If the publication is distributed under the terms of Article $25 \mathrm{fa}$ of the Dutch Copyright Act, indicated by the "Taverne" license above, 


\section{Progress in sacral neuromodulation of the lower urinary tract}


Vooral voor mijn vader $(† 19-7-1987)$ en moeder. Het is verbazingwekkend hoeveel we op elkaar lijken... 


\title{
Progress in sacral neuromodulation \\ of the lower urinary tract
}

\author{
PROEFSCHRIFT
}

ter verkrijging van de graad van doctor

aan de Universiteit Maastricht

op gezag van de Rector Magnificus,

Prof. dr. A.C. Nieuwenhuijzen Kruseman

volgens het besluit van het College van Decanen, in het openbaar te verdedigen

op vrijdag 5 december 2003 om 14:00 uur precies

door

Wouterus Antonius Scheepens 


\section{Promotor:}

Prof. dr. Ph.E.V. van Kerrebroeck

\section{Co-promotores:}

Dr. R.A. de Bie

Dr. E.H.J. Weil

Beoordelingscommissie:

Prof. dr. F. Spaans, (voorzitter)

Prof. dr. C.G.M.I. Baeten

Prof. dr. ir. P.A. van den Brandt

Prof. dr. A.A.B. Lycklama à Nijeholt (Universiteit Leiden)

Prof. dr. H.W.M. Steinbusch

ISBN 90-9017544-X

(C) Wout Scheepens, Eindhoven 2003

Productie: Datawyse Maastricht

This publication of this thesis was realised by financial support of:

Medtronic Interstim, Bard, Hitachi Medical Systems, Karl Storz endoscopy, Lilly BV, Sanofi Synthelabo, Stichting Wetenschappelijke Activiteiten Maastrichtse Urologie, Uroplasty: manufacturer of Macroplastique, Yamanouchi, MSD 


\section{Contents}

Chapter 1 General introduction and aims of the thesis 7

Chapter 2 Anatomy and physiology of the lower urinary tract

Chapter 3 Sacral neuromodulation: historical background and clinical aspects

Intermezzo: technical aspects

Chapter 4 Predictive factors for sacral neuromodulation in chronic lower urinary tract dysfunction

Chapter 5 Urodynamic results of sacral neuromodulation correlate with subjective improvement in patients with an overactive bladder

Chapter 6 Unilateral versus bilateral sacral neuromodulation in patients with chronic lower urinary tract dysfunction

Chapter 7 Long-term efficacy and safety results of the two-stage implantation technique in sacral neuromodulation

Chapter 8 Buttock placement of the implantable pulse generator: a new implantation technique for sacral neuromodulation - a multicentre study

Chapter 9 Summary and conclusions

Chapter 10 Samenvatting en conclusies

Dankwoord en Curriculum Vitae 



\section{Chapter 1}

General introduction and aims of the thesis 


\section{General introduction}

Dysfunctions of the lower urinary tract (such as urgency frequency, urge incontinence and urinary retention) constitute an important quality-of-life issue and contribute substantially to increasing general health-care $\operatorname{costs}^{1.5}$. Urinary incontinence affects millions of people world-wide. At least 10 million people in the United States are affected. The direct annual costs for care of patients with incontinence were estimated to exceed $\$ 10.3$ billion in the United States alone ${ }^{6}$. A survey among Dutch women aged 45 to 70 shows a prevalence of incontinence for $57.1 \%$ of these women. Stress urinary incontinence affected $28.7 \%$. Urge urinary incontinence affected $5.6 \%$, and $22.7 \%$ of the patients reported mixed (stress and urge) urinary incontinence?. Six percent of the patients, mainly with urge incontinence, reported serious discomfort. Loss of urinary control affects the social, psychological, domestic, occupational, physical and sexual lives of $15 \%$ to $30 \%$ of women of all ages ${ }^{8}$.

It has become clear that effective treatments are a necessity in order to cure patients suffering from these conditions and to reduce health-care costs. Treatment of lower urinary tract dysfunction can be conservative (medication or physiotherapy) or invasive (bladder augmentation or urinary diversion). However, standard treatment options, widely available for patients with incontinence and urinary retention, do not provide satisfactory results for $62.6 \%$ of the patients". For a number of years, sacral neuromodulation has been advocated more and more often when conservative therapies fail, and it should at least be considered prior to more invasive surgery ${ }^{10}$. Sacral neuromodulation is based on the application of electrical currents to sacral nerves in order to rebalance or modulate the reflexes involved in lower urinary tract control.

This therapy was introduced about 20 years ago as a result of expanding knowledge about physiology and pathophysiology of lower urinary tract function and dysfunction. One of the advantages of this therapy is that it can be tested on an individual patient before implantation. Randomised controlled trials have proven the efficacy of sacral neuromodulation therapy, but knowledge about predictive factors and options for improving therapy outcome are unknown ${ }^{11-15}$.

\section{Aims of this thesis}

Sacral neuromodulation is now an established therapy for the treatment of lower urinary tract dysfunctions. However, the broad variation in the patients' clinical presentation makes it difficult to provide exact information about therapy success or failure ${ }^{14}$. Moreover, a positive test for sacral neuromodulation therapy does not guarantee therapy success after implantation. The degree of success after implantation may diminish for individual cases ${ }^{11-13}$.

This thesis focuses on the identification of predictive factors and studies to improve therapy outcome for patients with overactive bladders (urinary urge incontinence and urgency frequency) and urinary retention. This thesis starts with an overview of the anatomy and physiology of the lower urinary tract, the development of sacral neuromodulation and its clinical and technical aspects 
(Chapters 2 and 3). Chapter 4 discusses predictive factors for sacral neuromodulation, while Chapter 5 provides urodynamic evidence for neuromodulation efficacy. Chapters $6-8$ provide information about various sacral neuromodulation techniques in subgroups of patients. Chapters 9 and 10 conclude this thesis.

\section{References}

1. Grimby A, Milsom I, Molander U, Wiklund I and Ekelund P: The influence of urinary incontinence on the quality of life of elderly women. Age-Ageing, 22: 82-89, 1993.

2. Kobelt-Nguyen G, Johannesson M, Mattiasson A and Abrams P: Correlations between symptoms of urge incontinence and scores of a generic quality of life instrument (SF-36) and health status measurements (EuroQol) and between changes in symptoms and Qol scores: 27th Annual Meeting of ICS. (Abstract) Yokahama, Japan, Neurourol Urodyn. 16,1997 .

3. Swami S and Abrams P: Urge incontinence. Urol Clin North Am. 23: 417-425, 1996.

4. Samuelsson E, Mansson L and Milsom I: Incontinence aids in Sweden: users and costs. BJU Int. 88: 893-898, 2001.

5. Langa K, Fultz N, Saint S, Kabeto M and Herzog A: Informal caregiving time and costs for urinary incontinence in older individuals in the United States. J Am Geriatr Soc. 50: 733-737, 2002.

6. Consensus Conference: Urinary incontinence in adults. JAMA. 261: 2685-2690, 1989.

7. Vaart C van der, Leeuw J de, Roovers J and Heintz A: De invloed van urine-incontinentic op de kwaliteit van leven bij thuiswonende Nederlandse vrouwen van 45-70 jaar. Ned Tijdschr Geneeskd. 144: 894-7, 2000.

8. Jackson S: The patient with an overactive bladder-symptoms and quality-of-life issues. Urology, 50: 18-22, 1997.

9. Janknegt R, Hassouna M, Siegel S, Schmidt R, Gajewski J, Rivas D, Elhilali M, Milam D, Kerrebroeck P van, Dijkema $\mathrm{H}$ et al: Long-term effectiveness of sacral nerve stimulation for refractory urge incontinence. Eur Urol. 39: 101-106, 2001.

10. Kerrebroeck P van: A treatment algorithm for the overactive bladder. Br J Urol. 83: 29-30, 1999.

11. Schmidt R, Jonas U, Oleson K, Janknegt R, Hassouna M, Siegel S and Kerrebroeck P van: Sacral nerve stimulation for treatment of refractory urinary urge incontinence. Sacral Nerve Stimulation Study Group. J Urol. 162: 352-357, 1999.

12. Hassouna MM, Siegel SW, Lycklama à Nyeholt AA, Elhilali MM, Kerrebroeck PE van, Das AK, Gajewski JB, Janknegt RA, Rivas DA, Dijkema H et al:: Sacral neuromodulation in the treatment of urgency-frequency symptoms: a multicenter study on efficacy and safety. J Urol. 163: 1849-1854, 2000.

13. Jonas U, Fowler CJ, Chancellor MB, Elhilali MM, Fall M, Gajewski JB, Grünewald V, Hassouna MM, Hombergh U, Janknegt R et al: Efficacy of sacral nerve stimulation for urinary retention: results 18 months after implantation. J UroL. 165: 15-19, 2001.

14. Koldewijn EL, Rosier PF, Meuleman EJ, Koster AM, Debruyne FM and Kerrebroeck PE van: Predictors of success with neuromodulation in lower urinary tract dysfunction: results of trial stimulation in 100 patients. J Urol. 152: 2071-2075, 1994.

15. Bemelmans BL, Mundy AR and Craggs MD: Neuromodulation by implant for treating lower urinary tract symptoms and dysfunction. Eur Urol. 36: 81-91, 1999. 
Chapter 2

\section{Anatomy and physiology of the lower urinary tract}




\section{Anatomy and physiology of the lower urinary tract}

The lower urinary tract consists of the urinary bladder, the lower one-third of both ureters together with the ureterovesical junction, the prostate gland and the urethra with its smooth and striated muscles, and the external urethral sphincter. The urinary bladder is a hollow, musculomembranous organ for storing urine. In adults, the empty bladder lies in the pelvis minor, slightly posterior and slightly superior to the pubic bone. As it fills, it ascends into the pelvis major; a very full bladder may even reach the level of the umbilicus. The bladder has a strong muscular wall, which has the ability to distend. Normally, the bladder can hold $400-500 \mathrm{ml}$ of fluid. The mucous membranes of the bladder are usually lined with six layers of transitional epithelium, which are loosely connected to its muscular wall, excepting the trigone. Again excepting the trigone (because of its firm attachment to the muscular layer of the bladder), an empty bladder is thrown into numerous rugae. The muscular wall of the bladder is predominantly composed of smooth muscle, called the detrusor. Classically, the detrusor consists of three muscle layers; the fibres of the outer layer run longitudinally, those of the middle layer form a circular pattern, and those of the inner layer compose a criss-cross arrangement'. Towards the bladder neck, these muscle fibres form the involuntary internal sphincter. Some of the fibres run radially and assist in opening the internal urethral orifice during bladder contraction. The muscle fibres in the male bladder neck are continuous with the stroma of the prostate, and in the female bladder, they are continuous with the muscle fibres in the wall of the urethra ${ }^{2-6}$.

The functions of the lower urinary tract are to store urine for periods of time to allow daily activities and to evacuate urine at behaviourally suitable times and places. These seemingly simple functions require a rather complicated neuronal control system. The micturition reflex is a spinal cord reflex, but it can be inhibited or facilitated by centres in the brain. In the normal situation, voiding is inhibited, for instance, during fight and flight reactions. When voiding would be inconvenient, centres in the central nervous system inhibit the bladder. In addition, during an activation of the micturition reflex, bladder contraction can be prevented by tonic contraction of the pelvic floor. This provides afferent input to the nervous system, preventing bladder contraction. Bladder neurophysiology and innervation is a complex system, of which the mechanisms remain partly unexplained ${ }^{\top}$.

The parasympathetic motor neurons of the detrusor are located in the intermediolateral cell group of the spinal segments S2-S4 (figure 1). These preganglionic fibres terminate in ganglion cells near the bladder wall. The postganglionic nerve fibres innervate the detrusor.

The sympathetic preganglionic motor neurons are located in the intermediolateral cell group of the lower thoracic and upper lumbar spinal cord segments. The axons are routed to the sympathetic chain. The postganglionic sympathetic fibres traverse the hypogastric and pelvic plexus. They innervate the bladder and, mainly, the bladder neck. It is alleged that these fibres play an important role in the urine storage phase $\mathrm{e}^{\mathrm{t} . .11}$. 


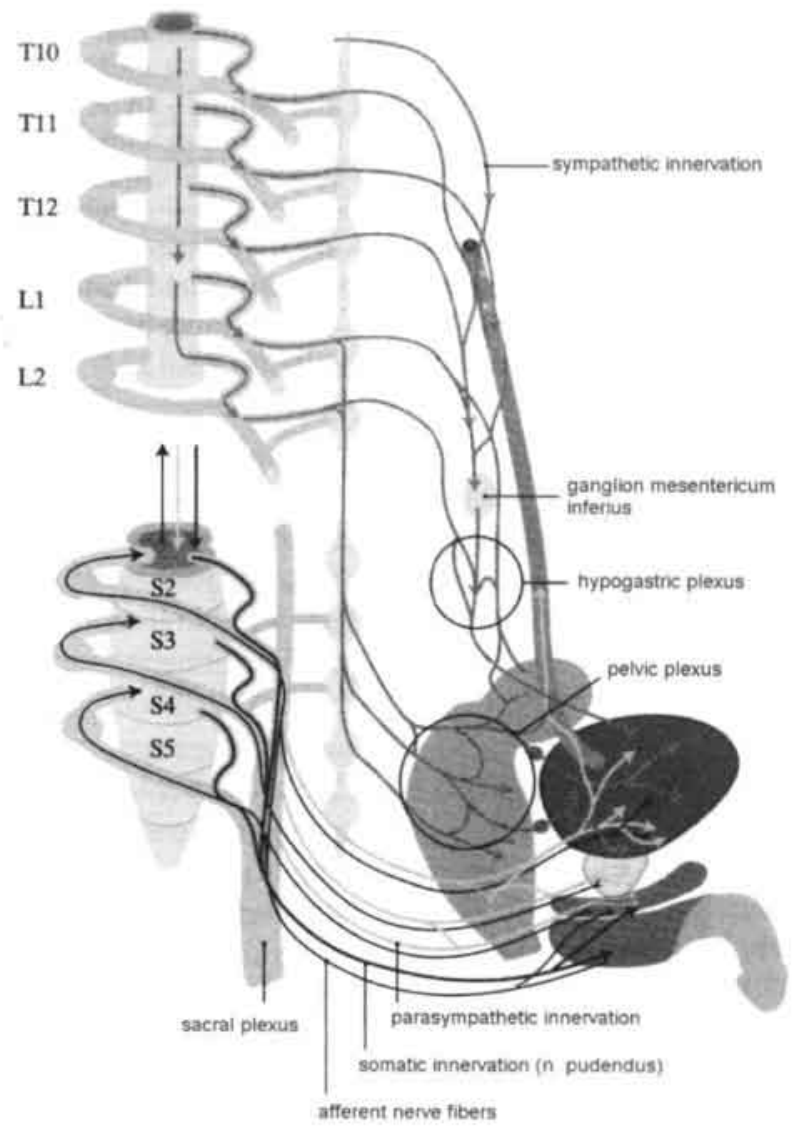

Figure 1. Schematic overview of the innervation of the lower urinary tract

(From WA Scheepens and PhEV van Kerrebroeck: Ned Tijdschr Geneesk 2001; 145:1730-1734. with permission)

The pudendal nerve innervates the external urethral sphincter. The motor neurons are located in Onuf's nucleus, named after Onufrowicz, in the spinal segments S1-S3 ${ }^{12}$. In 1925, Barrington discovered that micturition was not organised at the level of the spinal cord, but that coordination of voiding was located in the pons $^{13}$. This pontine micturition centre (PMC), or Barrington's area, can be divided in an $M$ region and an $L$ region because of their medial $(M)$ and lateral $(L)$ localisation in the pons ${ }^{14}$. The $\mathrm{M}$ region projects to the sacral intermediolateral cell group, which contains the parasympathetic preganglionic motor neurons of the urinary bladder. Stimulation of this area (in animal studies) showed a decrease of urethral pressure, followed by an increase of vesical pressure, causing normal micturition $^{14,15}$. 
The $\mathrm{L}$ region projects to Onuf's nucleus. Stimulation of this area induces a pelvic floor contraction and an increase in urethral pressure ${ }^{14}$. A bilateral lesion of the L region results in the inability to store urine, and urine is evacuated due to detrusor overactivity and urethral relaxation ${ }^{16}$. Therefore, the $\mathrm{M}$ and $\mathrm{L}$ regions function respectively as the on and off switch of micturition. The PMC can be modulated by inhibitory and excitatory influences from areas of the brain rostral to the pons ${ }^{17}$. This provides the ability to void at suitable times and places.

Afferent autonomic innervation from the bladder starts from the mechanoreceptors in the bladder wall. These mechanoreceptors project through the pelvic nerve to the spinal cord segments via slowly conducting $A \delta$ and $C$ fibres. Stimulation of the mechanoreceptors (A $\delta$ fibres) initiates the micturition reflex ${ }^{18}$.

The innervation of the bladder is bilateral, as each half of the bladder has its own defined innervation ${ }^{19,20}$. The small-diameter bladder afferents ( $\mathrm{A} \delta$ and $\mathrm{C}$ fibres) conduct the sensations of noxious stimuli (C fibres), urge to void and bladder distension due to bladder filling (A $\delta$ fibres) ${ }^{3}$. The bladder is innervated bilaterally, via the pelvic nerve. This suggests that bilateral sacral neuromodulation may provide better results than unilateral stimulation (Chapter 6).

Somatic afferent fibres from the bladder tension receptors pass through the pelvic nerve, and these project to Onuf's nucleus ${ }^{3,21,22}$. The pelvic floor and external urethral sphincter afferent $(A \alpha)$ fibres pass through the pudendal nerve to the spinal cord. It is suggested that these neurons also project to Onuf's nucleus, indicating a myotonic reflex $\operatorname{arc}^{21}$. Afferents from the urethra, travelling via the pudendal nerve, convey sensations of pain, temperature and passage of urine. These afferents and the pelvic floor afferents have a modulatory influence on micturition.

Micturition is a coordinated action between the detrusor and the urethral sphincter. During bladder filling, the bladder is relaxed and the sphincter is contracted; during voiding this activation pattern is reversed. For the bladder to function correctly, the PMC should be informed about bladder filling, in order to "know" when the bladder is full and voiding should take place. Afferent information about bladder filling, provided by bladder wall mechanoreceptors, is conducted via the $A \delta$ fibres in the pelvic nerve to the spinal cord. From there, the information is conveyed to the periaqueductal grey (PAG), where it is processed and filtered. When bladder filling makes voiding necessary, the $\mathrm{M}$ region is activated, if it is not inhibited by influences from other sources. This results in a coordinated voiding reflex because inhibitory fibres from the $M$ region also project on the Onuf's nucleus, initiating pelvic floor and external urethral sphincter relaxation ${ }^{23}$. The micturition reflex is organised as a positive feedback mechanism. A reflex detrusor contraction generates increased tension in the bladder wall, which leads to further activation of the mechanoreceptors and therefore to a stronger excitatory drive on the PMC. This reflex progressively escalates until pelvic motor output is maximal. When urine enters the bladder neck and the urethra, the reflex is further facilitated by the activation of urethral afferents ${ }^{24}$. This all-or-nothing behaviour of the parasympathetic motor output to the bladder provides a strong detrusor contraction and an efficient bladder evacuation. At the end of this cycle, the bladder is empty and the pressure will drop. This ends the afferent drive of the 
The L region projects to Onuf's nucleus. Stimulation of this area induces a pelvic floor contraction and an increase in urethral pressure ${ }^{14}$. A bilateral lesion of the $\mathrm{L}$ region results in the inability to store urine, and urine is evacuated due to detrusor overactivity and urethral relaxation ${ }^{16}$. Therefore, the $\mathrm{M}$ and $\mathrm{L}$ regions function respectively as the on and off switch of micturition. The PMC can be modulated by inhibitory and excitatory influences from areas of the brain rostral to the pons $^{17}$. This provides the ability to void at suitable times and places.

Afferent autonomic innervation from the bladder starts from the mechanoreceptors in the bladder wall. These mechanoreceptors project through the pelvic nerve to the spinal cord segments via slowly conducting $A \delta$ and $C$ fibres. Stimulation of the mechanoreceptors (A $\delta$ fibres) initiates the micturition reflex ${ }^{1 \mathrm{t}}$.

The innervation of the bladder is bilateral, as each half of the bladder has its own defined innervation ${ }^{19,20}$. The small-diameter bladder afferents ( $\mathrm{A} \delta$ and $\mathrm{C}$ fibres) conduct the sensations of noxious stimuli (C fibres), urge to void and bladder distension due to bladder filling (A $\delta$ fibres). The bladder is innervated bilaterally, via the pelvic nerve. This suggests that bilateral sacral neuromodulation may provide better results than unilateral stimulation (Chapter 6).

Somatic afferent fibres from the bladder tension receptors pass through the pelvic nerve, and these project to Onuf's nucleus ${ }^{3,21,22}$. The pelvic floor and external urethral sphincter afferent $(A \alpha)$ fibres pass through the pudendal nerve to the spinal cord. It is suggested that these neurons also project to Onuf's nucleus, indicating a myotonic reflex $\operatorname{arc}^{21}$. Afferents from the urethra, travelling via the pudendal nerve, convey sensations of pain, temperature and passage of urine. These afferents and the pelvic floor afferents have a modulatory influence on micturition.

Micturition is a coordinated action between the detrusor and the urethral sphincter. During bladder filling, the bladder is relaxed and the sphincter is contracted; during voiding this activation pattern is reversed. For the bladder to function correctly, the PMC should be informed about bladder filling, in order to "know" when the bladder is full and voiding should take place. Afferent information about bladder filling, provided by bladder wall mechanoreceptors, is conducted via the $A \delta$ fibres in the pelvic nerve to the spinal cord. From there, the information is conveyed to the periaqueductal grey (PAG), where it is processed and filtered. When bladder filling makes voiding necessary, the $\mathrm{M}$ region is activated, if it is not inhibited by influences from other sources. This results in a coordinated voiding reflex because inhibitory fibres from the $\mathrm{M}$ region also project on the Onuf's nucleus, initiating pelvic floor and external urethral sphincter relaxation ${ }^{23}$. The micturition reflex is organised as a positive feedback mechanism. A reflex detrusor contraction generates increased tension in the bladder wall, which leads to further activation of the mechanoreceptors and therefore to a stronger excitatory drive on the PMC. This reflex progressively escalates until pelvic motor output is maximal. When urine enters the bladder neck and the urethra, the reflex is further facilitated by the activation of urethral afferents ${ }^{24}$. This all-or-nothing behaviour of the parasympathetic motor output to the bladder provides a strong detrusor contraction and an efficient bladder evacuation. At the end of this cycle, the bladder is empty and the pressure will drop. This ends the afferent drive of the 


\section{References}

1. Juskiewenski S, Vaysse P, Guitard J, Moscovici J and Fourtanier G: Innervation of the bladder and urethra. Anat Clin. 2: 243-263, 1981.

2. Brooks JD: Anatomy of the lower urinary tract and male genitalia, in Walsh PC, Retik AB, Vaughan ED and Wein AJ: Campbell's Urology. Philadelphia, Saunders, pp 89-128, 1998.

3. De Groat W: Anatomy and physiology of the lower urinary tract. Urol Clin North Am. 20: 383-401, 1993.

4. Moore K: Clinically oriented anatomy. Baltimore, Williams and Wilkins, pp 243-322, 1992.

5. Gray H: Gray's anatomy. New York, Churchill Livingstone, pp 1813-1847, 1995.

6. DeLancey J: Anatomy and embryology of the lower urinary tract. Obstet Gynecol Clin North Am. 16: 717-731, 1989.

7. Bradley W and Sundin T: The physiology and pharmacology of urinary tract dysfunction. Clin Neuropharmacol. 5: 131-158, 1982.

8. Torrens $\mathrm{M}$ and Morrison J: The physiology of the lower urinary tract, in Torrens $\mathrm{M}$ and Morrison J: Human physiology. Heidelberg, London, Springer, pp 333-350, 1987.

9. Pick $\mathrm{J}$ : The autonomic nervous system: morphological, comparative, clinical and surgical aspects. Philadelphia, Lippincott, 1970.

10. De Groat W and Saum W: Sympathetic inhibition of the urinary bladder and of pelvic ganglionic transmission in the cat. J Physiol. 220: 297-314, 1972.

11. Gosling JA and Dixon JS: The structure and innervation of smooth muscle in the wall of the bladder neek and proximal urethra. BJU Int. 47: 549-558, 1975.

12. Juenemann KP, Lue TF, Schmidt RA and Tanagho EA: Clinical significance of sacral and pudendal nerve anatomy. J Urol. 139: 74-80, 1988.

13. Barrington FJF: The effect of lesions of the hind-and mid-brain on micturition in the cat. QJ Exp Psychol. 15: 81-102, 1925.

14. Holstege G, Griffiths D, de Wall H and Dalm E: Anatomical and physiological observations on supraspinal control of bladder and urethral sphincter muscles in the cat. J Comp Neurol. 250: 449-461, 1986.

15. Zermann DH, Ishigooka M, Doggweiler $\mathrm{R}$ and Schmidt RA: Central autonomic innervation of the lower urinary tract - a neuroanatomy study. World J Urol. 16: 417-422, 1998.

16. Griffiths D, Holstege G, De Wall H and Dalm E: Control and coordination of bladder and urethral function in the brain stem of the cat Neurourol Urodyn. 9: 63-82, 1990.

17. Blok BF: The organization of central control of micturition in cats and in humans. Anatomical and physiological investigations. Groningen, University of Groningen, Thesis, 1998.

18. Iggo A: Tension receptors in the stomach and urinary bladder. J Physiol. 128: 593-607, 1955.

19. Diokno AC, Davis R and Lapides J: The effect of pelvic nerve stimulation on detrusor contraction. Invest Urol. 11: 178-181, 1973.

20. Ingersoll EH, Jones LL and Hegre ES: Effect on urinary bladder of unilateral stimulation of pelvic nerves in the dog. Am J Physiol. 189: 167-172, 1957.

21. Kinder MV, Bastiaanssen EH, Janknegt RA and Marani E: Neuronal circuitry of the lower urinary tract; central and peripheral neuronal control of the micturition cycle. Anat Embryol Berl. 192: 195-209, 1995. 
22. De Groat W and Steers W: Autonomic regulation of the urinary bladder and sexual organs, in Loewy A and Spyer K: Central regulation of autonomic functions. Oxford, Oxford University Press, 1990, pp 310-323.

23. Blok BFM, Weerd $\mathrm{H}$ de and Holstege $\mathrm{G}$ : The pontine micturition center projects to sacral cord GABA immunoreactive neurons in the cat. Neurosci Lett. 233: 109-112, 1997.

24. Mazières L, Jiang C and Lindström S: Bladder parasympathetic response to electrical stimulation of urethral afferents in the cat. Abstract. Neurourol Urodyn. 16: 471-472, 1997.

25. Blok B, Willemsen A and Holstege G: A PET study on brain control of micturition in humans. Brain. 120: 111-121, 1997.

26. Blok B, Sturms L and Holstege G: A PET study on cortical and subcortical control of pelvic floor musculature in women. J Comp Neurol. 389: 535-544, 1997.

27. Lindström S and Sudsuang R: Functionally specific bladder reflexes from pelvic and pudendal nerve branches; an experimental study in the cat. Neurourol Urodyn. 8: 392 $393,1989$.

28. Fall $\mathrm{M}$ and Lindstrom S: Electrical stimulation: a physiologic approach to the treatment of urinary incontinence. Urol Clin North Am. 18: 393-407, 1991.

29. Shaker H, Wang Y, Loung D, Balbaa L, Fehlings MG and Hassouna MM: Role of Cafferent fibres in the mechanism of action of sacral nerve root neuromodulation in chronic spinal cord injury. BJU Int. 85; 905-910, 2000. 


\section{Chapter 3}

\section{Sacral neuromodulation: historical background and clinical aspects}

Adapted from:

Neuromodulation and neurostimulation in urology

WA Scheepens \& PhEV van Kerrebroeck

Nederlands Tijdschrift voor Geneeskunde 2001;145: 1730-1734

Original title: Neuromodulatic en neurostimulatie in de urologie

and

Sacral neuromodulation: the indications

WA Scheepens, GA van Koeveringe, EHJ Weil \& PhEV van

Kerrebroeck

Nederlands Tijdschrift voor Urologie 2002; 1:13-21

Original title: Sacrale neuromodulatie: de indicatiestelling 


\section{Sacral neuromodulation: historical background}

In 1790, Luigi Galvani stimulated a frog's leg, which induced a muscle contraction. This formed the foundation for electrophysiology. Functional electrical stimulation (FES) was used in the development of functional anatomy, research in brain function and cardiac pacing. In the field of urology, electrical currents were and are used particularly in the bladder, pelvic floor muscles and sacral nerve roots, and such currents are tested for their ability to support lower urinary tract functions.

FES can be divided into two major forms of stimulation, namely, neuromodulation and neurostimulation. Neuromodulation aims at remodelling the neuronal reflex loops by stimulating sensory afferent nerve fibres that influence these reflex loops. Stimulation at a higher amplitude will not automatically increase the therapeutic effect. Neurostimulation aims at stimulating motor efferent fibres, which elicits a direct response from the effector organ; for instance, a muscle contraction. Stimulation at a higher level will cause a greater response from this effector organ.

Initial research focussed mainly on neurostimulation to treat neurologically impaired and neurologically intact patients. Different methods to induce a bladder contraction and urethra relaxation (normal voiding) included: direct detrusor stimulation $^{1.3}$, stimulation of peripheral nerves of the bladder ${ }^{+6}$, pelvic floor stimulation $^{7.9}$ and stimulation of sacral roots ${ }^{10.12}$.

\section{Stimulation of sacral roots}

A paper that evoked great scientific interest was published in 1971. Nashold et al. reported the successful implantation of a neural prosthesis in the sacral segment of the spinal cord. The implant was used to activate voiding in a patient with spinal injury ${ }^{10}$. As a result of this research, Jonas and Tanagho tried to improve this prosthesis, because not only the bladder, but also the urinary sphincter contracted during stimulation. Hence, little to no urine was expelled from the bladder $^{11}$. This led to the development of poststimulus voiding, where urine was expelled from the bladder after stimulation. At the same time, Brindley developed a neurostimulator so that patients with spinal cord injuries could evacuate urine ${ }^{13}$.

In the search for the optimal stimulation site, Thüroff determined the existence of two nuclei, a pudendal nucleus and a parasympathetic nucleus. The striated urethral sphincter is also innervated via the pudendal nucleus ${ }^{12}$. There was no basic difference between this and the innervation of other pelvic floor muscles ${ }^{12}$. Thus, separate stimulation of either nucleus was difficult, and extradural sacral root stimulation was tried, where electrodes were placed at the site of the sacral nerve roots.

During these experiments, it became clear that stimulation with lower amplitudes does not induce a detrusor contraction, but does increase urethral pressure. Consequently, afferent pudendal nerve stimulation induced bladder inhibition and sacral nerve stimulation induced bladder contraction. Therefore, sacral nerve root stimulation was primarily developed for patients with spinal cord injuries; and afferent pudendal nerve stimulation, for patients without neurogenic bladders. Schmidt and Tanagho continued their experiments and developed sacral 
neuromodulation for patients with idiopathic bladder overactivity. The first results were astonishing: the voiding symptomatology of $70 \%$ of the patients with bladder overactivity diminished, in some cases by as much as $90 \%$. These patients were refractory to conservative therapies ${ }^{1+19}$.

Nowadays, sacral neuromodulation provides effective help for patients with refractory voiding dysfunctions like urinary retention, urgency frequency and urge incontinence. Sacral neuromodulation has evolved into a therapy, which is clinically applied on allmost a world-wide basis ${ }^{20-22}$.

\section{Sacral neuromodulation: clinical aspects}

To evaluate the eligibility of a patient with chronic lower urinary tract dysfunction for sacral neuromodulation therapy, a test stimulation called peripheral nerve evaluation (PNE) is performed ${ }^{23}$. This test consists of two parts. The first part is the acute phase, where a test needle in inserted into the third foramen of the sacrum to stimulate the root of S3. Proper motoric and sensory reactions should be obtained during this test. During the subchronic phase, the sacral root is continuously stimulated for 4 to 7 days. During the acute phase of the test, the S3 root is stimulated. This should elicit a pelvic floor contraction that pulls the perineum inward (bellows-like contraction). At this time, a plantar flexion of the first digit of the ipsilateral foot can be seen. The patient often has a tingling, pulsing sensation in the anal, perineal, vaginal, and/or scrotal region. Next, a thin, temporary test lead is placed in proximity to the nerve through the needle (Figure 1).

While the sacral root is continuously being stimulated for 4 to 7 days in an outpatient setting, the patient should keep accurate voiding diaries. The final voiding parameters are determined from these diaries. The voiding diary data obtained during the PNE are compared to voiding diary data noted before and after the evaluation. If an improvement of at least $50 \%$ in the most important voiding parameters is obtained (Table 1), the patient is considered a suitable candidate for permanent implantation of a sacral neuromodulation system ${ }^{23.24}$. Generally, $50 \%$ to $60 \%$ of the patients tested are selected for implantation ${ }^{25.30}$.

Table 1. Peripheral nerve evaluation

\begin{tabular}{ll}
\hline Idiopathic lower urinary tract dysfunction & Primary voiding parameters \\
\hline Urgency frequency & $\begin{array}{l}\text { Number of voids in } 24 \text { hours } \\
\text { Volume voided per void } \\
\text { Degree of urgency before void }\end{array}$ \\
Urge incontinence & Number of voids in 24 hours \\
& Volume per void \\
& Degree of urgency before void \\
& Number of leakages in 24 hours \\
& Pad use \\
Urine retention & Volume per void \\
& Volume per catheterisation \\
\hline
\end{tabular}




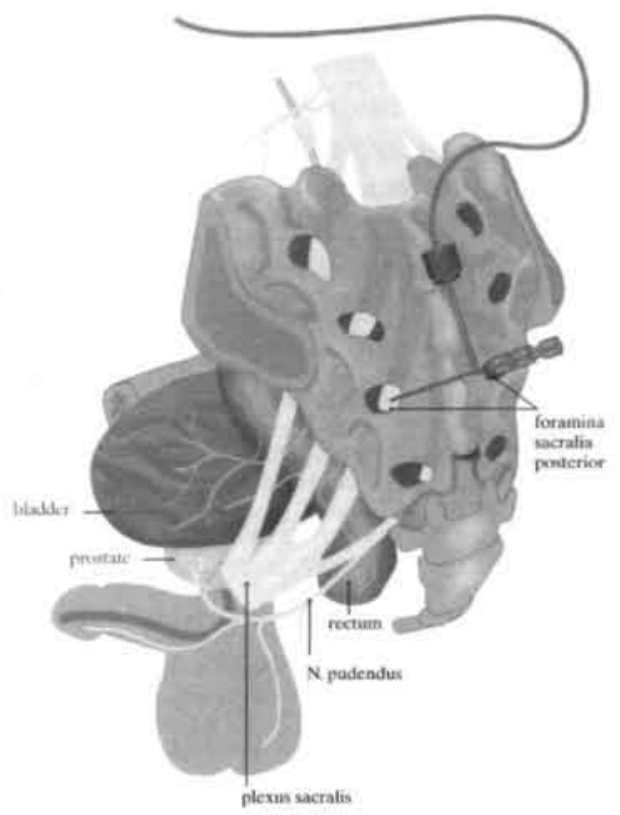

Figure 1. Test stimulation setting for evaluating the eligibility of a patient for implantation of the sacral neuromodulation system. A test needle is used to probe and localise the third sacral foramen. Next, a thin, temporary test lead is placed in proximity to the nerve via the needle, and connected to an external stimulator for 4 to 7 days. The patient can adjust the amplitude level at the correct level. (WA Scheepens and PhEV van Kerrebroeck: Ned Tijdschr Geneesk 2001;145:1730-1734, with permission)

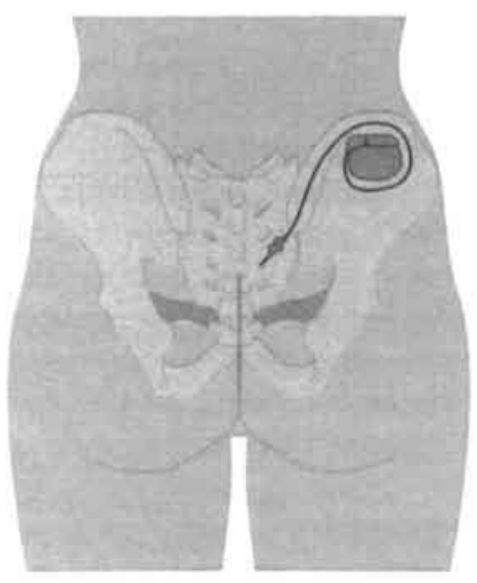

Figure 2. Buttock implantation of the neuromodulation system, with the IPG in the gluteal area and the lead in S3. (From WA Scheepens and PhEV van Kerrebroeck: Ned Tijdschr Geneesk 2001; 145:1730-1734, with permission) 
The patient is in a prone antidecubitus position and under general anaesthesia during the implantation. An incision is made near the sacrum, and the third sacral foramen is visualised. The permanent electrode is placed in this foramen. The correct position of the electrode is verified by obtaining the proper responses (bellows-like contraction and plantar flexion of the first digit of the ipsilateral foot), as they were observed during the acute phase of the PNE. Then, the electrode is fixed to the periosteum of the sacrum. The neurostimulator, or implantable pulse generator (IPG), is implanted. Originally, the IPG was implanted in the anterior abdominal wall. An alternative method is to place the IPG in the subcutaneous fat at the level of the upper, outer quadrant of the buttock (Figure 2). The latter position provides several advantages over the abdominal position, such as a shorter operation time and fewer postoperative complications (Chapter 8). After the IPG has been activated, the patient can determine the level of stimulation by remote control (Figure 3$)^{23}$.

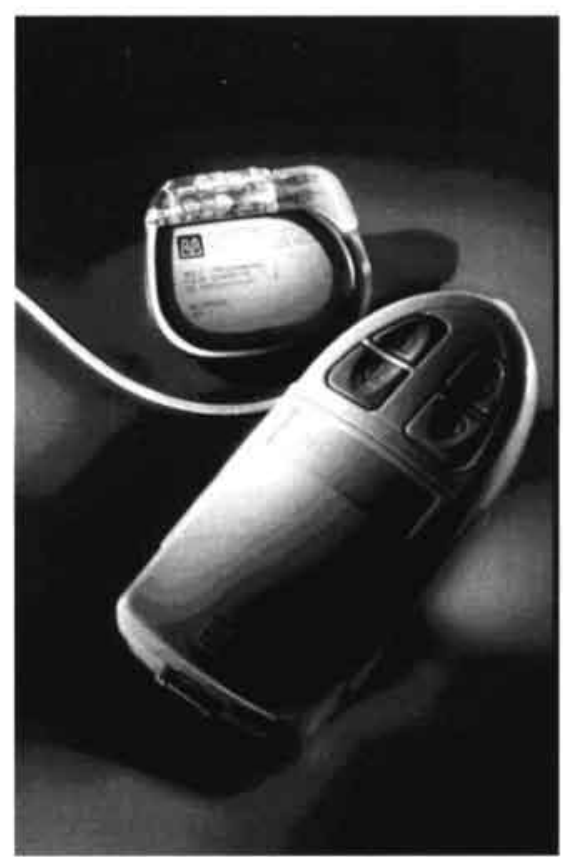

Figure 3. The Implantable pulse generator and its remote control, which the patient can use to apply the proper stimulation threshold

The battery of a functional and programmed stimulator has a longevity of 8 to 10 years. When the battery is empty, the whole IPG should be replaced. During the first experiences and utilisation of this technique, recurrent re-operations were needed because of technical failure and pain near the IPG ${ }^{20-22}$. 
The determination of the indications for this technique continues. The American Food and Drug Administration (FDA) has approved this therapy for the indications urgency frequency, urge incontinence and urinary retention, but other possible future indications are neurogenic bladder dysfunction, interstitial cystitis and genitourinary pain syndromes.

\section{Indication: idiopathic lower urinary tract dysfunction}

\section{Overactive bladder (urgency frequency syndrome and urinary urge incontinence)}

Bladder overactivity with involuntary loss of urine, along with a strong desire to void, that forms a social and hygienic problem is called urge incontinence. Bladder overactivity without urinary incontinence is called urgency frequency. This syndrome is characterised by a strong desire to void (urgency) that leads to frequent bladder evacuation (frequency), therefore voiding small amounts of urine. This is often accompanied by the feeling of incomplete emptying of the bladder. There may also be pain in the pubic region or at the level of the urethra or perineum. Urological entities that are related to this syndrome are: urethral syndrome, pelvic pain syndrome, prostatodynia, orchialgia and interstitial cystitis. Comorbidity, like irritable bowel syndrome and proctalgia, is often seen ${ }^{3 !}$.

Loss of urine in urinary urge incontinence is more apparent than in urgency frequency syndrome. Incontinence can be accompanied by involuntary bladder contractions that are objectified with urodynamic investigations (motor urge incontinence), or there may be no bladder contractions (sensory urge incontinence). Both can be accompanied by urethral relaxations. If a manifest neurological disease is the cause of the bladder overactivity (neurogenic bladder), the condition is called neurogenic detrusor overactivity ${ }^{31}$.

Knowledge about the aetiology of bladder overactivity is limited. The current, hypothesis is that a disturbed equilibrium between inhibiting and excitatory neuronal bladder control results in a hyperexcitatory micturition reflex ${ }^{32-35}$.

Initial treatment options for the overactive bladder encompass pharmacological therapy (anticholinergic drugs) and physiotherapy (pelvic floor exercises, bladder training, biofeedback and functional (intravaginal or intra-anal) electrical stimulation). This last type of physiotherapy is, in fact, also a form of neuromodulation ${ }^{9,36}$. These limited, conservative treatment options often do not result in sufficient symptom reduction. If such options (including combinations of them) have been exhausted and further treatment is desirable, then sacral neuromodulation becomes a therapeutic option. One should at least consider and try it before opting for more invasive therapies such as urinary diversion or ileocystoplasty ${ }^{37.38}$.

The results for sacral neuromodulation therapy in the treatment of bladder overactivity are promising, especially if one realises that previously no other therapeutic options were available, except the more invasive surgical interventions. A multicentre trial involving patients with urgency frequency syndrome shows that $56 \%$ of the patients who received implants improved significantly $(>50 \%)$, versus $4 \%$ in the control group (delayed implant) ${ }^{21}$. Another $32 \%$ improved somewhat, but the same improvement percentage was seen in the control group. Finally, $8 \%$ of the patients with implants did not improve at all, but $64 \%$ in the control group did. Because of therapy failure, $4 \%$ of the patients had their implants 
removed, and conservative treatment was given. These results remained constant after 12 months of follow-up ${ }^{21}$. Because of sacral neuromodulation therapy, $47 \%$ of the urge-incontinence patients were completely dry, and the symptoms of another $28 \%$ decreased by at least $50 \%{ }^{20}$.

The SF-36 Health Survey was used to measure the quality of life. It showed a significant improvement for patients with urgency frequency syndrome and urge incontinence 20,21 . Corroborative evidence from other comparable studies conform to these findings ${ }^{26-28,39-42}$.

Interstitial cystitis is a chronic inflammation of the bladder that is accompanied by evident and severe bladder symptomatology. It resembles bladder overactivity in some ways. There are indications that sacral neuromodulation could have a positive effect on these chronic cystitis symptoms ${ }^{43-46}$. Especially frequency and pain symptoms are expected to diminish due to sacral neuromodulation therapy. In general, bladder overactivity symptoms are a good indication for this therapy, and a considerable number of the patients benefit from sacral neuromodulation.

\section{Bladder evacuation disorders (complete and incomplete urinary retention)}

An altogether different type of problem is caused by bladder evacuation disorders or chronic (nonobstructive) urinary retention. Patients suffering from this syndrome are totally dependent on clean, intermittent self-catheterisation. Urinary retention may also be incomplete. These patients are still able to void, but residual urine in the bladder is chronically more than $100 \mathrm{ml}$. An acontractile detrusor, detrusor underactivity or urethral overactivity can cause urinary retention. The symptoms consist of hesitation, decreased flow and the feeling of residual urine in the bladder. If the cause of an acontractile detrusor is neurological, the condition is called bladder areflexia. The idiopathic, nonobstructive hypocontractile or acontractile bladder is still an unresolved entity. Besides bladder overdistention, other causes might be abnormal voiding habits or forced toilet training. This could evolve to manifest symptomatology in the long term, and it is also called "dysfunctional voiding" when the striated peri-urethral muscle contracts during voiding. Age also plays a prominent role, as the ageing bladder decreases in contractility in both men and women.

Another cause of urinary retention is abnormal urethral function, such as urethral overactivity. If the pelvic floor is tetanically contracted, bladder contraction is inhibited even to the point where the bladder will overflow. Fowler et al. described Fowler's syndrome in young women with chronic urinary retention ${ }^{\text {f }}$. EMG measurements show that the external urethral sphincter is abnormally active As a consequence, the sphincter is not able to relax, which causes urinary retention ${ }^{47}$. Especially these patients benefit from sacral neuromodulation ${ }^{\text {th }}$.

One of the theories about the working mechanism in retention patients is based on this fact. Sacral neuromodulation provides sensation and localisation of the pelvic floor. This ensures that voluntary control to relax the pelvic floor is regained ${ }^{14}$. Another theory proclaims that the bladder inhibition caused by chronic overactive contraction of the pelvic floor is diminished by stimulation of the sacral roots, which restores the natural equilibrium. The latter theory is more coherent with the fact that continuous stimulation is needed for a prolonged effect. This theory especially applies to patients with Fowler's syndrome. In this 
"ideal" patient group, success rates up to $68 \%$ during PNE are achieved, which is above average ${ }^{48}$.

Initial treatment of chronic urinary retention consists of clean, intermittent self-catheterisation of the bladder. Conservative treatment options, such as pharmacological interventions and physiotherapy (i.e. biofeedback), provide some benefit. However, pharmacological therapies using muscarinergic agonists are of limited value. If conservative treatments fail and further therapy is needed, sacral nerve stimulation should at least be considered before more invasive surgical interventions are chosen.

Multicentre studies show that, after implantation, $69 \%$ of the patients were able to void to completion and intermittent self-catheterisation was no longer required. The number of intermittent self-catheterisations needed in another $14 \%$ of the patients was reduced by at least $50 \%$. After 18 months of follow-up, the results were still good for $69 \%$ of the patients, unsatisfactory for $13 \%(<50 \%$ decrease in the intermittent self-catheterisations needed) and there was no benefit at all for $17 \%$ \%2,3, 39, $41,49 \cdot 52$. There is an on-and-off phenomenon especially for urinary retention patients; more than for overactive bladder patients. In other words, sacral neuromodulation either works or it does not for urinary retention, while there is a more gradual scale in the effect for urge incontinence.

Therefore, sacral neuromodulation should be a treatment option early after the patient's diagnostic work-up. A urodynamic investigation during PNE is preferable to determine whether the bladder is completely emptied, whether there is detrusor contraction, and whether voiding takes place solely because of urethral relaxation. Only when sacral neuromodulation produces no clinical benefit can more experimental interventions, for instance detrusormyoplasty using the latissimus dorsi muscle, be considered ${ }^{53}$.

\section{Indication: neurngenic bladder dysfunction}

As already mentioned, sacral neuromodulation can be successful for patients with idiopathic bladder dysfunctions. It is quite possible that sacral neuromodulation can also benefit patients with neurogenic bladder dysfunctions. Long-term results (43 months) of 23 patients with neurogenic bladder dysfunction and their treatment with sacral neuromodulation have been reported upon ${ }^{54}$. Incontinence diminished significantly for all parients, and five patients were completely dry. The mean voiding frequency decreased from 16.1 to 8.2 times per day. There was also an improvement from a urodynamic point of view. These results show that there may be an indication for treating patients with neurogenic bladder dysfunctions with sacral neuromodulation. However, patients with neurogenic bladder dysfunctions have a four times greater chance of an unsuccessful PNE than patients with idiopathic voiding dysfunctions (Chapter 4). Furthermore, patients with spinal cord injuries may suffer from neurogenic detrusor overactivity and possibly sphincter-detrusor dyssynergia. Therefore, the problems of incontinence, high pressures in the bladder (hence, reflux) and urinary retention remain. 


\section{A treatment algorithm for sacral neuromodulation}

Sacral neuromodulation by means of PNE should be considered for neurogenic and non-neurogenic functional bladder dysfunctions for which conservative treatments have failed (according the algorithm provided in Figure 4) ${ }^{55}$. Predictive factors forecast therapy outcome for patient categories in general. However, there is only one way to evaluate possible successful therapy outcome for the individual patient, and that is with a trial stimulation using the PNE.

The fact that detrusor overactivity (during a urodynamic investigation) remains present, does not correlate with the eventual clinical benefit of sacral neuromodulation ${ }^{56}$. Therefore, detrusor overactivity during sacral neuromodulation may not form an exclusion criterion for implantation. However, ambulant cystometries provide a more quantitative method for bladder overactivity. Improvement during these measurements did provide a correlation between urodynamic parameters and sacral neuromodulation results (Chapter 5).

If there is still any doubt about the quality of the PNE and the voiding diary data, it is possible to perform a two-stage implant (Chapter 7). Next to the knowledge about the predictive factors (Chapter 4), we depend on the selection of patients via PNE. This is a minimally invasive, outpatient method that is easy to perform. Therefore, this test should be considered for all patients with lower urinary tract dysfunctions (neurogenic or non-neurogenic) that are refractory conservative treatments.

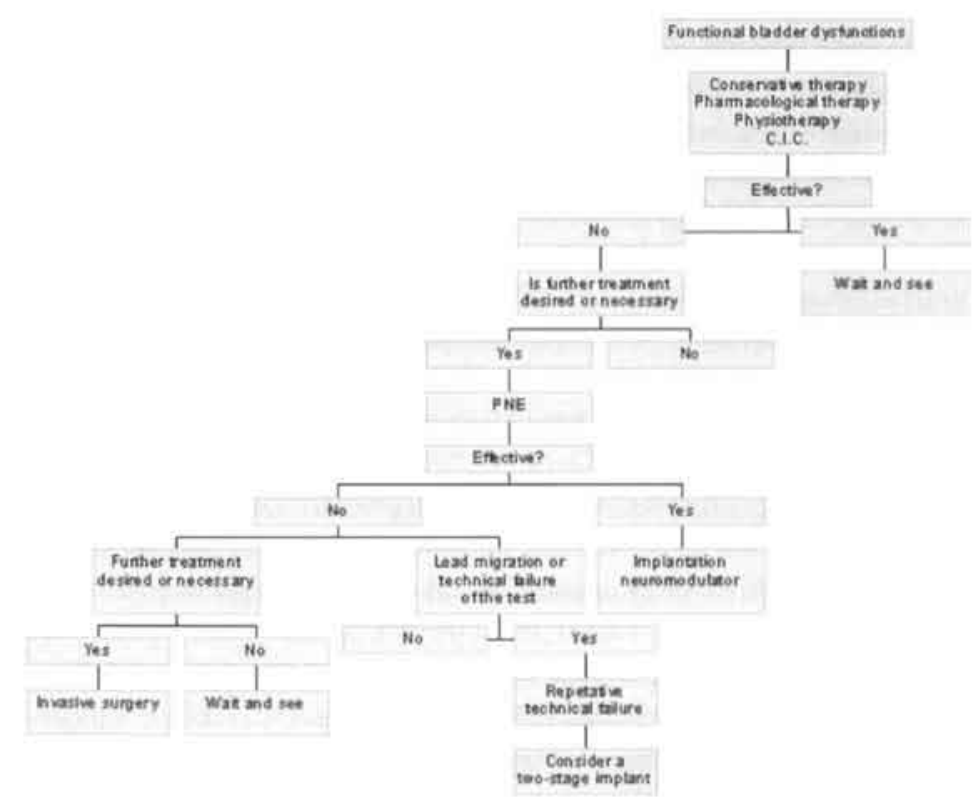

Figure 4. Algorithm for sacral neuromodulation. c.i.c.: clean intermittent selfcatheterisation. 


\section{References}

1. Bradley WE, Wittmers LE, Chou SN and French LA: Use of a radio transmitter receiver unit for the treatment of neurogenic bladder: a preliminary report. J Neurosurg. 19: 782$786,1962$.

2. Ebner $A$, Jiang $C$ and Lindström S: Intravesical electrical stimulation - an experimental analysis of the mechanism of action. J Urol. 148: 920-924, 1992.

3. Jonas $U$ and Hohenfellner R: Late results of bladder stimulation in 11 patients:Followup to 4 years. J Urol. 113: 565-568, 1978.

4. Ingersoll EH, Jones LL and Hegre ES: Effect on urinary bladder of unilateral stimulation of pelvic nerves in the dog. Am J Physiol. 189: 167-172, 1957.

5. Hald T, Argawal G and Kantrowitz A: Studies in stimulation of the bladder and its motor nerves. Surgery. 60: 848-856, 1966.

6. Bradley WE, Timm GW and Scott FB: A decade of experience with electronic stimularion of the micturition reflex. Urol Int. 26: 283-303, 1971.

7. Glen E: Guard for intra-anal-plug electrode. Lancet. 2: 325-326, 1969.

8. Fall $\mathrm{M}$, Erlandson BE, Sundin $\mathrm{T}$ and Waagstein $\mathrm{F}$ : Intravaginal electrical stimulation. Clinical experiments on bladder inhibition. Scand J Urol Nephrol. suppl 44: 41-48, 1978.

9. Lindström S, Fall M, Carlsson C and Erlandson B: The neurophysiological basis of bladder inhibition in response to intravaginal electrical stimulation. J Urol. 129: 405-410, 1983.

10. Nashold B, Friedman $\mathrm{H}$ and Boyarsky S: Electrical activation of micturition by spinal cord stimulation. J Surg Res. 11: 144-170, 1971.

11. Jonas $\mathrm{U}$ and Tanagho EA: Studies on the feasibility of urinary bladder evacuation by direct spinal cord stimulation. II. Poststimulus voiding: a way to overcome outflow resistance. Investig Urol. 13: 151-153, 1975.

12. Thüroff JW, Bazeed MA, Schmidt RA, Luu DH and Tanagho EA: Regional topography of spinal cord neurons innervating pelvic floor muscles and bladder neck in the dog: a study by combined horseradish peroxidase histochemistry and autoradiography. Urol Int. 37: 110-120, 1982.

13. Brindley GS: An implant to empty the bladder or close the urethra. J Neurol Neurosurg Psychiatry, 40: 358-369, 1977.

14. Schmidt R: Advances in genitourinary neurostimulation. Neurosurgery, 19: 1041-1044, 1986.

15. Schmidt RA: Applications of neurostimulation in urology. Neurourol Urodyn. 7: 585 $592,1988$.

16. Schmidt R, Senn E and Tanagho EA: Functional evaluation of sacral nerve root integrity. Report of a technique. Urology. 35: 388-392, 1990.

17. Schmidt RA and Tanagho EA: Klinische Anwendung der Neurostimulation. Urologe A. 29: 191-195, 1990.

18. Tanagho EA: Concepts of neuromodulation. Neurourol Urodyn. 12: 487-488, 1993.

19. Tanagho EA: Neuromodulation in the management of voiding dysfunction in children. J Urol. 148: 655-657, 1992.

20. Schmidt R, Jonas U, Oleson K, Janknegt R, Hassouna M, Siegel S and van Kerrebroeck P: Sacral nerve stimulation for treatment of refractory urinary urge incontinence. Sacral Nerve Stimulation Study Group. J Urol. 162: 352-357, 1999. 
21. Hassouna MM, Siegel SW, Lycklama à Nyeholt AA, Elhilali MM, van Kerrebroeck PE, Das AK, Gajewski JB, Janknegt RA, Rivas DA, Dijkema H et al: Sacral neuromodulation in the treatment of urgency-frequency symptoms: a multicenter study on efficacy and safety. J Urol. 163: 1849-1854, 2000.

22. Jonas U, Fowler CJ, Chancellor MB, Elhilali MM, Fall M, Gajewski JB, Grünewald V, Hassouna MM, Hombergh U, Janknegt R et al: Efficacy of sacral nerve stimulation for urinary retention: results 18 months after implantation. J Urol. 165: 15-19, 2001.

23. Siegel S: Management of voiding dysfunction with an implantable neuroprosthesis. Urol Clin North Am. 19:163-170, 1992.

24. Thon and Gruenwald: Neurostimulation. Urology: 295-302, 1993.

25. Bemelmans BL, Mundy AR and Craggs MD: Neuromodulation by implant for treating lower urinary tract symptoms and dysfunction. Eur Urol. 36: 81-91, 1999.

26. Bosch J and Groen J: Sacral (S3) segmental nerve stimulation as a treatment for urge incontinence in patients with detrusor instability: results of chronic electrical stimulation using an implantable neural prosthesis. J Urol. 154: 504-507, 1995.

27. Bosch JL and Groen J: Sacral nerve neuromodulation in the treatment of patients with refractory motor unge incontinence: long-term results of a prospective longitudinal study. J Urol. 163: 1219-1222, 2000.

28. Dijkema H, Weil E, Mijs P and Janknegt R: Neuromodulation of sacral nerves for incontinence and voiding dysfunctions. Clinical results and complications. Eur Urol. 24: 72-76, 1993.

29. Goodwin RJ, Swinn MJ and Fowler CJ: The neurophysiology of urinary retention in young women and its treatment by neuromodulation. World J Urol. 16: 305-307, 1998.

30. Janknegt RA, Weil EH and Eerdmans PH: Improving neuromodulation technique for refractory voiding dysfunctions: two-stage implant. Urology. 49: 358-362, 1997.

31. Abrams P, Cardozo L, Fall M, Griffiths D, Rosier P, Ulmsten U, van Kerrebroeck P, Victor $A$ and Wein $A$ : The standardisation of terminology of lower urinary tract function: report from the standardisation sub-committee of the international continence society. Am J Obstet Gynecol. 187: 116-126, 2002.

32. Blaivas JG: Pathophysiology of lower urinary tract dysfunction. Clin Obstet Gynecol. 12: 295-309, 1985.

33. De Groat W: Central nervous system control of micturation, in O'Donnell P: Urinary Incontinence. St Louis, Mosby, 1997, pp 33-47.

34. Blok B, De Weerd $\mathrm{H}$ and Holstege $\mathrm{G}$ : Ultrastructural evidence for a paucity of projections from the lumbosacral cord to the pontine micturition center or M-region in the cat: a new concept for the organization of the micturition reflex with the periaqueductal gray as central relay. J Comp Neurol. 359: 300-309, 1995.

35. Zvara P, Sahi S and Hassouna MM: An animal model for the neuromodulation of neurogenic bladder dysfunction. Br J Urol. 82: 267-271, 1998.

36. Fall M: Does electrostimulation cure urinary incontinence? J Urol. 131: 664-667, 1984.

37. Swami S and Abrams P: Urge incontinence. Urol Clin North Am. 23: 417-425, 1996.

38. Kerrebroeck P: A treatment algorithm for the overactive bladder. Br J Urol. 83: 29-30, 1999.

39. Elabbady A, Hassouna $M$ and Elhilali $M$ : Neural stimulation for chronic voiding dysfunctions. J Urol. 152: 2076-2080, 1994. 
40. Janknegt R, Van Kerrebroeck P, Lycklama a Nijeholt A, Schmidt R, Hassouna M and Siegel S: Sacral nerve modulation for urge incontinence; a multinational, multicenter randomized study (abstract). J Urol. 157: 1237, 1997.

41. Weil E, Ruiz Cerda J, Eerdmans P, Janknegt R and Van Kerrebroeck P: Clinical results of sacral neuromodulation for chronic voiding dysfunction using unilateral sacral foramen electrodes. World J Urol. 16: 313-321, 1998.

42. Weil E, Ruiz Cerda J, Eerdmans P, Janknegt R, Bemelmans B and van Kerrebroeck P: Sacral root neuromodulation in the treatment of refractory urinary urge incontinence: a prospective randomized clinical trial. Eur Urol. 37: 161-171, 2000.

43. Zermann D, Weirich $\mathrm{T}$, Wunderlich $\mathrm{H}$, Reichelt $\mathrm{O}$ and Schubert J: Sacral nerve stimulation for pain relief in interstitial cystitis. Urol Int. 65: 120-121, 2000.

44. Chai TC, Zhang C, Warren JW and Keay S: Percutaneous sacral third nerve root neurostimulation improves symptoms and normalizes urinary HB-EGF levels and antiproliferative activity in patients with interstitial cystitis, Urology. 55: 643-646, 2000.

45. Maher C, Carey M, Dwyer P and Schluter P: Percutaneous sacral nerve root neuromodulation for intractable interstitial cystitis. J Urol. 165: 884-886, 2001.

46. Zermann D, Ishigooka $M$ and Schubert J: Percutaneous sacral third nerve root neurostimulation improves symptoms and normalizes urinary HB-EGF levels and antiproliferative activity in patients with interstitial cystitis. Urology. 55: 643-646, 2001.

47. Fowler CJ, Christmas TJ, Chapple CR, Parkhouse HF, Kirby RS and Jacobs HS: Abnormal electromyographic activity of the urethral sphincter, voiding dysfunction, and polycystic ovaries: a new syndrome? BMJ. 297: 1436-1438, 1988.

48. Swinn M, Kitchen N, Goodwin R and Fowler C: Sacral neuromodulation for women with Fowler's syndrome. Eur Urol. 38: 439-443, 2000.

49. De Ridder D, Van Cleynenbreugel B and Baert L: Sacral nerve stimulation for female urinary retention: a two year follow-up (abstract). Eur Urol. 35: 17, 1999.

50. Shaker $\mathrm{H}$ and Hassouna $\mathrm{M}$ : Sacral root neuromodulation in idiopathic nonobstructive chronic urinary retention. J Urol. 159: 1476-1478, 1998.

51. Swinn M, Goodwin R and Fowler C: Sacral neuromodulation for young women in urinary retention (abstract). Eur Urol. 35: 17, 1999.

52. Vapnek J and Schmidt R: Restoration of voiding in chronic urinary retention using the neuroprosthesis. World J Urol. 9: 142-144, 1991.

53. Stenzl A, Ninkovic M, Kolle D, Knapp R, Anderl H and Bartsch G: Restoration of voluntary emptying of the bladder by transplantation of innervated free skeletal muscle. Lancet. 351: 1483-1485, 1998.

54. Chartier-Kastler EJ, Bosch RJLH, Perrigot M, Chancellor MB, Richard F and Denys P: Long-term results of sacral nerve stimulation (S3) for the treatment of neurogenic refractory urge incontinence related to detrusor hyperreflexia. J Urol. 164: 1476-1480, 2000.

55. Scheepens WA, Koeveringe van GA, Weil EHJ and Kerrebroeck PEV: Sacrale Neuromodulatie: de Indicatiestelling. Ned Tijdschr Urol. 1: 13-21, 2002.

56. Bosch JL and Groen J: Neuromodulation: urodynamic effects of sacral (S3) spinal nerve stimulation in patients with detrusor instability or detrusor hyperflexia. Behav Brain Res. 92: $141-150,1998$. 


\section{Intermezzo}

Sacral neuromodulation: technical aspects 


\section{Sacral neuromodulation: technical aspects}

Very little has been published about stimulation parameters for sacral neuromodulation. It is important to apply the correct sacral nerve stimulation (SNS) to obtain a good result. This section describes one method of postoperative management, postoperative programming of the implantable pulse generator (IPG), stimulation parameters at follow-up and electrophysiological considerations.

\section{Starting up the IPG}

If the patient is mobilised after surgery, then on the first day after implantation, the IPG can be activated with the programmer (Medtronic Interstim Console Programmer Model 7432). A sacral radiograph will show whether the electrode is correctly positioned and provides a control for follow-up. The programmer is used to review the parameter settings. For the quadripolar IPG, Medtronic Interstim model 3023, standard settings are:

Table 1. Standard IPG values

\begin{tabular}{lcl}
\hline Parameter & Standard IPG setting & Allowed range \\
\hline Amplitude (V) & 0.0 & $0.0-10.5$ \\
Pulse Width (msec) & 210 & $60-450$ \\
Rate $(\mathrm{Hz})$ & 31 & $2-130$ \\
Mode & cont & cont $/$ cyc \\
IPG battery & OK & OK/Low $/$ EOL \\
IPG output & Off & On $/$ Off \\
Polarity (+.Off,-) & $3+0$. & $\mathrm{C}(+/$ off $) 0-3$ \\
\hline
\end{tabular}

Cont: continues stimulation; cyc: cyclic stimulation (on and off);

EOL: end of life (battery is empty)

\section{Rate adjustment}

The first and most important step is to decrease the rate of the pulses from 31 $\mathrm{Hz}$, which is the standard setting when starting up the IPG, to $10-15 \mathrm{~Hz}$. Pulse rates at $31 \mathrm{~Hz}$ may be painful to the patient. Stimulation of nerves at high frequencies may even cause nerve damage and thereby compromise the success of the therapy. Therefore, it is advisable to set the rate at 10 to $15 \mathrm{~Hz}$. Besides reducing the possibility of nerve damage, this will increase the battery life. This pulse rate is also used in vaginal and rectal stimulation in the treatment of the overactive bladder ${ }^{24}$, and is advised for sacral nerve stimulation ${ }^{5.1}$.

\section{Optimisation of the pulse width}

The rectangular shape of the pulses generated by the IPG can be divided into amplitude and pulse width. The area of this rectangular shape correlates with the amount of charge applied to the nerve (Figure 1). Thus, changing either the pulse width or the amplitude can alter the amount of energy applied to the nerve. 


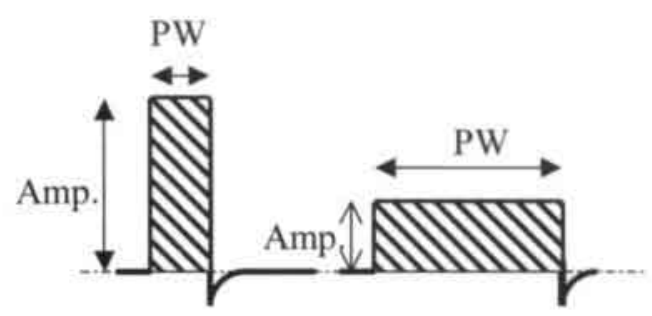

Area $=$ amplitude $($ volts $) \times$ pulse width $=$ amount of charge

Figure 1. Pulses made by the IPG divided into amplitude and pulse width Amp., amplitude; PW, pulse width

The amount of charge also represents the energy drawn from the battery. To extend the lifespan of the battery, the use of battery energy needs to be optimised. The pulse width for minimum energy use is at the bottom of the energy curve (Figure 2). Therefore, a pulse width of $210 \mathrm{msec}$ should be used, although slight variations are allowed.

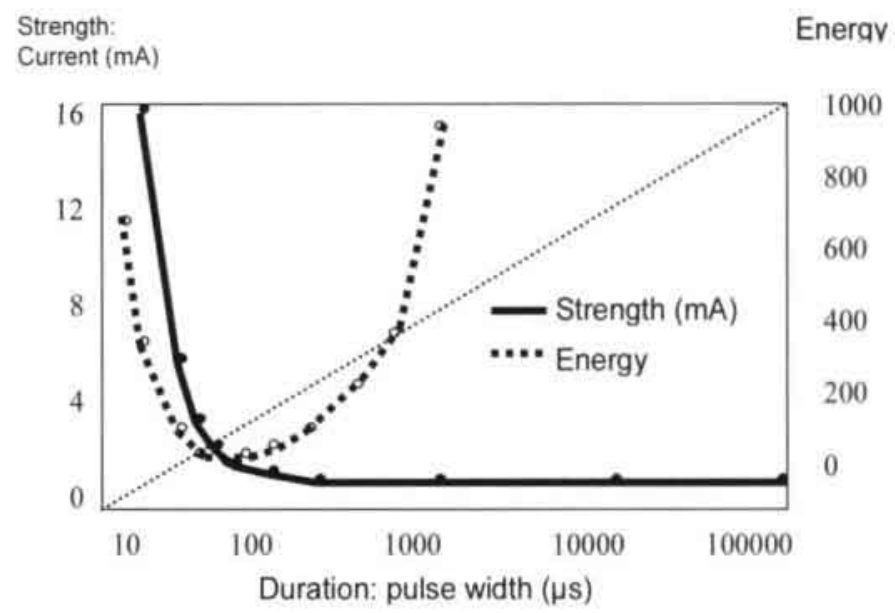

Figure 2. Strength-duration curve

\section{Mode of stimulation adjustment}

Postoperatively, the IPG uses continuous stimulation to begin with. Later on, at follow-up, this mode can be changed to cyclic stimulation. This can be done when high amplitudes are necessary to obtain depolarisation of the nerve. The cyclic mode can also be programmed if the patient gets used to the stimulation 
and has to increase the amplitude frequently. In both cases, the cyclic mode will save battery energy, as it is turned off for some time. If the cyclic mode is used, a rhythm of $10 \mathrm{sec}$ on and $2 \mathrm{sec}$ off can be used. Other configurations can also be used if needed. A soft-start mode can be programmed, in which case the IPG will use the programmed time to increase the amplitude at the start of the "on" time. Most patients prefer to use the soft-start mode. Some soft-start times can be sampled and the patient is asked to say which time is the most convenient.

\section{IPG-battery, IPG output}

The IPG battery should indicate "OK" after implantation. The IPG output, which was off, is turned on.

\section{Polarity}

The IPG is started with unipolar stimulation (case: positive and electrodes 1, 2, 3, or 0 : negative). This is because the implanted system has a lower impedance in unipolar stimulation than in bipolar stimulation (one or more of the electrodes are negative, one electrode is positive). This is easy to understand if we note that the large case of the IPG has a much larger contact surface than the small contact surfaces of the electrodes, which provides lower impedance. The unipolar setting also has the advantage of stimulating a large field, so that selected nerves can be stimulated.

\section{Amplitude}

One should check the compliance before slowly increasing the amplitude. Most of the time, this compliance test will indicate that the IPG has been activated for some time, which is not the case. Therefore this data should be reset in order to obtain reliable compliance data at follow-up, when compliance is measured using the programming device. The patient will feel the stimulation by slowly increasing the amplitude. This is a pounding, beating, pulsating or paresthetic feeling. The patients should ideally feel this in the anal region, perineum, scrotum, testis, penis, labia, and/or vagina, but stimulation can also be felt in the buttock, leg, flank and feet. If the stimulation is felt in the preferred area, the chosen electrode configuration can be maintained. If not, other electrode configurations should be tried. Low amplitudes (lower than 5.0 volts) are preferred in the chosen configuration to maintain battery longevity.

\section{Postoperative management}

Bladder residuals of chronic retention patients must be measured after every void during their hospital stay. This can be done with ultrasound, bladder scans or clean, intermittent self-catheterisation (CIC). Residuals of less than $100 \mathrm{ml}$ are considered acceptable. If the residuals are larger, the patient is advised to keep on performing $\mathrm{CIC}$ once during the daytime, depending on the volume. If there are residuals of less than $100 \mathrm{ml}$ during hospitalisation, patients are advised to check 
for the first 6 weeks, 2 to 3 times a week, for bladder residuals by CIC. Then they should write down the data and show them at the follow-up visit in the outpatients' clinic. After having carefully instructed about the use of the patient programmer and the IPG, the patient can go home (day 2 after surgery), provided that he or she is feeling well, is mobilised and there is no infection. The patient is seen 6 weeks after the operation for follow-up. During the first 6 weeks, the stimulation sensation may change. This is probably because the lead in the sacral foramen moves as collagen tissue is formed around it. The patients are instructed to minimise physical activity, especially bending and cycling, to prevent lead migration. After the first 6 weeks, the lead is firmly attached and all physical activity may be resumed. Sometimes, lead migration is severe in the first 6 weeks after surgery. This may be due to insufficient sutures, fixating the lead in the foramen and/or patient movements. If this cannot be corrected with the programmer, a radiograph of the sacrum is obtained and the patient has to be evaluated for reoperation.

In the first weeks after implantation, the stimulation amplitude has to be increased in most cases because of tissue fibrosis and adaptation of the nerve to the stimulation. The patient has to be instructed to feel the stimulation. If the patient does not feel the stimulation, he or she must increase the amplitude with the patient programmer. If the stimulation is painful, the patient must decrease it. A range can be programmed to allow the patient to increase or decrease the amplitude safely. The programmed range can allow for an approximate 1.5-volt increase. The lower range can be set at 0.0 volts. In this way, the patient has sufficient range to apply the stimulation correctly and can decrease it if it becomes painful, to zero if necessary. An important factor in amplitude setting is the electrodeto-nerve distance. The densities of the electrical field applied to the nerve decrease with increasing distance between the electrode and the nerve. For instance, if the distance of the nerve to the electrode is increased by a factor of two, the current density is decreased by a factor of four ${ }^{12}$. This implies that, if the electrode is placed, or has moved, far from the nerve, the amplitude has to be increased. The patient will feel whether the amplitude is adequate because of the nature of the sensations.

Nerve fibres with large diameters (A $\alpha$ type) need a relatively smaller current to depolarise the membrane and cause an action potential. These are the nerves we want to stimulate ${ }^{13}$. If the amplitude is set too high, small-diameter nerve fibres will depolarise as well $(A \delta, C$ type). If these fibre types depolarise, they can cause pain. If, however, high amplitudes are necessary for adequate sensation in the correct areas, other electrode configurations should be tried to diminish the chance of pain and other side effects and to save battery power.

Basically, the IPG is set postoperatively in a unipolar configuration, with electrode $0,1,2$, or 3 negatively charged, depending on the best area of sensation and the lowest amplitude.

\section{Follow-up}

After 6 weeks, the patient is seen at the outpatient clinic. The wounds are inspected and a subjective result is asked for. The patient is asked if the amplitude has 
changed, and if the sensation is still in the correct area. Further, a voiding pattern has to be obtained; the retention patient is asked about residual urine and if any side effects have been noticed during the first 6 weeks. If the patient is doing well (normal voiding pattern, sensation in the correct area, less than $100 \mathrm{ml}$ residual urine volume, no side effects), the IPG can be checked and a normal follow-up is scheduled at 3 months, 6 months and every following year.

Several parameters should be measured and noted: amplitude, pulse width, battery status, continuous or cyclic mode, electrode configuration and site of sensation. We advise measuring the impedance. If impedance is less than $50 \mathrm{ohm}$ or more than $4000 \mathrm{ohm}$, there is a short circuit or respectively, a broken wire in the system. Every electrode has to be examined separately to obtain reliable information. An out-of-range impedance is an indication for reoperation to replace the damaged material. A small impedance at certain amplitudes causes a greater current and therefore a greater energy drain from the battery and a shorter battery life. Thus, the electrode configuration should not have an impedance that is to low. Measuring the impedance can provide this information. The longevity of the battery can also be calculated. Officially, the correct information can only be obtained if the longevity is calculated directly after the operation. However, calculating the longevity after each configuration adjustment can provide the necessary information about energy drain from the battery. If the longevity has diminished, as compared to the former setting, impedance is probably very low or the amplitude and/or pulse width is very high. The following weeks after implantation, connective tissue will form around the electrode, which leads to an increase of impedance (and thus the amplitude should be increased).

The compliance (use) should also be measured to obtain individual obedience data. The patient's results may be inadequate or absent because the IPG has been turned off for some time (e.g. by microwaves or other magnetic fields).

If the patient is doing well and has no side effects, checking the IPG is sufficient. Electrode configurations need not be changed. If the patient's results are inadequate, suboptimal, or absent, and the parameters mentioned are correct, check all electrode configurations and note them as in Table 2 in the patient's chart.

Table 2. Electrode configurations

\begin{tabular}{lrrrl}
\hline Configuration & Amplitude & Sensation area & Impedance & Current \\
Case+ 0- & 3.2 & Buttock & $1065 \mathrm{~W}$ & $18 \mathrm{~mA}$ \\
Case+ 1- & 2.8 & Anal area & $1176 \mathrm{~W}$ & $16 \mathrm{~mA}$ \\
Case+ 2- & 1.8 & Perineal & $976 \mathrm{~W}$ & $15 \mathrm{~mA}$ \\
\hline
\end{tabular}

Continue this systematic procedure until an optimal setting has been achieved

The best configurations can be tried for 2 weeks at $10 \mathrm{~Hz}$ and $210 \mathrm{~ms}$. If changing the electrode configuration causes the effect to be inadequate, the frequency can be changed to $15 \mathrm{~Hz}$ at the best electrode configuration. Altering the pulse width by small amounts ( 30 to $60 \mathrm{msec}$ increase or decrease) can also produce changes. Possible factors to help in optimising the effect are mentioned (Table 3). Ultimately, 
more electrodes can be set negatively $(-)$, but this often does not result in a better effect. If these changes do not lead to any improvement, and all parameters and sensation sites are correct, then a difficult moment has arrived. No research in this area to advise the urologist has been done. The possibilities are: accept the situation, replace the lead, perform PNE on the contralateral side, add medication to the SNS therapy or add physiotherapy to the SNS therapy.

If the sensation cannot be felt in the correct areas, the probable cause is lead migration. A PNE, and/or replacing the lead by means of a reoperation, may solve this problem.

If a patient has sensations near the IPG, it is possible that the insulation of the lead or wire is defective. When pain is felt near the IPG site and touching the IPG is painful, the insulation might be damaged. Touching or manipulating the subcutaneous connecting cable can increase and/or decrease these sensations. It is then advisable to replace these wires. If lead migration or a wire defect is suspected, a radiograph will often point out the problem. These sensations around the IPG can also be felt if the IPG case is positively charged, as in unipolar stimulation. Changing to bipolar stimulation can solve such problems. When stimulation therapy has suboptimal effects or no effect at all, one can check the bellows-like responses. To achieve this, the patient is positioned as during a PNE, and all polarity possibilities are tried to evoke correct responses. It is important to programme the IPG on the polarity that gets the best responses. If no responses at all are seen, lead migration is possible. To objectify this, a sacral radiograph can give you the answer. If no responses are achieved, another possibility is wire damage or IPG failure.

Table 3. Algorithm for troubleshooting

\begin{tabular}{lll}
\hline Parameter & Symptoms/indications & \multicolumn{1}{c}{ Change } \\
\hline Amplitude & No effect (\&) & Increase amplitude \\
& no sensation & Increase amplitude \\
& Pain & Decrease amplitude \\
& Low longevity & Decrease amplitude \\
Pulse width & No effect & Decrease or increase \\
& Pain & Decrease PW \\
& Low longevity & Decrease PW \\
Rate & No effect & Decrease or increase rate (5-25) \\
& Pain & Decrease rate (5-15) \\
& Low longevity & Decrease rate (5-15) \\
Mode & Habituation & Change to cyclic mode \\
Polarity & Low longevity & Change to cyclic mode \\
& No effect & Try different electrode configurations \\
& Pain & Try different bipolar configurations \\
& Low longevity & Try different uni/bipolar \\
& & configurationsCompare uni- \\
& & and bipolar settings \\
\hline
\end{tabular}




\section{References}

1. Agnew WF, McCreery DB, Bullara LA and Yuen TGH: Effects of prolonged electrical stimulation of peripheral nerve, in Agnew WF andMcCreery DB: Neural prostheses: fundamental studies. Prentice Hall, Englewood Cliffs, New Jersey, pp 148-167, 1990.

2. Fall M: Does electrostimulation cure urinary incontinence? J Urol. 131; 664-667, 1984.

3. Fall $\mathrm{M}$ and Lindstrom S: Electrical stimulation: A physiologic approach to the treatment of urinary incontinence. Urol Clin North Am. 18: 393-407, 1991.

4. Lindström S, Fall M, Carlsson C and Erlandson B: The neurophysiological basis of bladder inhibition in response to intravaginal electrical stimulation. J Urol. 129: 405-410, 1983.

5. Bosch J and Groen J: Sacral (S3) segmental nerve stimulation as a treatment for urge incontinence in patients with detrusor instability: results of chronic electrical stimulation using an implantable neural prosthesis. J Urol. 154: 504-507, 1995.

6. Weil E, Ruiz Cerda J, Eerdmans P, Janknegt R and Van Kerrebroeck P: Clinical results of sacral neuromodulation for chronic voiding dysfunction using unilateral sacral foramen electrodes. World J Urol. 16: 313-321, 1998.

7. Gleason C: Electrophysical fundamentals of neurostimulation. World J Urol. 9:110-113, 1991.

8. Thon WF, Baskin LS, Jonas U, Tanagho EA and Schmidt RA: Neuromodulation of voiding dysfunction and pelvic pain. World J Urol. 9: 138-141, 1991.

9. Hohenfellner M, Schultz-Lampel D, Dahms S, Matzel K and Thuroff JW: Bilateral chronic sacral neuromodulation for treatment of lower urinary tract dysfunction.J Urol. 160: 821-824, 1998.

10. Schultz-Lampel D, Jiang C, Lindstrom S and Thuroff JW: Experimental results on mechanisms of action of electrical neuromodulation in chronic urinary retention. World JUrol. 16: 301-304, 1998.

11. Schmidt RA: Treatment of unstable bladder. Urology. 37: 28-32, 1991.

12. Rattay F: Ways to approximate current-distance relations for electrically stimulated fibers. J Theor Biol. 125: 339-349, 1987.

13. Lindström $\mathrm{S}$ and Sudsuang R: Functionally specific bladder reflexes from pelvic and pudendal nerve branches; an experimental study in the cat. Neurourol Urodyn. 8: 392 393,1989 . 


\section{Chapter 4}

\section{Predictive factors for sacral neuromodulation in chronic lower urinary tract dysfunction}

WA Scheepens, MMGJ Jongen, FHM. Nieman RA de Bie, EHJ Weil, PhEV van Kerrebroeck, The Netherlands. 


\section{Abstract}

\section{Objectives}

To investigate data from 211 patients who underwent a trial stimulation (percutaneous nerve evaluation [PNE]) to determine the clinical parameters that can enhance the prediction of PNE success. The advantageous effect of sacral neuromodulation depends on the accurate identification of suitable candidates during the preimplantation PNE.

\section{Methods}

A total of 211 patients ( 161 women and $50 \mathrm{men}$ ), with refractory urge incontinence, urgency-frequency syndrome and urinary retention, underwent a PNE. Patient data (demographics, medical history, urologic investigations and diagnosis) were collected. The PNE results were evaluated from a voiding diary and patient history. More than $50 \%$ improvement of voiding parameters was considered a successful $\mathrm{PNE}$, and those patients were selected for implantation. Logistic regression analysis was performed. The factors tested for predicting the test result were: sex, patient age, diagnosis, previous surgery, neurogenic bladder dysfunction, duration of complaints and previous treatments.

\section{Results}

The PNEs were positive in 85 patients $(40,3 \%)$ and negative in 105 patients $(49,8 \%)$. In 18 patients $(8,5 \%)$ the test electrode had migrated; 3 more patients were not assessable and were also excluded. Missing data on the variable "duration of complaints" reduced the number of patients in the analyses from 190 to 174 parients.

\section{Conclusions}

Intervertebral disk prolaps, duration of complaints, neurogenic bladder dysfunction, and urge incontinence were found to be significant predictive factors. However, a PNE remains necessary to evaluate a patients' chance of implant success objectively. 


\section{Introduction}

Sacral neuromodulation offers a well-tolerated treatment option for patients with a variety of voiding dysfunctions refractory to conservative treatment. An increasing number of studies has shown that sacral neuromodulation can be effective in patients with urge incontinence, urgency-frequency syndrome and voiding difficulty. ${ }^{1.9}$ The advantageous effect of sacral neuromodulation depends on the accurate identification of suitable candidates during preimplant percutaneous nerve evaluation (PNE). ${ }^{10}$ This PNE provides the clinician with the only available predictive tool for the possible application of sacral neuromodulation. Therefore, the test forms an integral and essential element of neuromodulation therapy. When using the PNE, 50 to $60 \%$ of patients with chronic lower urinary tract dysfunctions appear to be eligible for sacral neuromodulation (i.e. they exhibit a more than $50 \%$ improvement in their voiding parameters during the test stimulation period). The selected patients are candidates for final implantation of a neuromodulator system. ${ }^{11,12}$ However, after permanent implantation, more than $20 \%$ of patients with urgency-frequency, urge incontinence or voiding difficulty and initially favourable PNE results fail to respond for reasons as yet unknown., ${ }^{8,14}$ In a study done by Koldewijn et al., ${ }^{15}$ in which test stimulation was performed in 100 patients, no specific predictors of test success were found. Also, other studies found no pretreatment factors to predict the eventual effect of sacral neuromodulation. ${ }^{7}{ }^{13}$ With higher patient numbers and different possible predictors it may be possible to find such predictive factors. To define the selection criteria for patients, we investigated the data from 211 patients who underwent a trial stimulation (PNE) to find the clinical parameters that can assist in the process of patient selection.

\section{Materials and methods}

The study population consisted of all patients who underwent a PNE between May 1988 and May 1999 at the University Hospital Maastricht. All patients with refractory urge-incontinence, urgency-frequency syndrome and urinary retention who underwent a PNE were included. Patients with other indications, such as pelvic pain syndrome, were excluded from this study. All patients underwent a comprehensive evaluation consisting of history taking, physical examination and urodynamic investigation. To exclude urinary tract abnormalities, urine culture, cystoscopy, and when indicated, imaging of the upper urinary tract were performed. Urodynamic investigations consisted of medium-fill water cystometry $(50 \mathrm{ml} / \mathrm{min})$ with the water at room temperature. ${ }^{16}$ The bladder and rectal pressures were measured using microtip catheters. On the basis of the history and urodynamic findings, patients were classified as having motor-urge incontinence, sensory urge incontinence, urgency-frequency syndrome or urinary retention (complete/incomplete).

If a neurogenic cause was suspected, additional neuro-electro-physiologic investigations were performed $(\mathrm{n}=133)$ and were analysed by a neurophysiologist. The outcomes of the tests of the pelvic nerve were classified as no pelvic nerve 
lesion, mild pelvic nerve lesion or no reflex evoked (total pelvic nerve lesion suspected). The outcome of the pudendal nerve tests was classified as no pudendal nerve lesion, mild pudendal nerve lesion or no reflex evoked (total pudendal nerve lesion suspected). The neurophysiologic test outcome was correlated with the effect of temporary neuromodulation.

All patients underwent a PNE of the sacral nerve according to the procedure described by Schmidt et al. ${ }^{10} \mathrm{After} 4$ to 7 days, the clinical and eventually urodynamic effects were registered. After confirming that the electrode was still in the correct position, the test material was removed.

The PNE results were evaluated using data from a voiding diary, data from the patient's history, and determination of residual voided volume using catheterization. Dependending on the urinary dysfunction, if an improvement of more than $50 \%$ in the key voiding parameters occurred (e.g. voided volumes per void, number of void urges before voiding, pad use, and catheterized volume per catheterisation), the PNE was considered a success, and those patients were selected for implantation. ${ }^{8,13,14}$ If a lead migration was suspected or a previous PNE was not conclusive enough to select a patient for permanent implantation, additional PNEs were performed.

\section{Statistical analysis}

To test for the predictive factors, consecutive PNE results were combined (up to three). Logistic regression analysis was performed for patients with positive or negative test results. The factors used in predicting the test result were: sex, patient age, diagnosis, previous surgery, neurogenic bladder dysfunction, duration of complaints (in years), and previous treatment for complaints (pelvic floor exercises, biofeedback, vaginal electrostimulation, medication).

Factors were consecutively entered into the regression equation and were at first kept in the model if the $p$ value of the log-likelihood chi-square belonging to a predictor turned out to be less than 0.10 . This process of retaining statistically significant predictors and at the same time deleting predictors that appeared to have no significant $p$ values resulted in a provisional multiple prediction model for a favorable or non-favorable test outcome. Next, this provisional model was tested by backward elimination of each predictor provisionally included, with the exception of sex and patient age, which were retained in each tested model, regardless of their statistical significance. The staristical significance was now kept at $p<0.05$. The resulting model containing the direct effects of risk factors for negative test results was eventually tested for the interactive effects of the risk factors: all pairwise combinations of risk factors were entered hierarchically into the model to test for statistical significance. The final model resulting from this procedure was tested for outliers by Studentized residuals inspection. Listwise deletion of missing cases was used in constructing the regression model. Next, the predicted value for a negative test result on the combined predictor information was plotted into a receiver operating characteristic curve estimation to establish cut off points with regard to the sensitivity and specificity of the prediction. 
All data analysis was performed using Statistical Package for the Social Sciencespe version 10.0 (SPSS, Chicago, Ill).

\section{Results}

The data from 50 men $(23.7 \%)$ and 161 women $(76.3 \%)$ were reviewed. The mean patient age was 51,5 years (SD 10.5, range 25 to 79 ). The men ( 55.3 years, SD 10.1) were significantly older (Student's $t$ test, $p=0.003)$ than the women $(50.3$ years, SD 10.4). In total, 15 patients $(7.0 \%)$ were diagnosed with urgency-frequency syndrome, $94(43.7 \%)$ with motor urge incontinence, $13(6.0 \%)$ with sensory urge incontinence, $41(19.1 \%)$ with complete chronic urinary retention, and $48(22.3 \%)$ with incomplete voiding (residual volume greater than $100 \mathrm{~mL}$ ).

The mean period of complaints was 7,3 years (SD 8,4, range 1 to 60). In 23 patients, no previous treatment had been given; these were all patients with retention (12 complete, 11 incomplete). Previous treatments consisted of medication, pelvic floor exercises, biofeedback training of the pelvic floor, vaginal or anal electrostimulation and surgical intervention (i.e. urethrotomia interna, bladder distension, suspension operations, bladderneck incision/transurethral resection of the prostate, and even ileocystoplasty). A group of 11 patients had mixed (stress and urge) incontinence. In total $24(11.4 \%)$ of 211 patients had a neurogenic bladder dysfunction: 3 cerebrovascular accident, 6 partial spinal cord injury, 5 caudal syndrome, 3 spinal trauma, 6 multiple sclerosis, and 1 meningeomyelocele.

A total of 133 patients underwent neurophysiological testing. In 116 patients, the pelvic nerve was tested; 97 patients $(83.6 \%)$ had no pelvic nerve lesion, 13 patients $(11.2 \%)$ had a mild pelvic nerve lesion and $6(5.2 \%)$ had no evoked reflex. Pudendal nerve examination was performed in 132 patients; 81 patients $(61.4 \%)$ had no pudendal nerve lesion, $42(31.8 \%)$ had a mild lesion, $9(6.8 \%)$ had presented no pudendal reflex activity. No significant correlation was found between the neurophysiological test outcome and the effect of temporary neuromodulation $(p=0.309$ for the pelvic nerve lesion and $p=0.294$ for pudendal nerve lesion).

The combined results from up to three tests showed the following: a positive result in 85 patients $(40,3 \%)$ and negative in 105 patients $(49,8 \%)$. In 18 patients $(8,5 \%)$, the test electrode had migrated, so no test result resulted, 1 patient had unknown results, 1 a contradictory result, and 1 patient underwent no further tests after the first one failed to give conclusive results. These 21 patients were not included in the analysis for predictive factors. Missing data on the variable "duration of complaints" reduced the number of patients in the analyses from 190 to 174 patients.

Table I provides the results from the final model used to predict test success (or failure) in neuromodulation. The higher the patient age, the more test failures (odds ratio 1.03). Previous surgery to treat an intervertebral disk prolaps (IDP) appears to be a protective factor; it reduced the chance on a negative test outcome (odds ratio 0.27). Also, the duration of complaints had a relationship with success or failure. Longer lasting complaints result in a higher risk of a negative test (odds ratio 1.09). Patients with neurogenic bladder dysfunction had a four times higher 
chance on negative test results compared with patients having no obvious neurological problems. Patients with urinary retention showed a 2.51 times higher chance of having a negative test result compared with patients with urge incontinence.

Table II shows results of backward elimination testing of each predictive factor tested. The changes in log-likelihood ratio chi-squares, if each effect is omitted from the model, are given, together with their $p$ values. The duration of complaints appeared to be the major determinant for success or failure, followed by IDP surgery.

The calculated specificity and sensitivity in this model for a negative test result was respectively, $74 \%$ and $63 \%$. Figure 1 displays the receiver operating characteristic curve for various cutoff points in the estimated probability of a negative test result.

Next to this basic model, all two-way interactions were calculated and tested for each pair of the six determinants or risk factors. Only 1 of all possible 15 pairs, the combination of diagnosis and former IDP surgery, appeared to be statistically significant, and it was added to the model. The log-likelihood ratio chi-square difference between the interaction-enhanced model and the basic 6effects model was 8.66, 2 degrees of freedom, $p=0.013$, and variance explained amounts to 0.176 (versus 0.140 in the basic model). The risk of a negative test result for patients with urge incontinence who had undergone previous IDP surgery appeared to be 0 , and the risk of a negative test result in patients with retention and urgency-frequency syndrome for those who underwent surgery and those who did not appeared to be equal.

Table I. Results of final no-interaction model (test success $=0$, failure $=1$ )

\begin{tabular}{|c|c|c|c|c|c|c|c|}
\hline Predictor & B & seB & Wald & df & $p$ & Odds-ratio & $95 \%$ C.I. for $\operatorname{Exp}(B)$ \\
\hline Sex & -0.14 & 0.43 & 0.11 & 1 & 0.74 & 0.87 & $0.38-2.00$ \\
\hline Age & 0.03 & 0.02 & 3.03 & 1 & 0.82 & 1.03 & $1.00-1.07$ \\
\hline IDP surgery & -1.33 & 0.60 & 4.95 & 1 & 0.03 & 0.27 & $0.08-0.85$ \\
\hline Complaint duration $(\mathrm{yr})$ & 0.09 & 0.03 & 7.84 & & 0.01 & 1.09 & $1.03-1.16$ \\
\hline Comorbidity & & & 5.22 & 2 & 0.07 & & \\
\hline \multicolumn{8}{|l|}{ - none vs neurogenic } \\
\hline bladder & 1.40 & 0.61 & 5.21 & 1 & 0.02 & 4.04 & $1.22-13.42$ \\
\hline \multicolumn{8}{|l|}{ - none vs PP } \\
\hline and SPFS & 0.07 & 1.50 & 0.00 & 1 & 0.96 & 1.08 & $0.06-20.27$ \\
\hline Diagnoses & & & 6.27 & 2 & 0.04 & & \\
\hline - urge-inc/urine ret & 0.92 & 0.37 & 6.06 & 1 & 0.01 & 2.51 & $1.21-5.23$ \\
\hline - urge-inc/urge-freq & 0.70 & 0.64 & 1.18 & 1 & 0.28 & 2.01 & $0.57-7.09$ \\
\hline Constant & -2.28 & 1.09 & 4.35 & 1 & 0.04 & 0.10 & \\
\hline
\end{tabular}

$\chi_{1}^{2}=33.47, \mathrm{DF}=8, P<0.001$.

Key: $\mathrm{B}=$ logistic regression coefficient; $\mathrm{se} \mathrm{B}=$ standard error of $\mathrm{B} ; \mathrm{DF}=$ degrees of freedom; $\mathrm{Cl}$ $=$ confidence interval; $\operatorname{Exp}(\mathrm{B})=$ estimated odds ratio (=odds ratio); IDP = intervertebral disk prolapse; $\mathrm{PP}=$ psychiatric problems; $\mathrm{SPFS}=$ spastic pelvic floor syndrome; Urge-Ine = urge incontinence; Urine Ret $=$ urinary retention; Urge-Freq = urgency frequency. 
Table II. Backward elimination testing of predictive factors (-2L.LR chi-spuare): Change in loglikelihood ratio chi-square, if removed from the basic six effects model.

\begin{tabular}{lllc}
\hline & Change & df & $p$ change \\
\hline Age & 3.11 & 1 & 0.078 \\
IDP operation & 5.47 & 1 & 0.019 \\
complaintduration & 11.77 & 1 & 0.001 \\
Comorbidity & 6.16 & 2 & 0.046 \\
Diagnoses & 6.50 & 2 & 0.039 \\
\hline
\end{tabular}

\section{ROC Curve}

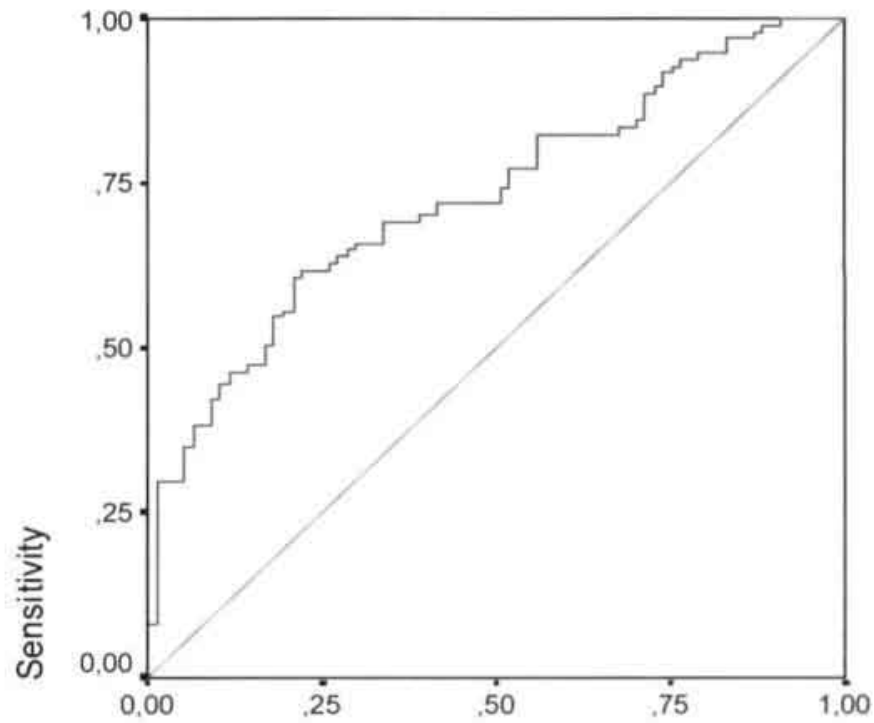

\section{1 - Specificity}

Figure 1. Receiver operating characteristic curve for various cut off points in estimated probability of a negative test result. Area under the curve 0.73 (standard error: 0.038 ; range 0.657 to 0.804 ). 


\section{Comment}

Sacral neuromodulation is an effective therapy for patients with various voiding dysfunctions. However, until now no single predictive factor has been found to predict which patients with voiding dysfunction will benefit from this therapy. Reports addressing this subject have shown no conclusive predictive factor, possibly because patient numbers were too small to achieve statistical significance. $8,14,15,17$

This analysis of the data from a larger group of patients found several predictors of test success in sacral neuromodulation (Tables I and II).

IDP surgery. Patients who underwent IDP surgery had a 3.7 times higher chance on a positive test. Owing to the IDP, the sacral roots are irritated and can therefore cause urge-incontinence and urinary retention. ${ }^{18.19}$ Looking more closely at our data, an interaction effect was found concerning patients who had urgeincontinence and had undergone IPD surgery. This could mean that the irritative afferent input from the sacral nerves is inhibited at the level of the spinal cord that resolves the urge complaints. Kiss et al. ${ }^{30}$ described the use of cortical evoked potentials as a predictive test for patients suitable for intravesical electrostimulation. They showed the importance of intact nerve afferents for the positive effect of intravesical electrostimulation. Additional research in this area may produce more predictive data in the case of sacral neuromodulation. Our clinical neurophysiological investigations, which did not involve cortical evoked potentials, showed no relationship with therapy outcome.

In our group, however, no patients who had undergone IDP surgery had a negative test result. This could have caused a bias in the interpretation of the results of the data analysis. Patients in the retention group who had undergone IDP surgery had no higher or lower chance of a positive PNE.

Duration of complaints. Patients with urinary tract dysfunctions for a relatively long period have a lower chance on a positive test compared with patients with dysfunction for a relatively short period. The cut off point was less than seven months versus seven months or longer. With sacral neuromodulation, we are probably remodelling sensory and motor neural pathways of the lower urinary tract. $^{.1 .14 .1721}$ If a disorder is present for a longer time, it could mean that it is more difficult to restore the natural equilibrium (ie, the normal balance) between the different reflexes.

Neurogenic bladder dysfunction. Earlier reports have shown that patients with neurogenic bladder dysfunction can be treated effectively using sacral neuromodulation. ${ }^{2,23}$ However, according to our data, these patients have four times lower chance of a positive PNE compared with patients with idiopathic voiding dysfunction. In our series, all patients with neurogenic voiding dysfunction had central nervous system disorders. This could mean that only smaller lesions (such as IDP) and more peripheral neural lesions are treated more effectively by sacral neuromodulation. Patients with a complete spinal cord injury can attain a higher bladder capacity during sacral neuromodulation. ${ }^{23}$ This indicates that the working mechanism of sacral neuromodulation may also be effective at the sacral spinal level or lower. 
Diagnostic Group. Patients with urge incontinence responded better (2.51 times) to the PNE than did patients in the other diagnostic groups. One of the reasons could be that the selection criteria for a positive or a negative test are stricter for patients with urinary retention. Patients with overactive bladder dysfunction, as well as patients with urinary retention, need to improve at least $50 \%$ in the important voiding parameters. In our opinion, the PNE for patients with urinary retention is either effective and conclusive or is not (on/off phenomenon). Patients with retention often start to void or do not; therefore, the variation in the success of the test is smaller. Moreover, the sensitivity of the PNE could be higher in the patients with retention compared with the groups with urge incontinence and urgency frequency. This may also explain why the long-term efficacy results are better in patients with urinary retention than in the other groups. ${ }^{8,14,17}$

The neurophysiological test outcome did not correlate with the effect of the PNE. This suggests that patients with subtle nerve lesions are also candidates for PNE, although patients with neurogenic bladder dysfunction have a smaller chance of a positive PNE than non-neurogenic patients.

Further investigations in the field of predictive factors are necessary to reduce the high number of failures in the PNE and implant groups. To discover more about the predictive factors for therapy and PNE success, prospective studies with concurrent data gathering and sufficient numbers of patients are required. However, at first it would be advisable that our results be corroborated with other data sets.

\section{Conclusion}

In this study, some indicators to predict PNE outcome were found. A higher chance of a positive PNE was present in patients who underwent IDP surgery and in patients with urge incontinence. A higher chance of a negative PNE was found with patients with neurogenic bladder dysfunction and in patients with a relatively long duration of lower urinary tract dysfunction. However, the PNE is still necessary to determine whether patients can be successfully implanted. 


\section{References}

1. Tanagho EA: Principles and indications of electrostimulation of the urinary bladder. Urolog 29: 185-190, 1990.

2. Thon WF, Baskin LS, Jonas U, et at Neuromodulation of voiding dysfunction and pelvic pain. World J Urol. 9: 138-141, 1991.

3. Dijkema HE, Weil EH, Mijs PT et at. Neuromodulation of sacral nerves for incontinence and voiding dysfunctions: Clinical results and complications. Eur Urol. 24: 72-76, 1993.

4. Goodwin RJ, Swinn MJ and Fowler CJ: The neurophysiology of urinary retention in young women and its treatment by neuromodulation. World J Urol. 16: 305-307, 1998.

5. Shaker HS and Hassouna M: Sacral root neuromodulation in idiopathic nonobstructive chronic urinary retention. J Urol. 159: 1476-1478, 1998,

6. Weil EH, Ruiz Cerda J, Eerdmans PH, et at. Clinical results of sacral neuromodulation for chronic voiding dysfunction using unilateral sacral foramen electrodes. World $\mathrm{J}$ Urol. 16: 313-321, 1998.

7. Weil EH, Ruiz Cerda JL, Eerdmans $\mathrm{PH}$, et at. Sacral root neuromodulation in the treatment of refractory urinary urge incontinence: a prospective randomized clinical trial. Eur Urol. 37: 161-171, 2000.

8. Hassouna MM, Siegel SW, Nyeholt AA, et at: Sacral neuromodulation in the treatment of urgency-frequency symptoms: a multicenter study on efficacy and safety. J Urol. 163: 1849-1854, 2000.

9. Bosch JL and Groen J: Sacral nerve neuromodulation in the treatment of patients with refractory motor urge incontinence: long-term results of a prospective longitudinal study. J Urol. 163: 1219-1222, 2000.

10. Schmidt RA, Senn Eand Tanagho EA: Functional evaluation of sacral nerve root integrity: Report of a technique. Umology. 35: 388-392, 1990.

11. Janknegt RA, Weil EH and Eerdmans PH: Improving neuromodulation technique for refractory voiding dysfunctions: two-stage implant. Urology, 49: 358-362, 1997.

12. Bosch JL and Groen J: Sacral (S3) segmental nerve stimulation as a treatment for urge incontinence in patients with detrusor instability: results of chronic electrical stimulation using an implantable neural prosthesis. J Urol. 154: 504-507, 1995.

13. Schmidt RA, Jonas U, Oleson KA, et al, and the Sacral Nerve Stimulation Study Group: Sacral nerve stimulation for treatment of refractory urinary urge incontinence. J Urol. 162: 352-357, 1999.

14. Jonas L, Fowler CJ, Chancellor MB, et al:: Efficacy of sacral nerve stimulation for urinary retention: results 18 months after implantation. J Urol. 165: 15-19, 2001.

15. Koldewijn EL, Rosier PF, Meuleman EJ, et at. Predictors of success with neuromodulation in lower urinary tract dysfunction: results of trial stimulation in 100 patients. J Urol. 152: 2071-2075, 1994.

16. Abrams P, Blaivas JG, Stanton SL et aland The International Continence Society Committee on Standardisation of Terminology: The standardisation of terminology of lower urinary tract function., Scand J Urol Nephrol. 114: 5-19, 1988.

17. Schmidt RA, Jonas U, Oleson KA, et al and the Sacral Nerve Stimulation Study Group: Sacral nerve stimulation for treatment of refractory urinary urge incontinence. J Urol. 162 : 352-357, 1999. 
18. Yamanishi T, Yasuda K, Sakakibara R, ef al: Detrusor overactivity and penile erection in patients with lower lumbar spine lesions. Eur Urol. 34: 360-364, 1998.

19. O'Flynn KJ, Murphy R and Thomas DG: Neurogenic bladder dysfunction in lumbar intervertebral disc prolapse. Br J Urol. 69: 38-40, 1992.

20. Kiss G, Madersbacher $\mathrm{H}$ and Poewe W: Cortical evoked potentials of the vesicourethral junction- a predictor for the outcome of intravesical electrostimulation in patients with sensory and motor detrusor dysfunction. World J Urol. 16: 308-312, 1998.

21. Bemelmans BL, Mundy AR and Craggs MD: Neuromodulation by implant for treating lower urinary tract symptoms and dysfunction. Eur Urol. 36: 81-91, 1999.

22. Bosch JL and Groen J: Treatment of refractory urge urinary incontinence with sacral spinal nerve stimulation in multiple sclerosis patients. Lancet. 348: 717-719, 1996.

23. Chartier-Kastler EJ, Bosch RJLH, Perrigot M, et at. Long-term results of sacral nerve stimulation $(\mathrm{S} 3)$ for the treatment of neurogenic refractory urge incontinence related to detrusor hyperreflexia. J Urol. 164: 1476-1480, 2000. 


\section{Chapter 5}

Urodynamic results of sacral neuromodulation correlate with subjective improvement in patients with an overactive bladder

WA Scheepens, GA van Koeveringe, RA de Bie, EHJ Weil, PhEV van Kerrebroeck 


\section{Abstract}

\section{Objectives}

Standard urodynamic investigations showed no correlation between the efficacy of sacral neuromodulation (SNS) and urodynamic data. Ambulant urodynamic investigations $(A C M)$ are presented as more sensitive and reliable in detecting and quantifying bladder overactivity. In this study we looked at the correlation and results of ambulant urodynamic data and the clinical effects of SNS.

\section{Methods}

Data of patients with bladder overactivity, who underwent an ACM before and during SNS were investigated. Blind analyses of the ACM were performed and the detrusor activity index (DAI) was calculated as the degree of bladder overactivity of the detrusor. The ACM parameters, before and during SNS, were analyzed and correlated to the clinical effect of SNS.

\section{Results}

In 22 of the 34 patients a DAI before and during stimulation could be calculated because of quality aspects. In all other patients, the other ambulatory urodynamic parameters could be analyzed and a significant reduction was found in bladder overactivity. A significant correlation $(\mathrm{p}=0.03)$ was found in DAI reduction of the ACM before and during SNS as compared to the clinical improvement in overactive bladder symptoms.

\section{Conclusions}

The objective and subjective results show a decrease in bladder overactivity during SNS. During SNS bladder instabilities are still present, which is in accordance with the published literature. The reduction of the DAI during SNS as compared to before SNS correlates significantly to the clinical effect of SNS. 


\section{Introduction}

Sacral neuromodulation (SNS) gains increasing support as an effective treatment modality for patients with urge incontinence, urgency frequency and chronic urinary retention ${ }^{1-4}$. Until now no predictive factors have been recognized to predict therapy outcome in patients with chronic lower urinary tract dysfunction 1,3-5. Also standard urodynamics showed no or minimal correlation between the effect of SNS and the evaluation of urodynamic data in patients with bladder overactivity ${ }^{6.7}$.

Urodynamic investigation is widely accepted as a tool to measure functional lower urinary tract abnormalities. Filling cystometry is used to investigate bladder overactivity when there are symptoms of urgency frequency and urge incontinence.

An ambulant urodynamic investigation or ambulant cystometry (ACM) is presented as more sensitive and reliable in detecting and quantifying bladder overactivity. Reported sensitivity and specificity are $85 \%{ }^{8}$. ACM can also provide us with the detrusor activity index (DAI), which is a quantification of bladder overactivity $^{8}$. This DAI is a number between 0 and 1 . Where 0 means no bladder overactivity and 1 indicates an extremely overactive bladder. If the DAI is higher than 0.50 , it indicates bladder overactivity and a DAI of lower than 0.24 indicates that no significant overactivity is present (sensitivity and specificity are $85 \%$ ) ${ }^{8}$. ACM also frees the patient from the fixed urodynamics apparatus, therefore providing a monitoring of bladder behaviour during normal daily activities, moreover bladder filling occurs in a natural way and is not artificially influenced. Therefore ACM could be a better tool to correlate the clinical effect of sacral neuromodulation to the urodynamic result. In this study we looked at the urodynamic effect of SNS by means of ACM in patients with bladder overactivity and we correlated the effect of SNS to the ambulant urodynamic data.

\section{Materials and methods}

We set out to investigate retrospective data of patients with an overactive bladder, who underwent an ACM before and during SNS, which included PNE test (sub-chronic test stimulation) and implantation of the sacral neuromodulation system. The ACMs were performed according to the standardization report of the International Continence Society on ambulatory monitoring ". Patients who underwent these procedures were mostly among the first of our patients who were considered for sacral neuromodulation in our hospital, so there is a certain patient selection.

For recording a Gaeltec microtransducer catheter (five French) and a Gaeltec MPR3 recorder were used with a maximum sample frequency for storage set at $16 \mathrm{~Hz}$. Two transducers were applied. One transducer was inserted approximately $10 \mathrm{~cm}$ into the rectum. A dual sensor catheter (sensors $5-6 \mathrm{~cm}$ apart) was inserted in the bladder with the proximal sensor in the region of maximum urethral pressure to record the urethral pressure. This region was selected via an urethral pressure profile. After placement of the catheters these were fixed to the perineum or penis with brown adhesive tape. Planned duration of monitoring was 6 hours. 
Urinary leakage detection was performed using the pad-test. Patients were asked to drink a minimum of $250 \mathrm{ml} /$ hour during the entire test, to achieve sufficient bladder filling. Drinking and voiding behavior were recorded by means of a diary. If the patient experienced urge, a button had to be pressed, which was registered on the recorder. Voiding phases were marked by the patient with an event button that was pressed at the moment of entering and leaving the toilet. The possible bladder contraction during this voiding phase was not taken into account for evaluating bladder overactivity. Blind analyses of the ACMs were performed and the detrusor activity index (DAI) was calculated as the degree of bladder overactivity ${ }^{8,19}$. The $\mathrm{ACM}$ variables used to calculate the $\mathrm{DAI}$ are: mean drinking volume/hour; mean number of voids/hour; voided volume/hour; voided volume/void; uninhibited detrusor contractions/hour; amplitude of the uninhibited detrusor contractions/hour; duration of these uninhibited detrusor contractions/hour; number of voids and combinations of these variables 8,10 . Eventually a quality assessment of the ACM was performed. A quality score between 1 and 5 represents the quality of the investigation. Quality figures are: 5 : event button used correctly, duration investigation longer than 5 hours, transducers in right position, valid for research purposes; 4 : as 5 , but urethral transducers not in right position, some problems with interpretation due to the catheters; 3 : as 4, but event button used partly incorrect but registration can still be used for research purposes; 2: as 3, but unsuitable for research purposes, some clinical value; 1: no interpretable value; 0 : no data. A representative DAI is only calculated if quality scores are 3 or higher.

The efficacy of SNS therapy was measured by voiding diary parameters and patient satisfaction. Improved voiding parameters and patients' subjective improvement of more than $50 \%$ was defined as a successful implant (table 1$)^{1.3}$. The ACM parameters included: actual recording time, number of bladder contractions, maximum amplitude of bladder contraction, maximum duration of bladder contraction, number of voids, total voided volume, incontinence episodes, number of drinks, total drinking volume, number of urge-events, number of events, quality and the DAI.

The ACM parameters, before and during SNS for the whole group were analyzed and tested for statistical improvement by means of the two-sided Student's t-test. Also the urodynamic effects were correlated to the clinical effect of SNS by means of the Pearson's two-tailed correlation. In both analyses p-values $<0.05$ are considered statistically significant.

\section{Results}

We investigated the data of 34 patients, 7 male and 27 female, who were selected for SNS therapy. All 34 patients underwent an ACM before and during SNS. Mean age was 53 years (range 34-75, S.D. $=10.4$ ). All patients were diagnosed with an overactive bladder, 28 patients with urge incontinence and 6 with urgency frequency. 
Table 1. Urinary dysfunctions, the key voiding variables and their criteria for the indicating the implantation of the IPG. The asterisk indicates the most important selection variables

\begin{tabular}{lll}
\hline Urinary dysfunction & Key voiding parameters & Criterion $^{1}$ \\
\hline Urgency frequency & Number of voids per 24 hrs & decreased \\
& Voided volume per void & increased \\
decreased & Urge to void prior to voiding & decreased \\
Urge-incontinence & Number of voids per 24 hrs & increased \\
& Voided volume per void & decreased \\
& Urge to void prior to voiding & decreased* \\
& Number of leakage's per 24 hrs & decreased* \\
Urinary retention & Pad-use & increased \\
& Voided volume per void & decreased
\end{tabular}

${ }^{1}$, improved if decreased or increased by more than half; ${ }^{2}$ maximum catheterised volume $<100$ $\mathrm{ml}.)^{*}$

Of these patients, 24 patients underwent an ACM before and after implantation. Mean follow-up was 11 months post-implant (median 6 months, range 0-56, S.D. =13.7). And 10 patients underwent an ACM before and during temporary SNS, during the so called percutaneous nerve evaluation test (PNE test), after 4 days of stimulation.

Actual duration of recording was 6.2 hours (range 2.0-10.2, S.D. $=2.1$ ) at baseline ACM. During SNS the actual duration of recording was 5.9 hours (range $2.8-9.8$, S.D. $=1.6$ ). In all patients all ambulatory urodynamic parameters were analyzed and are presented in table 2 (Table 2). Due to quality demands (quality $=3$ or more) applicable to the DAI, a DAI could be calculated before and during SNS in 22 patients (Table 2). The DAI of both these groups is presented in figure 1. In total five patients $(16 \%)$ were urodynamically stable with sacral neuromodulation during follow-up. A total of 15 patients had urodynamically proven instabilities before and during SNS and a clinically noted successful implantation or test-stimulation.

Implanted group (24): At the time of the follow-up ACM, 13 of the 24 implanted patients had less than $50 \%$ improvement of the SNS $(54 \%)$. Of these 13 patients, 8 have been explanted with the SNS system and 5 patients had revision surgery of the SNS system after which the results became satisfactory in 3 patients. The other two patients did not achieve satisfactory results after their revision and the situation was accepted. Resulting in a failure rate of $42 \%$.

PNE group (10): Of the patients who had undergone temporary neuromodulation by means of a PNE test, 3 out of 10 had less than $50 \%$ improvement as appeared from their voiding diaries $(30 \%)$. These patients were not offered SNS therapy. The other seven patients were offered chronic SNS therapy by means of implantation of an SNS system.

In the whole group, implanted and PNE parients $(n=34), 18$ patients $(53 \%)$ had more than $50 \%$ improvement and $16(47 \%)$ had less than $50 \%$ improvement (Fig 1.). 
Table 2. Overview of different parameters before and during sacral neuromodulation

\begin{tabular}{lllcll}
\hline Parameter $(\mathrm{n}=34)$ & before SNS & sd & during SNS & sd & p-value \\
\hline Actual recording time (hrs) & 6.2 & 2.1 & 5.9 & 1.6 & 0.435 \\
$\begin{array}{l}\text { Number of bladdercontrations } \\
\text { Max. amplitude of }\end{array}$ & 15.1 & 18.6 & 10.9 & 12.7 & 0.097 \\
$\begin{array}{l}\text { Bladdercontraction (cm H2O) } \\
\text { Max. duration of }\end{array}$ & 66.4 & 64.4 & 71.5 & 80 & 0.592 \\
Bladdercontraction (s) & 11.5 & 2.9 & 10.5 & 4.4 & 0.293 \\
Number of voids & 4.6 & 2.2 & 3.4 & 2.3 & $\mathbf{0 . 0 1 1}$ \\
Total voided volume (ml) & 691.1 & 539.4 & 608.8 & 632.2 & 0.535 \\
Incontinence episodes & 3.3 & 3.1 & 2.1 & 2.3 & $\mathbf{0 . 0 0 8}$ \\
Total urine loss (ml) & 121.8 & 301.3 & 111.2 & 359.1 & 0.760 \\
Number of drinks & 6.1 & 3.2 & 6.1 & 3.4 & 0.965 \\
Total drinking volume (ml) & 1089.4 & 611.4 & 1204 & 606.9 & 0.373 \\
Number of urge events & 4.6 & 3.4 & 2.9 & 3 & $\mathbf{0 . 0 3 6}$ \\
Number of events & 6.5 & 6 & 5.7 & 5.6 & 0.302 \\
Quality & 2.7 & 1.7 & 2.7 & 1.6 & 1.000 \\
DAl ( $\mathrm{n}=22$ ) & 0.7 & 0.3 & 0.5 & 0.4 & $\mathbf{0 . 0 1 7}$ \\
\hline
\end{tabular}

Bold numbers indicate a statistically significant urodynamic parameter. The parameter data is for 34 patients. The DAI data is in 22 patients. No significant differences were noted concerning the execution of the ambulatory cystometries.

Comparing these two groups, the improved group (responders) showed comparable ACM results as the whole group and the failure group (nonresponders) showed no improvement in ACM parameters. In group I a DAI before and during SNS could be calculated in 13 patients, in group II a DAI before and during SNS could be calculated in 9 patients. Mean value of the DAI in group I (figure 2) showed a significant decrease in the DAI with SNS compared to without SNS $(\mathrm{p}=0.005)$. Group II, where no clinical benefit could be obtained showed no decrease in the DAI (figure 3).

A significant correlation (coefficient $=0.478, \mathrm{p}=0.03$ ) was found between DAI reduction of the ACM before and during SNS as compared to the clinical improvement in overactive bladder symptoms (table 1) for the whole group.

\section{Discussion}

Sacral neuromodulation is nowadays accepted as an effective treatment option in patients with chronic lower urinary tract dysfunctions such as urge incontinence urgency frequency-syndrome and chronic urinary retention. Urodynamic improvement due to sacral neuromodulation therapy has also been demonstrated ${ }^{1-4}$. Especially in urinary retention patients urodynamic effects are marked ". In the overactive bladder group urodynamic effects are less marked and no correlation between sacral neuromodulation therapy effect and urodynamic studies could be established ${ }^{6.7}$. It is disenchanting that therapy effect has not been found to correlate 
with urodynamic improvement, because objective data like urodynamics correlating to subjective therapy effect would provide more confidence in the therapy efficacy. Hasan et. al. have demonstrated that ACM provides significant improvement in urodynamic data using sacral neuromodulation ${ }^{12}$.

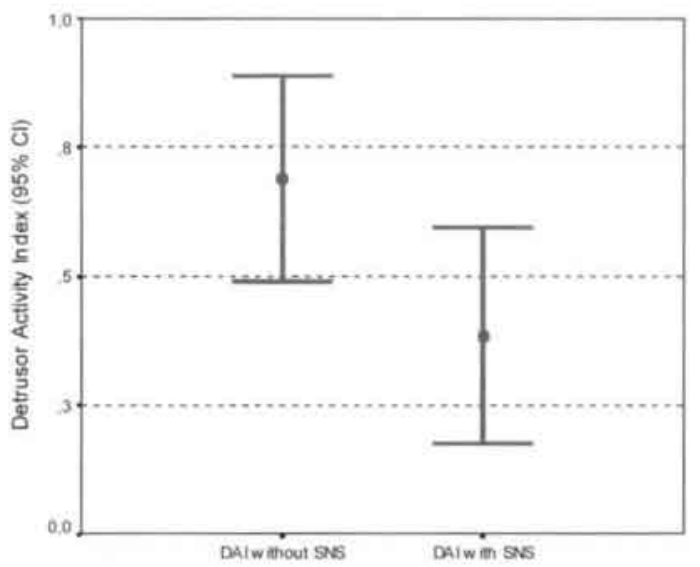

Figure 1. The detrusor activity (DAI) with and without sacral neuromodulation (SNS) in 22 patients (whole group, responders and non-responders). A statistically significant reduction in the DAI is shown during SNS $(95 \% \mathrm{CI})$.

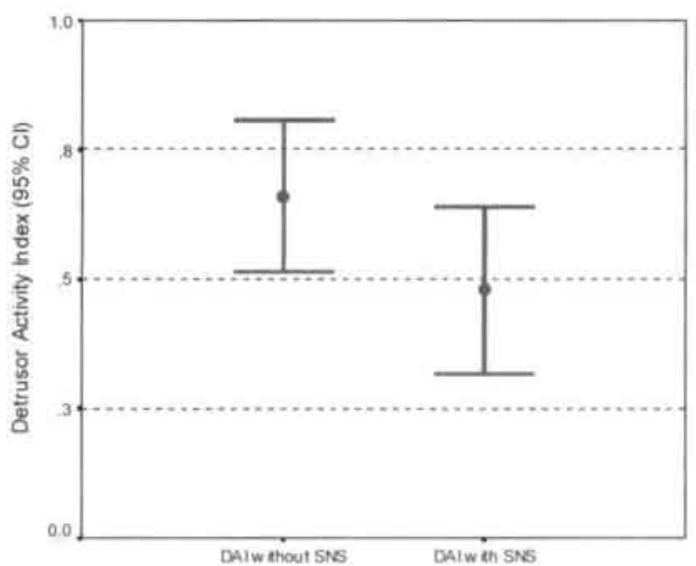

Figure 2. The detrusor activity (DAI) with and without sacral neuromodulation (SNS) of group $I$ (responders) in 13 patients. A statistically significant reduction in the DAI is shown during SNS,

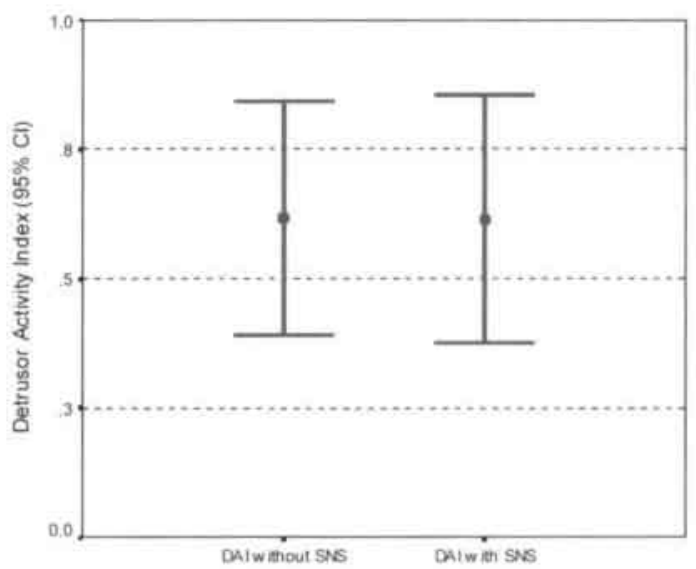

Figure 3. The detrusor activity (D) with and without sacral neuromodulation (SNS) of group II (non-responders) in nine patients. No statistically significant reduction in the DNI is shown during SNS. 
A significant improvement was found number of voids, incontinence episodes and number of urge events, uninhibited detrusor contractions were still present despite sacral neuromodulation. Also in our study significant improvement due to sacral neuromodulation therapy has been demonstrated even if uninhibited detrusor contractions were still present. The number of uninhibited detrusor contractions, however, did decrease but not significantly. The discrepancy between the presence of uninhibited detrusor contractions and a subjective effect of sacral neuromodulation, raises the question of the clinical significance of these contractions. We demonstrated significant urodynamic efficacy but uninhibited detrusor contractions were still present in $84 \%$ of the patients during sacral neuromodulation, $16 \%$ of the patients showed no uninhibited detrusor contractions during the follow-up ACM. The DAI provides us with an index that is calculated using additional factors apart from uninhibited detrusor contractions (see above). Other urodynamic parameters are also important and maybe even more important looking at the clinical aspect of urodynamics. A patient may suffer much less from frequency, urgency and incontinence episodes and have an increased bladder capacity, while uninhibited detrusor contractions may still be present. The DAI gives us a number that characterizes overactivity of the bladder, not only calculating uninhibited detrusor contractions, but also other factors as previously mentioned. Therefore, this method of urodynamic investigation can result in a more objective clinical picture. Moreover, ACM has a higher sensitivity and specificity compared to standard cystometry and therefore is a more representative measurement of bladder overactivity in a separate patient ${ }^{8,10}$.

Another theory is that the intravesical transducers cause bladder contractions (artifacts) because of bladderwall irritation. During SNS these contractions might be inhibited because of the SNS, because bladder hypersensivity is reduced due to SNS. But these patients have underwent ACM during and without SNS, and therefore these possible evoked bladder contractions should be equally divided and have no influence on the reduction of the DAI.

The reduction in DAI has a significant correlation (coefficient $=0.478, \mathrm{p}=0.03$ ) to the effect of sacral neuromodulation, which is represented by subjective effect and voiding dairies. The total result of our patient group is lower as could be expected from a normal population, this could be due a selected group of patients. Data of patients used in this study was data of the first patients considered for neuromodulation in our hospital and also patients who did not met the criteria for inclusion in the larger multicenter prospective study simultaneously running in our hospital. Therefore these patients may have a worse outcome as may be expected from this therapy.

\section{Conclusions}

The objective urodynamic and subjective results show a decrease in bladder overactivity during SNS. During SNS bladder instabilities are still present, but bladder overactivity is reduced. Improvements of ambulant cystometric parameters correlate with the clinical efficacy of SNS. 


\section{References}

1. Schmidt RA, Jonas U, Oleson KA, Janknegt RA, Hassouna MM, Siegel SW and van Kerrebroeck PE: Sacral nerve stimulation for treatment of refractory urinary urge incontinence. Sacral Nerve Stimulation Study Group. J Urol. 162: 352-357, 1999.

2. Weil EH, Ruiz Cerda JL, Eerdmans PH, Janknegt RA, Bemelmans BL and van Kerrebroeck PE: Sacral root neuromodulation in the treatment of refractory urinary unge incontinence: a prospective randomized clinical trial. Eur Urol. 37: 161-171, 2000.

3. Hassouna MM, Siegel SW, Lycklama à Nyeholt AA, Elhilali MM, van Kerrebroeck PE, Das AK, Gajewski JB, Janknegt RA, Rivas DA, Dijkema H et al: Sacral neuromodulation in the treatment of urgency-frequency symptoms: a multicenter study on efficacy and safety. J Urol. 163: 1849-1854, 2000.

4. Jonas U, Fowler CJ, Chancellor MB, Elhilali MM, Fall M, Gajewski JB, Grünewald V, Hassouna MM, Hombergh U, Janknegt R et al: Efficacy of sacral nerve stimulation for urinary retention: results 18 months after implantation. J Urol. 165: 15-19, 2001.

5. Koldewijn EI, Rosier PF, Meuleman EJ, Koster AM, Debruyne FM and van Kerrebroeck PE: Predictors of success with neuromodulation in lower urinary tract dysfunction: results of trial stimulation in 100 patients. J Urol. 152: 2071-2075, 1994.

6. Bosch JL and Groen J: Sacral (S3) segmental nerve stimulation as a treatment for urge incontinence in patients with detrusor instability: results of chronic electrical stimulation using an implantable neural prosthesis. J Urol. 154: 504-507, 1995.

7. Bosch $\mathrm{JL}$ and Groen J: Sacral nerve neuromodulation in the treatment of patients with refractory motor urge incontinence: long-term results of a prospective longitudinal study. J Urol. 163: 1219-1222, 2000.

8. van Waalwijk van Doom ES, Ambergen AW and Janknegt RA: Detrusor activity index: quantification of detrusor overactivity by ambulatory monitoring. J Urol. 157: 596-599, 1997.

9. van Waalwijk van Doorn E, Anders K, Khullar V, Kulseng Hanssen S, Pesce F, Robertson A, Rosario D and Schafer W: Standardisation of ambulatory urodynamic monitoring: Report of the Standardisation Sub-Committee of the International Continence Society for Ambulatory U rodynamic Studies. Neurourol Urodyn. 19: 113-125, 2000.

10. van Waalwijk van Doorn ES and Ambergen AW: Diagnostic assessment of the overactive bladder during the filling phase: the detrusor activity index. BJU Int. 83: 216-221, 1999.

11. Everaert K, Plancke H, Lefevere F and Oosterlinck W: The urodynamic evaluation of neuromodulation in patients with voiding dysfunction. Br J Urol. 79: 702-707, 1997.

12. Hasan ST, Robson WA, Pridie AK and Neal DE: Transcutaneous electrical nerve stimulation and temporary $\mathrm{S} 3$ neuromodulation in idiopathic detrusor instability. J Urol. 155; 2005-2011, 1996. 
60 


\section{Chapter 6}

\section{Unilateral versus bilateral sacral} neuromodulation in patients with chronic lower urinary tract dysfunction 


\section{Abstract}

\section{Purpose}

Bilateral sacral nerve neuromodulation has been proposed as a more effective treatment for chronic voiding dysfunction. However no comparison with the unilateral approach has been performed. We investigated the possible advantage of bilateral sacral neuromodulation.

\section{Materials and methods}

In a prospective randomized crossover trial we investigated 33 patients who underwent bilateral implantation of a temporary test lead. Unilateral and bilateral test stimulation was continued for 4 to 6 days in all patients. Patients were randomly assigned to start with bilateral or unilateral stimulation. Between the stimulation episodes a 2-day washout interval was scheduled. Voiding diaries were completed at baseline and during the entire stimulation period. Sacral $\mathrm{x}$-rays were taken to confirm lead positioning or possible migration after implantation and at the end of the test stimulation period. After 10 days the temporary leads were removed and voiding diaries were analyzed.

\section{Results}

After stimulation sacral $\mathrm{x}$-ray revealed test lead migration in 8 patients, leaving 12 patients with urge incontinence and 13 with voiding difficulty and urinary retention available for review. A statistically significant improvement in voiding parameters was seen during the test stimulation period. However no statistically significant improvement was seen due to bilateral stimulation compared to unilateral stimulation. Two patients with urinary retention only started voiding to completion during bilateral stimulation.

\section{Conclusions}

Bilateral is in general not superior to unilateral sacral neuromodulation. However, in some individuals bilateral stimulation may be more effective in relieving symptoms. Therefore, if unilateral percutaneous nerve evaluation fails, a bilateral test should be considered. 


\section{Introduction}

Unilateral sacral nerve stimulation is advocated as a relatively new treatment modality for patients with various refractory voiding disorders. The effectiveness of unilateral sacral nerve stimulation has been reported in various clinical trials for the treatment of urgency/frequency, urge incontinence and idiopathic urinary retention ${ }^{13}$. Patients who experience a sufficient subjective and objective improvement during a percutaneous nerve evaluation test are selected for final implant of a neuromodulation system ${ }^{45}$.

Although temporary and chronic sacral nerve stimulation can result in impressive clinical improvement up to complete relief of symptoms, a considerable group of patients still improve only partially, requiring further pad use or intermittent catheterization $^{13,6,7}$.

Percutaneous test stimulation is currently the only method available to evaluate whether neuromodulation leads to a significant improvement in an individual". This method also closely resembles implantation of the sacral neuromodulation system. Use of the new test lead design allows for correct identification of candidates for sacral neuromodulation and reduces the chances of lead migration ${ }^{\text {, } 10}$.

Bilateral sacral neuromodulation has been suggested to be a more effective technique for voiding dysfunction in animal studies ${ }^{11}$, as well as in neurologically intact patients ${ }^{12}$. However, to our knowledge the unilateral approach has not been compared to the bilateral approach. Therefore, we designed a prospective randomized crossover trial, in which each patient underwent unilateral as well as bilateral test stimulation to assess the possible advantages of bilateral stimulation.

\section{Materials and Methods}

From January 1999 to May 2001, 33 patients with chronic voiding dysfunction, defined as urge incontinence with or without urodynamic instabilities, complete urinary retention and incomplete voiding with residual of more than $100 \mathrm{ml}$. were randomized in a 2 -arm crossover design (fig. 1) after signed informed consent. This design was used so patients could act as their own control group and, therefore, it required a smaller sample size. All patients underwent baseline screening, including medical and urological history, physical examination and urodynamic testing. Patients were included in the study if the voiding disorder was refractory to appropriate conventional treatments. Eligible participants were older than 16 years and had no stress incontinence, untreated urinary tract infection, stone disease, psychiatric disturbance, pregnancy, neurogenic voiding disorders (including diabetes mellitus, spinal cord injury, multiple sclerosis), Reiter's syndrome, pelvic pain syndrome, cerebrovascular accident less than 6 months ago, anatomical obstructive voiding disorders, malignancy of the urinary tract, severe (grade III/ IV) pelvic prolapse, cystocele, urethrocele, enterocele, proven interstitial cystitis or evident functional neurological asymmetry 


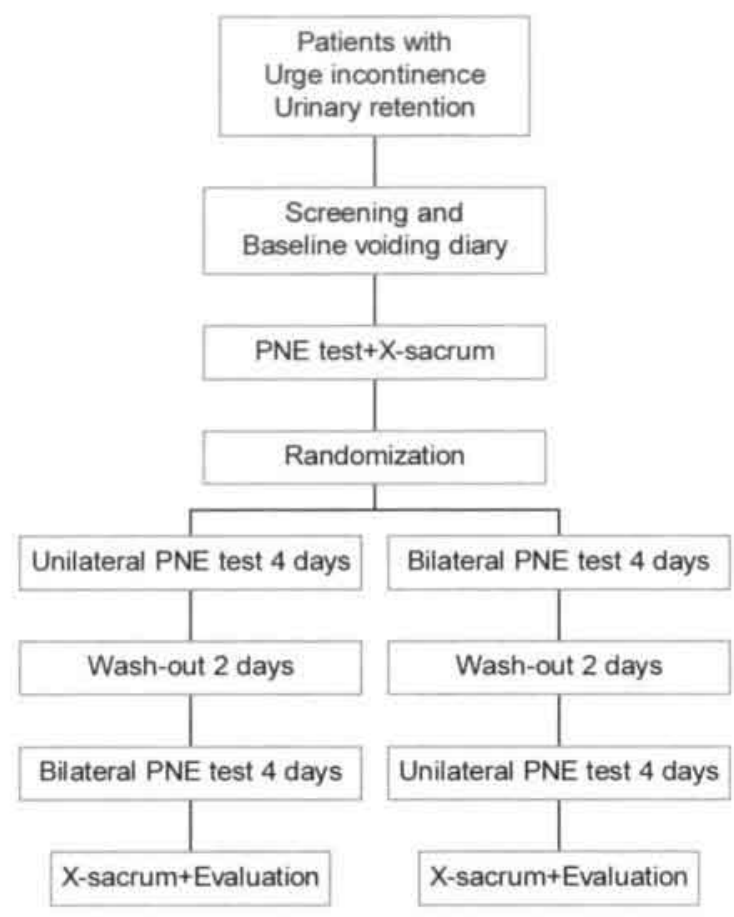

Fig. 1. Flow chart of percutaneous nerve evaluation $(P N E)$ test, interrupted by 2 -day washout period. During all phases and at baseline voiding diaries were completed. After implantation of leads and at end of 10-day test anter or posterior and lateral sacral $\mathrm{x}$-rays ( $\mathbf{x}$-sacrum) were obtained.

All 33 patients subsequently underwent a bilateral trial test stimulation of the sacral nerves in a standardized manner ${ }^{45}$. The test lead was connected to an external stimulation device suitable for bilateral stimulation (Medtronic Dualscreen 3628). This stimulator delivers alternating pulses left and right as would be the same situation in case of bilateral implant with the synergy implantable pulse generator (Medtronic Synergy 7427 Medtronic Europe S.A., Tolochenaz, Switzerland). Left and right amplitudes can be programmed individually, and were programmed at an amplitude just above sensory threshold. Patients were instructed to adjust the stimulation amplitude if necessary. Therefore, patients could not be blinded for unilateral or bilateral stimulation.

Unilateral and bilateral test stimulation was continued for at least 72 hours in all patients. Patients were randomly assigned to start with bilateral and unilateral stimulation. Between the stimulation episodes a 2-day washout interval was scheduled of at least 48 hours. During this period the external stimulator was switched off, so no stimulation was applied to the nerves. After this interval patients crossed over to unilateral or bilateral stimulation respectively. The unilateral side (left or right) was chosen based on where the best response at the lowest amplitude was necessary to elicit the proper sensory response during acute testing. 
No contralateral testing was used because the test stimulation protocol would last an additional 4 days of stimulation and an additional 2-day washout period, which would increase chances of lead migration and infection. In addition, during normal unilateral percutaneous nerve evaluation testing the side with the best response using the lowest amplitude was normally also chosen for evaluation.

Standardized voiding diaries were used to record voiding, catheterization and leaking episodes ${ }^{1.3}$. Patients collected and measured urine volume using standard measuring cups. The voiding diaries were completed at baseline and during the unilateral and bilateral stimulation periods and washout period. In addition, subjective improvement was scored using a urological questionnaire (Appendix 1).

Anterior-posterior and lateral sacral $\mathrm{x}$-rays were taken after implantation of the temporary lead and at the end of the test stimulation period to confirm lead positioning or possible migration. After 10 days the temporary leads were removed and voiding diaries were analyzed (fig. 1).

If lead migration occurred during the test, proven by sacral $\mathrm{x}$-ray and loss of appropriate reactions, the patient was excluded from study as no true bilateral treatment effect could be expected. A difference of $50 \%$ between unilateral and bilateral stimulation was assumed to be clinically relevant and worth the effort and costs for bilateral stimulation, as is the case of unilateral stimulation. A power analysis (Pocock) showed that 12 patients were needed to show $50 \%$ difference between unilateral and bilateral stimulation ( $\alpha 0.05,1-\beta 80 \%)$.

For analyses the voiding results were stratified for urge incontinence and urinary retention (patients with voiding difficulty and complete urinary retention). Based on the voiding diary data and questionnaire information, a comparative analysis between respectively baseline to unilateral, baseline to bilateral and unilateral to bilateral was performed using the Wilcoxon signed ranks test with $p<0.05$ considered statistically significant. For all data analysis SPSS software 9.0 (SPSS, Inc. Chicago, Illinois) was used.

\section{Results}

Patient characteristics are presented in the table, which also summarizes the different treatments patients underwent before they were offered a percutaneous nerve evaluation test. During the percutaneous nerve evaluation test 30 patients showed the correct motor ("bellows-like") response and 3 did not. All 33 patients did experience the typical well-known sensations in the perineal area ${ }^{4.5}$.

The first post-percutaneous nerve evaluation $\mathrm{x}$-rays showed that the electrodes were situated through the foramen of S3 in 31 patients and through S4 in 2. By means of randomization 16 of the 33 patients started with unilateral stimulation and 17 started with bilateral stimulation. The post-percutaneous nerve evaluation sacral $x$-rays at the end of the last stimulation period revealed unilateral lead migration in 8 patients and the appropriate reactions were also lost. Therefore, 12 patients with urge incontinence and 13 with retention group, were analyzed (Appendix 2). 
Table 1. Patient characteristics.

\begin{tabular}{lcl}
\hline Age & 45,5 years & range 28-65 \\
\hline Gender & number of patients & $\begin{array}{l}\text { percentage } \\
(18.2 \%)\end{array}$ \\
Male & 6 & $(81.8 \%)$ \\
Female & 27 & \\
\hline $\begin{array}{l}\text { Diagnosis } \\
\text { Urge incontinence }\end{array}$ & 18 & $(54.6 \%)$ \\
Voiding difficulty & 8 & $(24.2 \%)$ \\
Urinary tetention & 7 & $(21.2 \%)$ \\
& & \\
\hline Previous treatment & 24 & $(72.7 \%)$ \\
- Medication & 13 & $(39.4 \%)$ \\
- Physiotherapy & & \\
& & \\
- Operation & 21 & $(63.3 \%)$ \\
- None & 1 & $(3.0 \%)$ \\
- Burch suspension & 6 & $(18.2 \%)$ \\
- Sling suspension & 2 & $(6.1 \%)$ \\
- Bladder dilatation & 3 & $(9.1 \%)$ \\
- Urethral dilatation & & \\
\hline
\end{tabular}

The urge incontinence group had a significant reduction in pad use compared from baseline to unilateral and bilateral stimulation. No significant difference was found between unilateral and bilateral stimulation (fig.2). The severity of leakage reduced significantly compared from baseline to stimulation with no significant difference between the groups (fig.2). A significant reduction was also seen in the number of voids per 24 hours compared from baseline with no significant difference between the groups (fig.2). Also a significant increase in volume per void was found after with no significant difference between groups (fig.2).

In the retention group the volume per void did not increase significantly during unilateral stimulation but did increase significantly during bilateral stimulation. Comparing the volume per void between unilateral and bilateral stimulation, no significant difference was found during bilateral stimulation (fig. 2). However, the most important factor in these patients was catheterized volume, which decreased significantly from baseline with no significant difference between groups (fig. 2). The questionnaires revealed no significant subjective difference between the unilateral and bilateral stimulation period, in the urge incontinence $(p=0.541)$ or in retention $(p=0.362)$ groups. However, 2 patients with retention started voiding only during bilateral stimulation with residuals of less than $100 \mathrm{ml}$. Both patients underwent a bilateral implant with the implantable pulse generator (Medtronic 


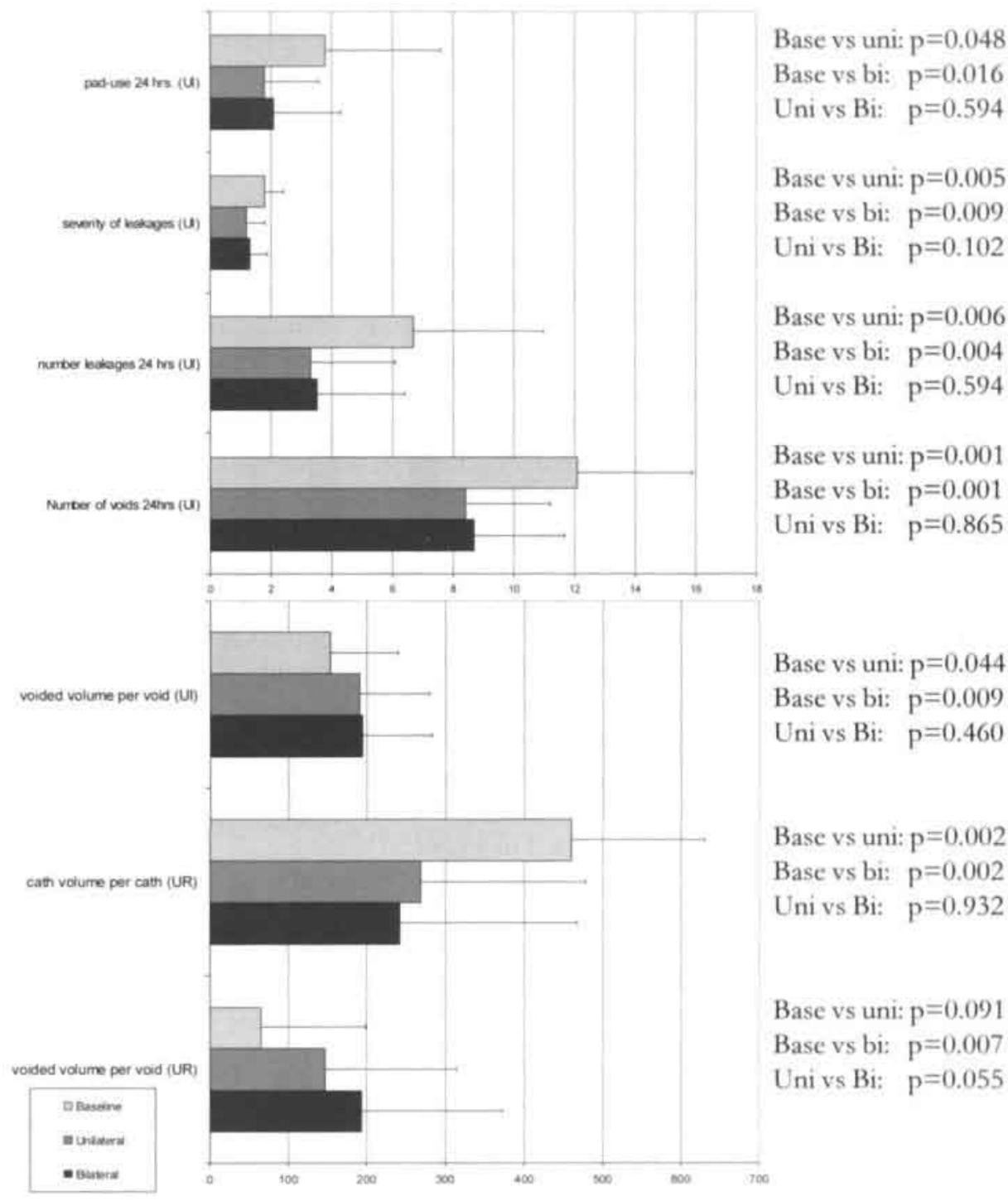

Figure 2. Key voiding diary data of urge incontinent (UI) and urinary retention (UR) at baseline, and during unilateral (umi) and bilateral $(b i)$ stimulation. Significance levels are provided comparing baseline versus unilateral stimulation (base vs uni), baseline versus bilateral stimulation (base vs bi) and unilateral versus bilateral (uni is $b i)$. Severity of leakages are quantified as 0 -no leakage, 1drops of urine loss, $2-3 \mathrm{ml}$. urine loss and 3-totally wet pad or diaper. Volumes are presented in ml. catb volume per catb, catheterized volume per catheterization 
Synergy 7427) and are still voiding with less than $100 \mathrm{ml}$. residual urine after 6 months of follow up (fig. 3 ) during which both patients completed a voiding diary for at least 72 hours. They performed at least once daily clean intermittent self-catheterization for retention measurements and do not perform catheterization anymore.

\section{Discussion}

Innervation of the bladder is considered to be bilateral, as each half of the bladder has its own confined innervation ${ }^{13.14}$. The small bladder afferents $(A \delta$ and $C$ fibers) are conducting the sensations of noxious stimuli, urge and bladder distention, ${ }^{15}$ and are also considered to be bilateral via the pelvic nerve. Therefore, unilateral neuromodulation might only be partially effective, either by not influencing the entire bladder or allowing new formation of pathophysiological pathways. Consequently, bilateral neuromodulation was introduced and has been propagated as a more effective method of sacral neuromodulation ${ }^{12,16}$.

In a cat animal model bilateral neuromodulation showed to be more effective in inhibiting detrusor contractions than unilateral or multisegmental (multiple ipsilateral sacral nerves) neuromodulation" ${ }^{11}$.

Bilateral stimulation of the $\mathrm{S} 3$ nerve has also been reported as a tool to treat stress incontinence in patients with spinal cord injury after implantation of a sacral anterior root stimulator and posterior rhizotomies ${ }^{17}$. However a high amount of current is necessary to achieve constant contraction of the pelvic floor. These reports suggest that bilateral sacral neuromodulation is a better method for neuromodulation of the lower urinary tract. However, no comparison with the unilateral method has been performed in a clinical setting.

Our data do not support the effectiveness of bilateral implantation for most patients. In total 23 patients had no additional effect of bilateral compared to unilateral stimulation. Only 2 of our 25 patients $(8 \%)$ had additional benefit during bilateral compared to unilateral stimulation. These 2 patients, with complete urinary retention started voiding to completion only during bilateral stimulation. The rationale in these 2 cases could be that with bilateral stimulation sufficient sacral nerve afferents are stimulated to achieve marked effect at the level of the central nervous system. All other patients with urinary retention had no additional benefit from bilateral stimulation. No factor could be found to predict possible suitable candidates for bilateral stimulation other than urinary retention. It is possible that in these patients only bilateral neuromodulation provides sufficient electrical input to the sacral nerves to achieve a clinical effect. In both patients with retention the Synergy implantable pulse generator was used for bilateral stimulation and are after 6 months of followup, both are voiding with less than $100 \mathrm{ml}$. residual urine (fig. 3).

Thus, some individuals may benefit from bilateral neuromodulation. However, during unilateral stimulation $92 \%$ of the patients achieved more than sufficient improvement of complaints and therefore, bilateral stimulation could not bring about additional results. However, in the perspective of cost-effectiveness it seems obvious to try unilateral before bilateral sacral neuromodulation. If a unilateral 
percutaneous nerve evaluation test fails, a bilateral test should at least be considered. If a bilateral test is successful patients can be implanted with the bilateral neuromodulation system.

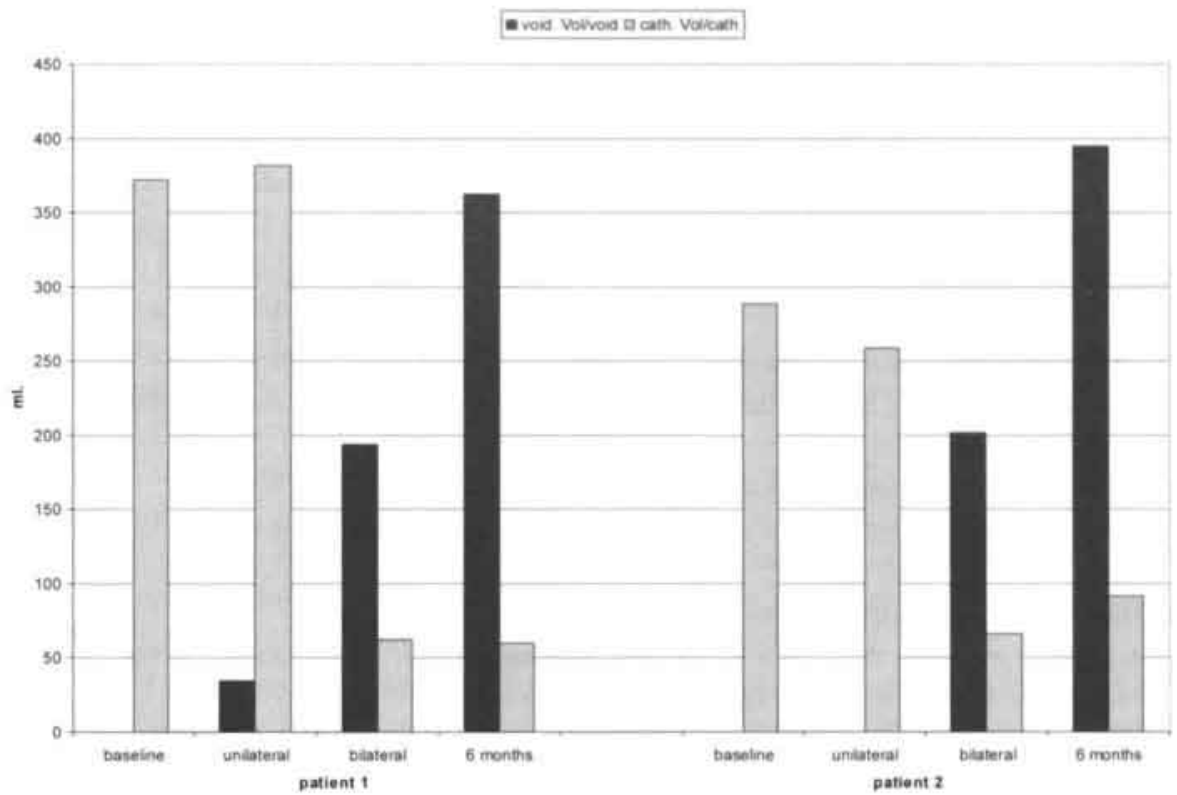

Fig. 3. Diary data voided volume per void (void Vol/void) and catheterized volume per catheterization (catb. vol/cath) of 2 patients who only started voiding during bilateral stimulation. Both were implanted with implantable pulse generator and are still voiding with less than $100 \mathrm{ml}$. residual urine after 6 months of followup.

\section{Conclusions}

In this randomized trial we compared the clinical effect of temporary unilateral versus bilateral sacral nerve stimulation. Significant differences in unilateral versus bilateral neuromodulation could not be demonstrated. However, in some individuals only bilateral stimulation was effective in relieving symptoms. Therefore, if a unilateral percutaneous nerve evaluation test fails a bilateral test should be considered. 
Questionnaire

1.Do you think that voiding in general goes better?

No, ir's much worse / no it's worse / no difference / yes, some improvement / yes, a lot better

2.Do you think that you flow has improved?

No, it's much worse / no it's worse / no difference / yes, some improvement / yes, a lot better

3.Does your bladder feel emptier?

No, it feels much fuller / No, it feels a bit fuller / no difference / yes, it's emptier / yes, it's much emptier

4.Do you think that you are drier?

No, much wetter / no, a bit wetter / no difference / yes, a bit dricr / yes, much drier

5. Have your urge-sensations changed?

Clearly worsened / a bit worse / no difference / a bit less / clearly diminished

6.Has your voiding frequency changed?

No, I had to go more often / No, I had to go a bit more often / no difference / Yes, I had to go somewhat less often / Yes, 1 clearly had to go less often

7.Do you have more control over your bladder?

No, it's worse / No, it's somewhat worse / no difference / yes, it's better / yes, it's much better

\section{Appendix 1}

\begin{tabular}{ll}
\hline Urinary dysfunction & Key voiding parameters \\
\hline Urge-incontinence & Number of voids per 24 hrs \\
& Voided volume per void \\
& Number of leakages per 24 hrs \\
& Severity of leakages \\
& Pad-use \\
Urinary retention & Catheterised volume per catheterisation \\
& Voided volume per void \\
\hline
\end{tabular}

Appendix 2 . Key voiding parameters collected from voiding diary data per urinary dysfunction. 


\section{References}

1. Hassouna MM, Siegel SW, Lycklama à Nyeholt AA, Elhilali MM, van Kerrebroeck PE, Das AK, Gajewski JB, Janknegt RA, Rivas DA, Dijkema H et al: Sacral neuromodulation in the treatment of urgency-frequency symptoms: a multicenter study on efficacy and safety. J Urol. 163:1849-1854, 2000.

2. Schmidt R, Jonas U, Oleson K, Janknegt R, Hassouna M, Siegel S and van Kerrebroeck P: Sacral nerve stimulation for treatment of refractory urinary urge incontinence. Sacral Nerve Stimulation Study Group. J Urol. 162: 352-357, 1999.

3. Jonas U, Fowler CJ, Chancellor MB, Elhilali MM, Fall M, Gajewski JB, Grünewald V, Hassouna MM, Hombergh U, Janknegt R et al: Efficacy of sacral nerve stimulation for urinary retention: results 18 months after implantation. J Urol. 165: 15-19, 2001.

4. Schmidt R, Senn E and Tanagho E: Functional evaluation of sacral nerve root integrity. Report of a technique. Urology. 35: 388-392, 1990.

5. Sieget S: Management of voiding dysfunction with an implantable neuroprosthesis. Urol Clin North Am. 19: 163-170, 1992.

6. Bosch JL and Groen J: Sacral nerve neuromodulation in the treatment of patients with refractory motor urge incontinence: long-term results of a prospective longitudinal study. J Urol. 163: 1219-1222, 2000.

7. Weil E, Ruiz Cerda J, Eerdmans P, Janknegt R, Bemelmans B and van Kerrebroeck P: Sacral root neuromodulation in the treatment of refractory urinary urge incontinence: a prospective randomized clinical trial. Eur Urol. 37: 161-171, 2000.

8. Koldewijn EL, Rosier PF, Meuleman EJ, Koster AM, Debruyne FM and van Kerrebroeck PE: Predictors of success with neuromodulation in lower urinary tract dysfunction: results of trial stimulation in 100 patients. J Urol. 152: 2071-2075, 1994.

9. Weil EH, Ruiz Cerda JL, van den Bogaard AE and van Kerrebroeck PE; Novel test lead designs for sacral nerve stimulation: improved passive fixation in an animal model. J Urol. 164: 551-555, 2000.

10. Carey M, Fynes M, Murray C and Maher C: Sacral nerve root stimulation for lower urinary tract dysfunction: overcoming the problem of lead migration. BJU Int. 87: 15-18, 2001.

11. Schultz-Lampel, D.: Neurophysiological basis and clinical applications of sacral neuromodulation in the treatment of voiding dysfunction. Thesis, University of Witten/Herdecke Wupertal, 1997

12. Hohenfellner M, Schultz Lampel D, Dahms S, Matzel K and Thuroff JW: Bilateral chronic sacral neuromodulation for treatment of lower urinary tract dysfunction. J U rol. 160: 821-824, 1998.

13. Diokno AC, Davis R and Lapides ]: The effect of pelvic nerve stimulation on detrusor contraction. Invest Urol. 11:178-181, 1973.

14. Ingersoll EH, Jones LL and Hegre ES: Effect on urinary bladder of unilateral stimulation of pelvic nerves in the dog. Am J Physiol. 189: 167-172, 1957.

15. De Groat W: Anatomy and physiology of the lower urinary tract. Urol Clin North Am. 20: 383-401, 1993.

16. Hohenfellner M, Dahms SE, Matzel K and Thüroff JW: Sacral neuromodulation for treatment of lower urinary tract dysfunction. BJU Int. 85: 10-19, 2000.

17. Everaert K, Derie A, Van Laere M and Vandekerckhove T: Bilateral S3 nerve evaluation, a minimally invasive alternative treatment for postoperative stress incontinence after implantion of an anterior root stimulator with posterior rhizotomy: a preliminary observation. Spinal Cord. 38; 262-264, 2000. 


\section{Chapter 7}

\section{Long-term efficacy and safety results of the two stage implantation technique in sacral neuromodulation}

WA Scheepens, GA van Koeveringe, RA de Bie, EHJ Weil, PhEV van Kerrebroeck

BJU International 2002;90:840-845. 


\section{Abstract}

\section{Objective}

To asses the long-term efficacy and safety of two-stage sacral neuromodulation with an implantable pulse generator (IPG) in patients treated for urge incontinence (UI) and/or urinary retention (UR).

\section{Patients and methods}

The two-stage implantation technique is used if patients have a good responses during the acute phase of the percutaneous nerve evaluation (PNE) test, but have a poor response during the following 4-7 days (sub-chronic phase). In the first stage only the permanent electrode was implanted and connected to a temporary external stimulator, allowing patients to be assessed for longer. If main symptoms improved by more than half the patient proceeded to the second stage, the insertion of the IPG. We reviewed all patients who underwent a two-stage implantation the long-term efficacy and safety results of patients who underwent the twostage sacral neuromodulation Patients can be screened for a longer period of time We reviewed all patients who underwent a two-stage implantation; all had signed an informed consent and were asked to complete voiding diaries and a questionnaire to asses the subjective effects of the therapy. Safety was assessed from relevant medical events, management, and relative to the therapy and resolution. Residual urine was assessed by self-catheterization. Long-term voiding diary results were compared with baseline estimates and analysed statistically using the two- sided Student's $t$-test.

\section{Results}

Between 1991 and 1998, 15 patients (13 women and two men, mean age 53 years, range 44-66) underwent the two-stage technique, the mean (median, range) follow-up was $4.9(5.2,2.5-7.5)$ years. Seven patients had UI and seven had UR, with one having both. The mean (range) number of PNEs undertaken in each patient was $2.1(1-4)$ and these all failed in the sub-chronic phase. All patients underwent a first and a second stage implant after a mean (range) screening period of 12.2 (2-29) days. One patient was explanted after implantation of only the first stage, and two other explanted in a later phase because the IPG was ineffective during the follow-up. The voiding diary results of the remaining 12 patients showed improvement in all the main variables, and in the subjective assessment 11 reported an improvement and were satisfied with the therapy. There were 17 adverse events, 14 of which were resolved and seven of which required surgical intervention.

\section{Conclusion}

The long-term results of the two-stage implant show clinically and statistically significant improvements, probably because the implantation of the lead (first stage) more closely resembles the final therapy. If a temporary PNE-test is not optimal (lead migration, longer testing time needed), the two-stage technique can offer a good and safe alternative of comparable efficacy in the long-term. If the two-stage technique had not been available to these 12 patients, they would not have been offered neuromodulation. 


\section{Introduction}

Sacral neuromodulation (SN) is an established and FDA-approved treatment for patients with refractory chronic urinary dysfunction, like urgency/frequency, urge incontinence (UT) and urinary retention (UR) ${ }^{1.3}$. Other indications for SN, e.g. interstitial cystitis, multiple sclerosis and other neurogenic voiding dysfunction's, are also under investigation and show promising results ${ }^{4.7}$.

One of the advantages of this treatment is that the expected success of the final implant can be assessed beforehand by the percutaneous nerve evaluation (PNE) test. However a disadvantage is that the reported success rates of the PNE are only $40-50 \%{ }^{8}$. Although remaining patients are considered as not responding, the reason can be technical failure, i.e. displacement of the PNE-lead (testing-wire) from the original position close to the sacral roots, often visible on a sacral X-ray, with the wire is lying outside of the foramen.

Janknegt et.al. reported on the use of the two stage implantation technique and its short-term results in 10 patients ${ }^{8}$. This method can be used if patients have good responses during the acute phase of the PNE test (good sensory and motor response), but a poor response in the following 4-7 days of stimulation (sub-chronic part). In the first stage of this two-stage procedure only the permanent electrode was implanted and connected to a temporary external stimulator. Patients were screened for longer than the standard PNE procedure (4-7 days). If there is an improvement in the main symptoms recorded in the voiding diaries (by more than half) the patient is a candidate for the second stage, the insertion of the implantable pulse generator (IPG).

Long-term results for standard SN procedures are well documented and the reported success rate is $60-70 \%$ for various indications ${ }^{1-5}$. We assessed the longterm efficacy and safety results of patients who underwent the two-stage SN procedure.

\section{Patients and Methods}

All patients who were implanted using the two-stage technique for $\mathrm{SN}$ in our department were assessed. Before implantation all patients underwent successive PNE tests to evaluate whether they were candidates for implantation. The PNE test is divided into the acute and the subchronic phase: In the former, during stimulation of the sacral nerves, there should be an appropriate sensory reaction (in the perineal area) and a motor action consisting of levator contraction, as seen by a contraction of the anus ('bellows-like' contraction). A concomitant contraction of the ipsilateral big toe indicates whether $\mathrm{S} 3$ has been stimulated. Stimulating the foramen of S2 usually causes a rotation of the leg, but of S4 causes no leg or toe movement.

If adequate responses are present during the acute phase a stimulation wire is placed via the lumen of the test needle. The wire is then anchored to the skin with tape and connected to an external stimulator. The patient can apply stimulation using this external stimulator at sensory threshold. 
The chronic phase of the test comprises $4-7$ days during which the sacral nerve is stimulated continuously. During this phase the patient accurately completes a voiding diary for later evaluation. After the wire is removed the results from voiding diaries completed before, during and after the test are compared. To prevent as far as possible any psychogenic influences, a third diary is completed for another week after the test, in which there should be a return to the baseline values.

Currently, the criterion used for implanting the permanent stimulator (IPG) is that the patient shows an improvement by more than half in their primary voiding diary variables (Table 1), and thus is considered as responding, and than is a candidate for a permanent electrode implanted in the same foramen, eventually connected to a subcutaneous permanent IPG (Medtronic, Minneapolis, MN, USA).

Table 1. Urinary dysfunctions, the key voiding variables and their criteria for the indicating the implantation of the IPG. The asterisk indicates the most important selection variables

\begin{tabular}{|c|c|c|}
\hline Urinary dysfunction & Key voiding parameters & Criterion \\
\hline \multirow[t]{3}{*}{ urgency-frequency } & number of voids per $24 \mathrm{hrs}$ & decreased* \\
\hline & voided volume per void & increased \\
\hline & urge to void prior to voiding & decreased \\
\hline \multirow[t]{5}{*}{ urge-incontinence } & number of voids per $24 \mathrm{hrs}$ & decreased \\
\hline & voided volume per void & increased \\
\hline & urge to void prior to voiding & decreased \\
\hline & number of leakage's per $24 \mathrm{hrs}$ & decreased* \\
\hline & pad-use & decreased ${ }^{*}$ \\
\hline \multirow[t]{2}{*}{ urinary retention } & voided volume per void & increased \\
\hline & catheterised volume per catheterisation & decreased* \\
\hline
\end{tabular}

, improved if decreased or increased by more than half: ${ }^{2}$ maximum catheterised volume $<100$ $\mathrm{ml}.)^{*}$

All patients underwent the first stage of the two-stage implant, which comprised the following procedures: using a median incision over the sacrum, the permanent PICE-QUAD electrode (Medtronic) was implanted in the best sacral foramen determined during the testing. The lead was brought to the ipsilateral side in the flank, where a small additional incision was made. At that point, an extension wire was connected, which was brought subcutaneously to the contralateral side and exited the skin through a second small incision. The extension wire was connected to an external stimulator (Fig. 1a). The transposition to the contralateral side was used to prevent the risk of infection: with a long subcutaneous tunnel, this risk was minimized.

On the following days the patient completed a voiding diary as usual. If the diary showed an improvement more than half the IPG was implanted subcutaneously in the second stage. During this procedure the extension wire was removed and the IPG placed subcutaneously on the side of the first connection (Fig. 1b). 

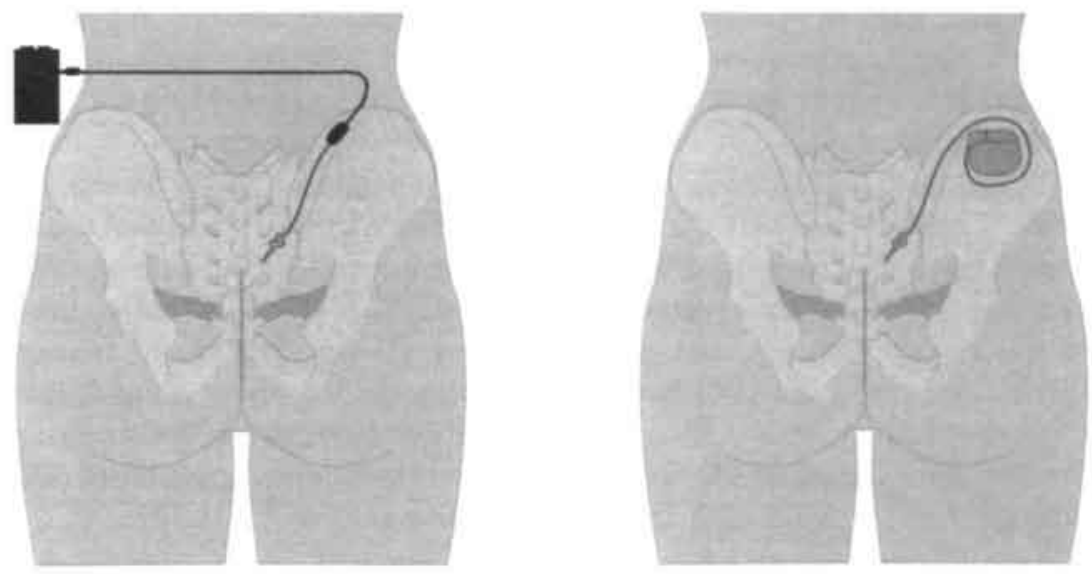

Figure 1a. Left the first stage implant: temporary wire to external stimulator

Figure 1b. Right: Second stage: permanent implant with the IPG in the Buttock

This procedure was undertaken in those patients who had failed during the usual PNE test criteria, but in whom success was anticipated because of good objective variables in the acute phase of the testing or first 2-3 days of the chronic phase.

To evaluate the long-term efficacy and safety of the two-stage procedure, the patients implanted using this procedure were asked to participate. All patients had signed an informed consent and were asked to complete their long-term voiding diaries. Residual urine was assessed by self-catheterization at least once daily to measure possible UR. An additional questionnaire was completed to assess the subjective effects of therapy (Appendix). The satisfaction and improvement score was obtained using a visual analogue scale. Long-term voiding diary results were compared with baseline diary results and statistically analysed using the two-sided Student's $t$-test.

Safety was assessed from relevant medical events, management, and in relation to the therapy and resolution status. Common definitions for classifying adverse events were used. Events not resolved after the initial report were followed until there was complete resolution or no further clinical improvement could be expected.

\section{Results}

Between 1991 and 1998, 15 patients (13 women and two men, mean age 53 years, range 44-66) were implanted using the two-stage technique for SN. The mean (median, range) follow-up was $4,9(5.2,2.5-7.5)$ years. Seven patients had UI, seven UR, and one had both after ileocystoplasty. The mean (range) number of PNEs used in each patient to evaluate the possible clinical use of SN was 2.1 (1-4). During the acute phase all patients had appropriate sensory and motor 
reactions, but failed in the subchronic phase. Failure consisted of: repeated lead migration in seven patients; an initially good response in two during the subchronic phase but that did not improve sufficiently overall; one had good subjective results but the objective results were not sufficient during the chronic phase; three had contradictory tests; and two had other technical failures caused by equipment problems. The right side was chosen for the S3 foramen in 10 patients the left in 5. All patients had a first-stage implant and the second stage implant followed after a mean (median, range) screening period of 12.2 (11, 3-29) days.

Of the 15 patients, one was explanted after the first stage, and two others later after implanting the IPG because it was ineffective during the follow-up. Thus follow-up data were available for 12 patients with the two-stage implantation. The voiding diary results are shown in table 2 : there were significant improvements in nearly all the main voiding diary variables compared with baseline.

Table 2. Diagnoses and the mean (SD) of the primary voiding diary variables at baseline and the long-term follow-up. Bold $p$ values are statistically significant.

\begin{tabular}{rlcl}
\hline Diagnosis Parameter & Baseline & Follow-up & p-value \\
\hline Urge incontinence & & & \\
voided volume/void $(\mathrm{ml})$ & $99.1(62.5)$ & $313.0(121.4)$ & $\mathbf{0 . 0 0 4}$ \\
number of voids & $12.9(5.8)$ & $7.9(2.2)$ & $\mathbf{0 . 0 5 0}$ \\
max voided volume $(\mathrm{ml})$ & $168.6(191.9)$ & $617.1(211.5)$ & $\mathbf{0 . 0 1 3}$ \\
severity of leakage ${ }^{*}$ & $1.8(0.3)$ & $1.3(0.3)$ & $\mathbf{0 . 0 4 1}$ \\
number of leakage & $9.0(4.3)$ & $3.2(3.4)$ & 0.079 \\
$\quad$ pad use & $5.0(2.4)$ & $1.0(1.3)$ & $\mathbf{0 . 0 0 3}$ \\
Urinary Retention & $152.5(212.6)$ & $352.9(119.5)$ & $\mathbf{0 . 0 1 7}$ \\
voided volume/void $(\mathrm{ml})$ & $302.7(128.5)$ & $70.7(40.4)$ & $\mathbf{0 . 0 2 7}$ \\
cath volume/cath $(\mathrm{ml})$ & $4.1(2.3)$ & $1.9(2.0)$ & $\mathbf{0 . 0 2 4}$ \\
number of cath & &
\end{tabular}

* Scale 0-3, where 0 is no leakage, 1 a few drops, 2:two to three tablespoons, 3: wet pad/ underwear.

The subjective results from the questionnaires and visual analogue scale showed that 11 patients perceived an improvement and were satisfied with the therapy, compared with baseline.

In all, 15 adverse events were reported by eight of the 15 patients. Adverse events requiring surgical repositioning, correction or replacement of implanted devices were reported in four patients and resolved in all but one. The commonest events associated with the use of the neuromodulation system or therapy included: leg pain and perineal pain, which were treated conservatively. Pain at the IPG site and flank pain were noted by two patients. There were no infections; 11 of these adverse events were resolved and required surgical intervention in five (Table 3). One patient reported an improvement in bowel function. 
Table 3. Adverse events and their treatments and resolvement status in 15 two-stage implanted patients.

\begin{tabular}{lcll}
\hline Adverse Event & N & cons/res & surg/res/type \\
\hline Abdominal pain & 1 & 1 & \\
Flank pain & 2 & $1 / 1$ & $1 / 1$,replace broken lead \\
No effect & 3 & $-1 / 3$ & $3 / 1 /$ explant (2), replace empty IPG (1) \\
Leg pain & 3 & $3 / 3$ & \\
Perincal pain & 3 & $3 / 3$ & \\
Pain at IPG & 2 & 2 & $1 / 0 /$ replace lead \\
Adverse bowel function & 1 & & \\
\hline
\end{tabular}

cons: conservative; res: resolved; surg:surgery has taken place; type: type of surgery

\section{Discussion}

The theory of the mechanism of action in $\mathrm{SN}$ is to correct, by regulating electrical impulses, the activities of the cholinergic, adrenergic and motor reflex pathways that initiate bladder storage and voiding. Some theories have been developed that explain the effects of SN but most of the results have been established in randomised clinical trails ${ }^{1.3}$. Animal experiments and electrophysiological studies in humans show that there is a spinal inhibitory action through the afferent branches of the pelvic and pudendal nerves ${ }^{\circ}$. Others maintain that there is a direct correction of the bladder-sphincter synchronization problems of the pelvic floor (pudendal nerve) by influencing the abnormal contractility of the pelvic floor $A$ normal reflex pathway is induced, thereby decreasing bladder instability '

In the present series, in those patients who were not successful $(<50 \%$ improvement), the PNE was repeated up to four times: it was not possible, even with the same parameters, to predict who would respond. To date there are no predictive factors, e.g. urodynamics, age, history, or gender ${ }^{10}$. Some patients have a successful acute PNE test and sometimes for 1-2 days, but it is insufficient for a permanent implant using our present criteria. Obese patients especially have this problem, as do those who are very active. In some centres therefore obesity is regarded as a contraindication for testing; these patients are not regarded as not responding, but only as technical failures, which is understandable when there may be a loose wire in the foramen, passing a layer of subcutaneous fat that may move during walking, bending or other activities. In addition, muscle contractions in active patients may also dislodge the loose wire.

However, because of the high cost of the IPG, most investigators require better confirmation of predicted success by including the subchronic testing phase. This is also arguably not absolute proof, because the patient may influence (consciously or unconsciously) the results by manipulating their voiding diary (e.g. by recording longer intervals between voids or less loss of urine).

The results of the PNE test could be improved with a more permanent electrode in the foramen, thereby preventing dislodgment of the test wire. The 
obvious disadvantage is that it involves surgery, but patients with appropriate values should not be refused $\mathrm{SN}$ only because of the present technical inability during the subchronic testing phase.

Janknegt et.al. ${ }^{8}$ showed in their short-term results that a two-stage implant can be a successful option, with success rates of $83 \%$ to $90 \%$. Patients with UI had a $50 \%-90 \%$ decrease in pad use or in incontinence episodes. Patients with urgency/ frequency also had a reduction in their frequency episodes by more than half. In those with UR there was an 'all-or-nothing' effect, i.e. $85 \%$ of these patients had normal voiding with no residual, with some residual in the remainder but otherwise practically normal voiding. None of these patients had to rely on selfcatheterization. Thus it suggests that the permanent electrode, combined with the external neurostimulator, is a reliable treatment or diagnostic method ${ }^{8}$.

In the present series all the patients were considered as unresponsive in the PNE test, on present criteria, and were therefore excluded from a permanent implant of an IPG. However, as they should were considered technical failures because the previous PNE technique was not ideal, the two-stage procedure was used improve the overall success score of testing. Current PNE is better because of the use of new coiled test leads, which are effective in applying $\mathrm{SN}$ with less likelihood of loss of responsiveness to the stimulation because of lead migration " In the past 5 years, there have been many technical improvements in the hardware; the testing needles, testing wire, implanted electrode, and stimulator have all been modified. Obviously, there is room for further improvement in the technology. Currently, the possibility of placing a permanent electrode via a minimally invasive procedure under local anaesthesia is under investigation. This provides the opportunity to undertake the acute phase of PNE and the patient can than confirm the correct sensations in the perineal area. After placing the permanent lead it can be connected to an external stimulator. Thus the two-stage implantation does not imply that a patient must undergo surgery under general anaesthesia twice. If a patient has a favourable outcome the IPG can be placed in the second stage, either under local or under general anaesthesia. Until then the two-stage implant is an alternative in those patients with an appropriate acute PNE test and an indication of a good response in the chronic test. In future, when this minimally invasive technique has been tested and developed, the twostage technique could be the standard test. The PNE technique as currently used could be an alternative or a screening method for the minimally invasive technique.

Candidates for the two-stage implant should be selected carefully; first, repeated PNEs should be tried, as it is easier to repeat a PNE than to undertake surgery, especially when this procedure is intended only as a test. There is no justification to proceed to a permanent implant if temporary testing has not separated those not responding from the technical failures. Until then, the indication for the twostage implant is limited. However, the present study shows that the long-term follow-up results of the two stage implant is satisfactory and comparable, if not better, than the normal procedure 1,2 . Therefore it is a justified option because most of the patients had a significant improvement in their symptoms, comparable with the normal procedure ${ }^{1,3,12}$. If the two-stage procedure had not been offered to the present 15 patients the 12 who were eventually successful would not have received $\mathrm{SN}$. 
Questionnaire

Do you think that voiding in general is better?

No, it's much worse / no it's worse / no difference / yes, some improvement/ yes, a lot better

Do you think that you flow has improved?

No, it's much worse / no it's worse / no difference / yes, some improvement / yes, a lot better

Does your bladder fecl emptier?

No, it feels much fuller / No, it feels a bit fuller / no difference / yes, it's emprier / yes, it's much emptier

Do you think that you are drier?

No, much wetter / no, a bit wetter / no difference / yes, a bit drier / yes, much drier

Have your urge-sensations changed?

Clearly worsened / a bit worse / no difference / a bit less / clearly diminished

Has your voiding frequency changed?

No, I had to go more often / No, I had to go a bit more often / no difference /

Yes, I had to go somewhat less often / Yes, I clearly had to go less often

Do you have more control over your bladder?

No, it's worse / No, it's somewhat worse / no difference / yes, it's better / yes, it's much better

\section{Appendix}




\section{References}

1. Schmidr RA, Jonas U, Oleson KA et.al: Sacral nerve stimulation for treatment of refractory urinary urge incontinence. Sacral Nerve Stimulation Study Group. J Urol. 162: 352-357, 1999.

2. Hassouna MM, Siegel SW, Lycklama à Nyeholt AA, et al: Sacral neuromodulation in the treatment of urgency-frequency symptoms: a multicenter study on efficacy and safety. J Urol. 163: 1849-1854, 2000.

3. Jonas U, Fowler CJ, Chancellor MB et al: Efficacy of sacral nerve stimulation for urinary retention: results 18 months after implantation. J Urol. 165: 15-19, 2001.

4. Fall M, Carlsson CA and Erlandson BE: Electrical stimulation in interstitial cystitis. J Urol. 123: 192-195, 1980.

5. Chai TC, Zhang C, Warren JW, Keay S: Percutaneous sacral third nerve root neurostimulation improves symptoms and normalizes urinary HB-EGF levels and antiproliferative activity in patients with interstitial cystitis. Urology. 55: 643-646, 2000.

6. Bosch JL and Groen J: Treatment of refractory urge urinary incontinence with sacral spinal nerve stimulation in multiple sclerosis patients. Lancet. 348: 717-719, 1996.

7. Chartier-Kastler EJ, Bosch RJLH, Perrigot M, Chancellor MB, Richard F and Denys P: Long-term results of sacral nerve stimulation (\$3) for the treatment of neurogenic refractory urge incontinence related to detrusor hyperreflexia. J Urol. 164: 1476-1480, 2000.

8. Janknegt RA, Weil EH and Eerdmans PH: Improving neuromodulation technique for refractory voiding dysfunctions: two-stage implant. Urology. 49: 358-362, 1997.

9. Lindström $\mathrm{S}$ and Sudsuang R: Functionally specific bladder reflexes from pelvic and pudendal nerve branches; an experimental study in the cat. Neurourol Urodyn. 8: 392 $393,1989$.

10. Koldewijn EL, Rosier PF, Meuleman EJ, Koster AM, Debruyne FM and van Kerrebrocck PE: Predictors of success with neuromodulation in lower urinary tract dysfunction: results of trial stimulation in 100 patients. J Urol. 152: 2071-2075, 1994.

11. Weil EH, Ruiz Cerda JL, van den Bogaard AE and van Kerrebroeck PE: Novel test lead designs for sacral nerve stimulation: improved passive fixation in an animal model. J Urol. 164: 551-555, 2000.

12. Weil EH, Ruiz Cerda JL, Eerdmans PH, Janknegt RA, Bemelmans BL and van Kerrebroeck PE: Sacral root neuromodulation in the treatment of refractory urinary urge incontinence: a prospective randomized clinical trial. Eur Urol. 37: 161-171, 2000. 


\section{Chapter 8}

\section{Buttock placement of the implantable pulse generator: a new implantation technique for sacral neuromodulation - a multicenter study}

WA Scheepens, EHJ Weil, GA van Koeveringe, D Rohrmann, HEM Hedlund, B Schurch, E Ostardo, M Pastorello, C Ratto, J Nordling, PhEV van Kerrebroeck 


\section{Abstract}

\section{Objective}

In the standard operation procedure for sacral neuromodulation, the implantable pulse generator (IPG) is implanted in a subcutaneous pocket at the lower part of the anterior abdominal wall. This procedure requires a long operation time and three incisions. With the IPG in the abdominal wall, some patients complain of displacement or pain at the IPG site postoperatively. By modifying the technique of placement of the IPG, these disadvantages are overcome.

\section{Methods}

Between August 1999 and July 2000, 39 patients underwent a buttock implant of the IPG. In 2 of these patients the position of the IPG was changed from abdominal region to the buttock. During follow-up, complications concerning the operation and location of the IPG were compared to the published literature.

\section{Results}

Operation time is reduced in all patients by approximately $1 \mathrm{~h}$. No repositioning of the patient is required during surgery. Only a short subcutaneous tunnel is required to connect the lead to the IPG. Pain at the level of the IPG was noted in $10 \%$ of the patients, which needed no further treatment. No infections were seen and the IPG did not displace postoperatively.

\section{Conclusion}

Buttock placement of the IPG in sacral nerve stimulation leads to shorter operation time; only two incisions are needed instead of three and a shorter subcutaneous tunnel is needed. Using this technique there are less complications and a lower reoperation rate. 


\section{Introduction}

Sacral neuromodulation is an established and FDA-approved therapy in patients with urgency-frequency, urge incontinence and idiopathic non-obstructive urinary retention, in whom conservative treatment has failed ${ }^{1-12}$. In this therapy, the sacral nerve is stimulated by means of an implantable pulse generator (IPG).

In the standard operation procedure, the Quad-lead (which is a wire with four electrodes) is placed in the desired sacral foramen and connected to the IPG by means of an extension cable. The IPG is placed in a subcutaneous pocket in the lower abdominal wall. During this operation, the patient has to be turned from a prone to a lateral decubitus position, re-prepared and re-draped. Three incisions have to be made. First, an incision at the level of the sacrum to implant the lead; a second incision in the flank to connect the lead to the extension cable, which has to be re-opened after turning the patient; a third incision is made in a skin crease in the lower quadrant of the abdominal wall to create a pocket that is large enough to accommodate the stimulator. This pocket is created above the fascia of the external oblique muscle, using this fascia as an anchor for the sutures fixing the IPG ${ }^{13,14}$.

This operation procedure entails a long operation time of approximately 2.5 h. With the IPG in the abdominal wall, some patients complain of displacement or pain at the IPG site postoperatively. In addition, some patients complain about the disturbing magnetic fields at certain shop counters. The IPG is sometimes turned off, because the abdominal region is in close proximity to this field. In addition, the receiver of the IPG is situated ventrally and thus facing this magnetic field. By modifying the technique of placement of the IPG from the abdominal to the buttock region, these disadvantages are overcome. This technique was first performed in the USA by Das et al. ${ }^{15}$ at Albany Medical Center, in 13 patients and turned out to be a safe technique for sacral neuromodulation.

As has been described by Siegel ${ }^{13}$, the implantation technique for this therapy had some disadvantages that were mentioned previously. Weil et al. ${ }^{17}$ showed that the main adverse event of sacral nerve stimulation is pain at the implantation site of the IPG in $29 \%$ of patients. This accounts for $42 \%$ of the total of adverse events noted in that study. Shaker and Hassouna ${ }^{0.9}$ noted 10 and $12 \%$ pain at the IPG site, which resulted in re-implantation of the IPG. Elabaddy et al. ' showed pain in 1 patient out of $17(6 \%)$, which resulted in removal of the IPG. Dijkema et al. ${ }^{5}$ presented 5 patients out of $19(26 \%)$ with pain at the IPG site. Bosch and Groen ${ }^{8}$ showed that 1 out of 18 patients $(6 \%)$ experienced pain at the IPG site, which resulted in re-implantation of the IPG. Weil et al. ${ }^{16}$ showed in 4 patients out of $36(12 \%)$ with pain at the IPG site, resulting in re-operation. Schmidt et al. ${ }^{18}$ presented in 83 of 157 patients adverse events, 23 of the patients $(15,9 \%)$ reported pain at the implantation site of the IPG. This resulted in 22 surgeries to reposition the IPG. Pain at the IPG-site is an important adverse event with the IPG in the abdominal wall, resulting in frequent re-operations. This article describes the technique of buttock placement and compares the results of abdominal versus buttock placement of the IPG to the published literature. 


\section{Materials and methods}

We reviewed 39 patients whom between August 1999 and July 2000 underwent a buttock implant of the IPG for sacral nerve modulation. Birth-date, indication for implantation, date of implantation, direct postoperative complications, late complications, current status and the patients' satisfaction with their IPGs were obtained during postoperative consultation at their urologist. All patients were implanted according to a similar technique. The implantation is performed under general anaesthesia, in different hospitals by the same surgical team. After administration of prophylactic intravenous antibiotics, the patient is positioned in a prone decubitus position, with 30 degrees anteflexion of the hips and 30 degrees flexion of the knees. The lower back, flanks, buttocks are prepared and draped sterile, using a transparent vertical sheet (Mölnlycke model 826020-21). Both feet and the perineum are exposed under this transparent drape in order to observe the typical motor reactions. The lead (Medtronic quadripolar lead, model 3080) is placed in the selected sacral foramen according to the standard procedure ${ }^{13,14}$. Once the lead is fixed, a transverse incision is made over the lateral-superior quadrant of the buttock approximately $5-10 \mathrm{~cm}$ caudal to the iliac crest, large enough to accommodate the IPG (Medtronic quadripolar IPG, model 3023). The pocket is created by means of blunt dissection in the subcutaneous fat, below Scarpa's fascia. The size of the pocket is sufficient if 3 digits can be inserted, and is about 5-6 centimetres deep. The lead is then tunnelled subcutaneously, between the sacral wound and the buttock wound using a special tunnelling device. The lead is connected to the lead extension of 10 centimetres (Medtronic, model 3095) mechanically and isolated. The lead-extension is connected to the IPG mechanically. The surplus wire is coiled up behind the IPG, which is then inserted into the subcutaneous pocket, with the inscripted part facing the skin, in order to allow telemetric programming. In buttock placement of the IPG only a short lead extension of $10 \mathrm{~cm}$ is used to reduce coiling of the wire behind the IPG. The IPG is connected to the extension cable and placed into this pocket. The wound is flushed with antibiotics and carefully closed in two layers. An X-ray of the position of the IPG is provided in $1 \mathrm{a}$ and $1 \mathrm{~b}$.

\section{RESULTS}

The average age of the patients was 51 years (range 33-72). Of these 39 patients, 22 were diagnosed with urge-incontinence, 6 with urgency-frequency syndrome, 9 patients with urinary retention, 1 with pelvic-pain syndrome and 1 with faecal incontinence. In 2 of these patients, the IPG was re-positioned from the abdominal position to the buttock on account of abdominal discomfort. The average followup time was 5.3 months (range 1-10 months). Operation time for the implantation of the neuromodulation system with the IPG in the buttock was approximately $1-1.5 \mathrm{~h}$. No repositioning of the patient is required during surgery using the buttock implant technique with respect to the IPG. Only two instead of three incisions have to be made, i.e. an incision in the flank is not needed anymore. Merely a 

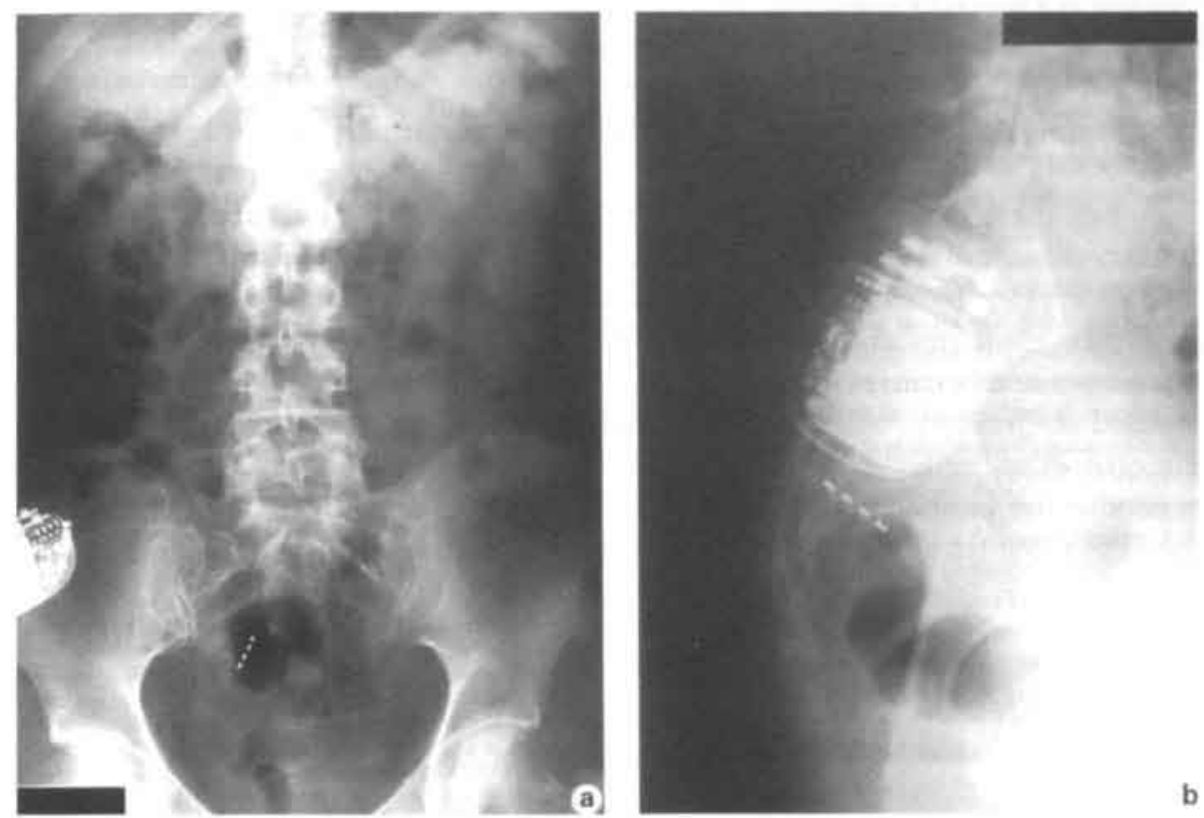

Fig. 1. Anterior-posterior (a) and lateral (b) X-ray of the final result, with the IPG in the right upper buttock and the lead in S3.

short subcutaneous tunnel is required to connect the lead at the level of the sacrum to the IPG at the level of the buttock.

During follow-up, 4 patients had some pain/discomfort at the level of the IPG implant site $(10 \%)$, which was treated with simple oral analgesics (e.g. paracetamol) postoperatively, if necessary. A re-operation to replace the IPG was not required in any of the patients. After 6 months, 3 out of 18 patients $(17 \%)$ had some pain/discomfort at the level of the IPG, which needed no further treatment. This accounts for $8 \%$ of the total group of patients. Two patients were seen with a postoperative hematoma $(5 \%)$. One hematoma was seen at the level of the IPG in the buttock, the other hematoma was seen at the abdominal region after removing the IPG at that level and placing it at the level of the buttock. These hematomas were treated conservatively and resolved completely. In this study, no infections were seen. The patient or the physician noted no problems concerning the programming of the IPG. No problems at shop counters due to magnetic fields were mentioned. The two patients with a previous abdominal placement of the IPG, reported no complaints and preferred the buttock position.

\section{DISCUSSION}

Sacral nerve stimulation is an exciting method for urologists as it offers treatment opportunities for patients for whom no treatment was available until now. This 
therapy is especially useful in patients with urge incontinence that is resistant to medication and idiopathic voiding dysfunction ${ }^{16}$.

Pain at the IPG site is the most frequent complication in sacral neuromodulation. Data from several studies, as mentioned previously, is presented in fig $2^{5-9,16-18}$.

When these data were combined (fig. 2), a mean of $15 \%$ of patients with pain at their abdominal IPG site was found, which led to a considerably high reoperation rate. In this study, after implantation of the IPG in the buttock, $10 \%$ of patients complained about pain at the IPG site. None of these patients needed to be re-operated because of pain at the IPG site over time. The pain at the IPG site seemed to decrease, as at 6 months only $8 \%$ of the patients noted some pain/ discomfort at the level of the IPG. Also in these cases no further treatment was needed. One patient complained about a numb feeling around the location of the IPG $(3 \%)$ that was not recovered after six months.

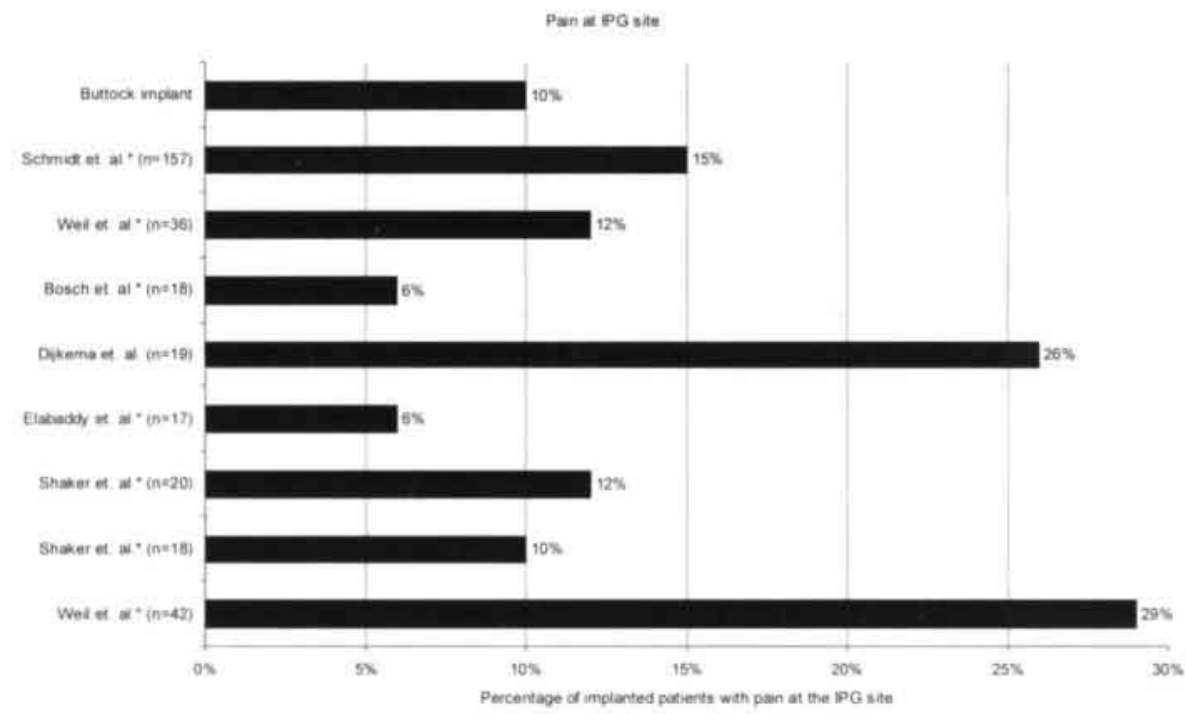

Figure 2. Percentage of patients with pain at the IPG site. In all studies the IPG was implanted in the abdominal wall. The buttock implant group $(10 \%)$ shows the results of this study, no reoperations were required. Studies marked with:* re-operations required to replace the IPG because of pain.

The operation time of the implantation of the neuromodulation system with the IPG in the abdominal region is approximately 2.5-3 h. Implantation of the neuromodulation system with the IPG in the buttock takes approximately 1-1.5 $\mathrm{h}$. This reduction in operation time from approximately 2.5 to $1-1.5 \mathrm{~h}$ is mainly due to the fact that the patient does not have to be turned from a prone to a lateral decubitus position. Only two incisions are needed in this technique instead of three. The incision in the flank, which needed to be closed two times (e.g. before turning the patient and after surgery), is not necessary. The patient does 
not have to be re-prepared and re-draped. In this technique, a short subcutaneous tunnel is needed to connect the IPG to the lead, as compared to the abdominal implantation. Leaving out these factors also reduces the risk of infection. With the IPG in the abdominal wall, infections were seen in $2,5-6.1 \%$ of the cases, in this study no infections were seen ${ }^{17,19}$. With the IPG in the buttock position no problems at shop counters were mentioned. This is probably due to a larger distance from the magnet; therefore the magnetic field has a lower intensity, so that the IPG is not switched off. In addition, the receiver of the IPG in the buttock region is facing dorsally and not facing the magnet and is therefore probably not influenc

The buttock implantation technique provides advantages to both the patient and to the urologist. Therefore, in our opinion, it can be considered an improvement for sacral nerve stimulation and the first choice implantation technique.

\section{CONCLUSION}

Buttock placement of the IPG in sacral nerve stimulation involves less pain at the IPG implantation site, shorter operation time, two instead of three incisions and a shorter subcutaneous tunnel. Patients, who previously had the IPG implanted in the abdominal wall, prefer the buttock position of the IPG. Applying this technique for sacral nerve stimulation is, in our opinion, the first choice of implantation technique. 


\section{References}

1. Kerrebroeck van PEV: A treatment algorithm for the overactive bladder. $\mathrm{Br}$ J Urol 83:(suppl 2): 29-30, 1999.

2. Schmidt RA: Applications of neurostimulation in urology. Neurourol Urodyn 7: 585592,1988 .

3. Schmidt RA, Senn E and Tanagho EA: Functional evaluation of sacral nerve root integrity. Report of a technique, Urology. 35: 388-392, 1990.

4. Thon WF, Baskin LS, Jonas U, Tanagho EA and Schmidt RA: Neuromodulation of voiding dysfunction and pelvic pain. World J Urol. 9: 138-141, 1991.

5. Dijkema HE, Weil EHJ, Mijs PT and Janknegt RA: Neuromodulation of sacral nerves for incontinence and voiding dysfunctions. Clinical results and complications. Eur Urol. 24: 72-76, 1993.

6. Shaker HS and Hassouna MM: Sacral nerve root neuromodulation: an effective treatment for refractory urge incontinence. J Urol. 159: 1516-1519, 1998.

7. Elabaddy AA, Hassouna MM and Elhilali MM: Neural stimulation for chronic voiding dysfunctions. J Urol. 152: 2076-2080, 1994.

8. Bosch JL and Groen J: Sacral (S3) segmental nerve stimulation as a treatment for urge incontinence in patients with detrusor instability: results of chronic electrical stimulation using an implantable neural prosthesis. J Urol. 154: 504-507, 1995.

9. Shaker HS and Hassouna MM: Sacral root neuromodulation in idiopathic nonobstructive chronic urinary retention. J Urol. 159: 1476-1478, 1998.

10. Vapnek J and Schmidt RA: Restoration of voiding in chronic urinary retention using the neuroprosthesis. World J Urol. 9: 142-144, 1991.

11. De Ridder D, Van Cleynenbreugel B and Baert L; Sacral nerve stimulation for female urinary retention: a two year follow-up. Eur Urol. 35: 17, 1999.

12. Swinn M, Goodwin R and Fowler C: Sacral neuromodulation for young women in urinary retention. Eur Urol. 35: 17, 1999.

13. Sicgel SW: Management of voiding dysfunction with an implantable neuroprosthesis. Urol Clin North Am. 19: 163-170, 1992.

14. Thon WF, Baskin LS, Jonas U, Tanagho EA and Schmidt R: Surgical principles of sacral foramen electrode implantation. World J Urol. 9: 133-137, 1991.

15. Das A, Siegel R and Schmidt R: Abdominal versus upper buttock placement of sacral nerve stimulator: 29th Annual Meeting of ICS. Denver, Colorado, USA, August 22 26,1999.

16. Weil E, Ruiz Cerda J, Eerdmans P, Janknegt R and Van Kerrebroeck P: Clinical results of sacral neuromodulation for chronic voiding dysfunction using unilateral sacral foramen electrodes. World J Urol. 16:313-321, 1998,

17. Weil E, Ruiz Cerda J, Eerdmans P, Janknegt R, Bemelmans B and van Kerrebroeck P: Sacral root neuromodulation in the treatment of refractory urinary urge incontinence: a prospective randomized clinical trial. Eur Urol. 37; 161-171,2000.

18. Schmidt R, Jonas U, Oleson K, Janknegt R, Hassouna M, Siegel S and van Kerrebroeck P: Sacral nerve stimulation for treatment of refractory urinary urge incontinence. Sacral Nerve Stimulation Study Group. J Urol. 162: 352-357, 1999.

19. Hassouna MM, Siegel SW, Lycklama à Nyeholt AAB, Elhilali MM, van Kerrebroeck PhEV, Das AK, Gajewski JB, Janknegt RA, Rivas DA, Dijkema HE ef al: Sacral neuromodulation in the treatment of urgency-frequency symptoms: a multicenter study on efficacy and safery. J Urol. 163: 1849-1854, 2000. 


\section{Chapter 9}

Summary, conclusions and future perspectives 


\section{Summary}

This thesis focuses on the treatment of lower urinary tract dysfunctions (urge incontinence, urgency frequency and chronic urinary retention) with sacral neuromodulation. The aim of this thesis is to find ways to improve the results of sacral neuromodulation and to study different strategies to perform it. A study of the identification of predictive factors for sacral neuromodulation is also included. An overview of the anatomy and physiology of the lower urinary tract is provided, and the developments of sacral neuromodulation, its clinical and technical aspects are discussed. This is the way in which the thesis contributes to the improvement of this therapy modality.

Lower urinary tract dysfunctions constitute a significant problem for the patients, and it entails great costs for society. Most patients suffering from urge incontinence and urgency frequency are initially treated conservatively, for example, with physiotherapy and anticholinergic drugs. However, the results are unsatisfactory for more than $60 \%$ of the patients. These refractory patients possibly face more invasive treatment options, such as bladder augmentation or even urinary diversion, with high recurrence rates and a large number of complications. Chronic retention often means life-long self-catheterisation for the patient.

Sacral neuromodulation is being advocated more often as a treatment option for patients refractory to conservative treatments. The patient can be tested in an outpatient setting to determine whether sacral neuromodulation is suitable. Peripheral nerve evaluation (PNE) is used for this purpose. This test consists of an acute phase and a subchronic phase. During the acute phase, a sacral foramen (usually the third) is punctured with a test needle, which is positioned in close proximity to the sacral root. Next, the needle is connected to an external stimulator. Motor responses can be observed during this stimulation. These can consist of a contraction of the pelvic floor musculature and dorsal flexion of the ipsilateral large toe. Sensory reactions can also be obtained. They can consist of tingling sensations in the anal/perineal area. If proper responses are obtained, the test electrode is positioned in proximity to the sacral root via the test needle. The patient can go home with the test electrode connected to an external stimulator. The stimulation is continued for 4 to 7 days, during which the patient carefully keeps a voiding diary. This is called the subchronic phase. Voiding data from the diary include: voiding frequency, voided volume, pad use, urine loss, degree of urgency and residual urine in the bladder. These parameters are compared with the same patient's voiding diary data without neuromodulation. If an improvement of more than $50 \%$ of these parameters is seen, the patient is considered eligible for implantation. During this procedure, the patient is operatively received an implant with the definitive electrode or lead, which is connected to the implantable neurostimulator - the implantable pulse generator (IPG).

This minimally invasive therapy is still a fascinating point for discussion, even after more than 20 years since the first pilot studies, mainly because many questions remain to be answered. Therefore, ongoing research is still improving the implementation and the efficacy of sacral neuromodulation. This thesis intends to answer some of these questions: Are there predictive factors for successful treatment outcome? Is there a correlation between sacral neuromodulation efficacy 
and urodynamic improvement? Is bilateral neuromodulation superior to unilateral? What are the long-term results of the two-stage implantation technique? Is the buttock IPG implantation superior to abdominal placement?

Chapter 1 provides an introduction to this thesis, which contains epidemiological information about lower urinary tract dysfunction, the costs of these dysfunctions for society, and the necessity of ongoing research for treatment modalities for urge incontinence, urgency frequency and chronic urinary retention. This chapter also presents the aim of the thesis.

Chapter 2 discusses the anatomy, physiology, dual function, and normal innervation of the lower urinary tract. An overview of the neurophysiology of the lower urinary tract, innervated via the peripheral and central nervous system pathways, is presented. In addition, the processes of continence and micturition are discussed. Continence mechanisms, bladder inhibition, and the rationale for sacral neuromodulation therapy are presented.

Chapter 3 describes the history of the development of sacral neuromodulation and the possibilities for intervention in bladder function. Sacral neuromodulation uses electrical stimulation applied to the S3 root, which modulates reflex loops that control the bladder. The clinical aspects of sacral neuromodulation, techniques for evaluating the peripheral nerves and for permanent implantation are described in this chapter. The different indications for sacral neuromodulation, such as urge incontinence, urgency frequency, and urinary retention, and the results for each indication are discussed. A treatment algorithm is provided to assist the clinician in taking the next steps in the patient work-up for sacral neuromodulation therapy. An in-depth account of the stimulation parameters is presented in the intermezzo of this chapter. The different stimulation parameters for sacral neuromodulation and their backgrounds are discussed separately. An algorithm for setting the stimulation parameters and troubleshooting is provided.

Chapter 4 gives the results of a study that set out to investigate possible predictive factors for sacral neuromodulation as a treatment for lower urinary tract dysfunctions. Data for 211 patients who underwent a trial stimulation for PNE were analysed. Patient data (demographics, medical history, urologic investigations and diagnosis) were collected. Data noted in a voiding diary during PNE and patient history were evaluated. An improvement of more than $50 \%$ in the voiding parameters and history was considered a positive PNE result. A logistic regression analysis of these data was performed. Factors tested for predicting the test result were gender, age of the patient, diagnosis, previous surgery, neurogenic bladder dysfunction, duration of complaints and previous treatments. Results showed that patients who underwent intervertebral disk prolapse surgery and patients with urge incontinence have a greater chance of a positive PNE. Patients with 
neurogenic bladder dysfunction and patients suffering a relatively long time from lower urinary tract dysfunction have a greater chance of a negative PNE.

Chapter 5 discusses the results of evaluating sacral neuromodulation with ambulant urodynamic investigations (ambulatory cystometry or ACM). Urodynamics provide objective information about the function of the lower urinary tract. Previous research involving patients with bladder overactivity (i.e. urge incontinence and urgency frequency) that uses standard, nonambulatory, urodynamic investigations shows no statistically significant correlation between the efficacy of sacral neuromodulation and the urodynamic data. ACM is presented as more sensitive and reliable in detecting and quantifying bladder overactivity than standard urodynamics. ACM also provides the detrusor activity index (DAI). This index represents a quantification of bladder overactivity, where 0 means no overactivity and 1 means very overactive. The DAI was reduced significantly during neuromodulation from 0.7 to 0.5 . The reduction of the DAI during sacral neurostimulation (SNS) compared to the DAI before SNS correlates significantly $(p=0.03)$ to the clinical effect of SNS.

Chapter 6 presents the results of a study in which unilateral sacral neuromodulation is compared to bilateral sacral neuromodulation in a prospective, randomised, crossover trial. This study was undertaken to determine whether bilateral sacral neuromodulation is superior to unilateral, since it has been proposed as a more effective treatment option. In total, 33 patients were investigated and all underwent a bilateral implantation of a temporary test lead. Unilateral and bilateral test stimulation continued at least 4 days, and it was interrupted by a washout period of 2 days. Radiographs of the sacrum were taken to confirm lead positioning or possible migration after the implantation of the temporary lead and at the end of both (unilateral and bilateral) test stimulation periods. Poststimulation radiographs of the sacrum revealed test lead migration in eight patients. This left analysable data from 25 patients, 12 patients with urge incontinence and 13 patients with nonobstructive urinary retention. A statistically significant improvement in the voiding parameters was seen during the unilateral and bilateral test stimulation period compared with the baseline (i.e. normal symptomatic period). However, no statistically significant improvement was seen between unilateral and bilateral stimulation for the whole group. Two patients with urinary retention only started voiding to completion during bilateral stimulation. Therefore, bilateral sacral neuromodulation is not superior to unilateral, in general. However, bilateral stimulation was more effective in relieving symptoms for some individual patients. Therefore, if a unilateral PNE fails, a bilateral PNE should be considered.

Chapter 7 deals with a different method for screening patients to determine whether they are candidates for sacral neuromodulation therapy. This is called the "two-stage" implantation technique. The two-stage implantation consists of a screening period after operative implantation of the definite lead (not the PNE lead), connected to an external test stimulator as used during the PNE. If sufficient 
improvement of voiding parameters was achieved, implantation of the implantable pulse generator (IPG) followed; the IPG was connected to the lead that was already in place. This implantation technique was performed on 15 parients who were included in this study. They had good motor responses during the acute phase of the peripheral nerve evaluation (PNE), but they showed no, or insufficient, clinical improvement during the following 4 to 7 days of stimulation (subchronic phase). The long-term efficacy and safety results for patients who underwent this two-stage sacral neuromodulation technique were investigated. There was improvement in the main parameters of the voiding diary data and the subjective results. The adverse events noted for these patients are comparable to normal one-stage adverse events data. The long-term results suggest that the two-stage implantation technique offers a better tool for screening patients, probably because the implantation of the lead (first stage) more closely resembles the final therapy. If the two-stage implantation option was not offered to these patients, neuromodulation was not a treatment option at all. This opens up possibilities for a minimally invasive technique for implantation of an electrode that can be connected to an external stimulator. If, for various reasons, a temporary PNE is not optimal (lead migration, longer testing time needed), the two-stage technique can offer a good and safe alternative with comparable efficacy at longterm follow-up.

Chapter 8 evaluates the results of a multicentre study of the buttock placement option for the positioning of the implantable pulse generator (IPG). In the standard operation for sacral neuromodulation, the IPG is implanted in a subcutaneous pocket at the lower part of the anterior,abdominal wall. This procedure requires a long time and three incisions. With the IPG in the abdominal wall, some patients complain of pain at the IPG site postoperatively. With the new technique. the IPG was implanted in a subcutaneous pocket in the lateral superior quadrant of the buttock of 39 patients. The operation time is reduced for all patients by approximately 1 hour. Because no repositioning of the patient is required during surgery, only a short subcutaneous tunnel is required to connect the lead to the IPG, and no extra incision in the flank is necessary to connect the electrode to the IPG. Pain around the IPG was less than the pain when the IPG is in abdominal position. Therefore, the buttock placement of the IPG in sacral neuromodulation is currently the first choice of implantation technique.

\section{Conclusions}

Sacral neuromodulation as described in this thesis is a reliable treatment option for patients with lower urinary tract dysfunctions that are refractory to conservative treatment. With knowledge about predictive factors, it can aid the general urologist in patient selection for sacral neuromodulation. However, this knowledge does not cancel out the necessity of a PNE before implantation. Nonetheless, it can be an aid to patient selection for a two-stage implantation procedure, which has 
proven to be at least as safe and effective as the normal implantation technique. The two-stage implantation technique can also benefit those patients for whom the PNE does not justify definitive implantation of the IPG. Bilateral stimulation of the sacral roots (bilateral sacral neuromodulation) is not superior to unilateral. However, if a unilateral PNE is negative, a bilateral PNE can be considered, especially for the nonobstructive retention patient. The results of sacral neuromodulation can be objectified by voiding diary data and by ambulatory cystometry for patients with overactive bladder symptoms. Buttock placement of the IPG has proven to be superior to standard abdominal placement. Therefore, the buttock is presently the first choice of implantation site.

\section{Future perspectives}

Many questions remain to be answered, not only about the working mechanism of this therapy, but, more importantly, about the pathophysiology and aetiology of lower urinary tract dysfunction. Research that uses functional MRI scanning and PET scanning may provide more knowledge about function and dysfunction of the lower urinary tract. Currently, such research is being donet. The most recent development of sacral neuromodulation therapy is the minimally invasive technique of the implantation of the sacral electrode at the third sacral foramen ${ }^{2}$. It can be expected that this unilateral two-stage implantation technique, performed under local anaesthesia, will be the standard screening method relatively soon. Nevertheless, if a patient is eligible for implantation, the current PNE is also a good tool. It easily tells us if sacral nerves are intact and it is an easy way to ascertain whether a patient is capable of dealing with sacral neuromodulation therapy. A PNE gives a good indication of patient compliance to the therapy. Future research may focus an a number of topics; apart from those already mentioned, parameter setting of the pulse generator, prevention of complications, faecal incontinence, constipation, and expanding indications for the treatment of other forms of lower urinary tract dysfunctions.

\section{References}

1. Blok BE, Groen J, Bosch JL, Veltman DJ and Lammertsma AA: Brain activation and urodynamics during sacral neuromodulation in urge incontinence: a PET study. J Urol. suppl. Abstract book 100th annual meeting of the AUA: abstract 1075, 2002.

2. Spinelli M, Giardiello G, Arduini A and Hombergh U van den: New percutaneous rechnique of sacral nerve stimulation has high initial success rate: preliminary results. Eur Urol. 43: 70-74, 2003. 


\section{Chapter 10}

Samenvatting, conclusies en toekomstverwachtingen 


\section{Samenvatting}

Dit proefschrift beschrijft de sacrale neuromodulatiebehandeling van lage urinewegproblemen, zoals overactieve blaas (aandrangincontinentie, urgency frequency syndroom) en chronische urineretentie. Het doel van dit proefschrift is om verschillende technieken van neuromodulatie te bestuderen en de resultaten te verbeteren. Tevens is een studie verricht naar mogelijke voorspellende factoren voor een succesvolle behandeling. Verder wordt in dit proefschrift een overzicht gegeven van de anatomie en de fysiologie van de lage urinewegen. De ontwikkeling van de therapie en haar klinische en technische aspecten worden ook besproken.

Stoornissen van de lage urinewegen vormen een probleem zowel voor de patiënt als voor de maatschappij, aangezien deze problematiek aanzienlijke kosten met zich mee brengt. Over het algemeen worden patiënten met een overactieve blaas conservatief behandeld door middel van fysiotherapie (zoals bekkenbodemspieroefeningen) en blaasremmende medicatie (zoals anticholinergica). Echter, ongeveer $60 \%$ van de patiënten behaalt hiermee een onbevredigend resultaat. Deze patiënten konden voor de komst van neuromodulatie alleen behandeld worden met invasieve chirurgische ingrepen, zoals een blaasvergrotende operatie of een blaasvervangende operatie. Deze ingrepen brengen een hoge mate van blijvende problemen met zich mee en leiden tot anzienlijke complicaties. Voor patiënten met blaasevacuatiestoornissen is levenslang zelfcatheterisatie vaak noodzakelijk.

Sacrale neuromodulatie wordt steeds vaker voorgesteld als een behandeling indien conservatieve mogelijkheden niet succesvol waren.

Om te verifiëren of een patiënt in aanmerking komt voor sacrale neuromodulatie, kan het effect van de therapie in een poliklinische setting worden uitgeprobeerd. Dit wordt gedaan met behulp van de "peripheral nerve evaluation" (PNE). Deze test bestaat uit twee fases. Een acute fase: hierbij wordt met een naald door het (derde) sacrale foramen geprikt, zodat de punt van de naald in de buurt van de (derde) sacrale wortel is gepositioneerd. Op de naald wordt vervolgens een stimulator aangesloten. Tijdens stimulatie worden motorische responsen waargenomen. Deze kunnen zijn: aanspannen van de bekkenbodem musculatuur en plantaire flexie van de ipsilaterale grote teen. Daarnaast kan een sensorische reactie worden waargenomen, zoals tintelingen in de anale of perineale regio. Indien goede responsen zijn verkregen wordt door de testnaald een elektrode geschoven, welke gedurende 4-7 dagen wordt achtergelaten. Gedurende deze testperiode kan de patiënt naar huis en houdt thuis nauwkeurig een mictiedagboekje bij. Dit wordt de subchronische fase genoemd. Aan de hand van dit mictiedagboekje worden de mictieparameters vastgesteld. Deze zijn: mictie hoeveelheid, mictiefrequentie, het antal gebruikte verbanden, de hoeveelheid urineverlies, de mate van aandrang en de hoeveelheid achtergebleven urine in de blaas. Deze parameters worden vergeleken met parameters van dezelfde patiënt zonder neuromodulatic. Indien een verbetering van meer dan $50 \%$ van deze parameters wordt waargenomen, spreken we van een goed resultaat en komt de patiënt in aanmerking voor definitieve implantatie. De definitieve elektrode (lead) wordt operatief geplaatst, op de zelfde plaats als tijdens de test. Vervolgens wordt de 
elektrode verbonden met een onderhuids gelegen implanteerbarc stimulator (implantable pulse generator, IPG).

Deze weinig invasieve behandelingsmethode is 20 jaar na het verschijnen van de eerste pilotstudies nog steeds een interessant punt van discussie. Dit komt omdat een groot aantal vragen omtrent de therapie vooralsnog onbeantwoord zijn. Om deze vragen te beantwoorden is het uitvoeren van wetenschappelijk onderzoek een voorwaarde. Dit proefschrift is bedoeld om enkele vragen betreffende neuromodulatie te beantwoorden. $\mathrm{Zijn}$ er voorspellende factoren voor een succesvolle test? Is er een correlatie tussen urodynamische effecten en klinische effecten? Is bilaterale neuromodulatie superieur aan unilaterale? Is de tweestappen implantatie techniek een goede methode? Is plaatsing van de IPG in de bil beter dan in de buikwand?

In Hoofdstuk 1 wordt een algemene inleiding gegeven over de epidemiologische gegevens van lage urinewegproblemen en de kosten die deze met zich meebrengen voor de maatschappij. In het tweede deel van Hoofdstuk 1 worden de doelstellingen van dit proefschrift uiteengezet.

In Hoofdstuk 2 worden de anatomie, fysiologie, de dubbele functie van de blaas en de innervatie van de lage urinewegen beschreven. Tevens wordt de neurofysiologie van de blaas besproken. Daarnaast worden de mechanismen uiteengezet die ten grondslag liggen aan continentie, incontinentie en mictie. Dit wordt gevolgd door mogelijkheden van blaasremming en de rationale voor sacrale neuromodulatie.

In Hoofdstuk 3 wordt een overzicht van de ontwikkeling van de sacrale neuromodulatie en de mogelijkheden voor interventie van blaas(dys)functie gegeven. Bij sacrale neuromodulatie wordt met elektrische stimulatie de (derde) sacrale wortel geprikkeld, waardoor de reflexbanen, die de blaas aansturen, worden beïnvloed. De klinische aspecten van sacrale neuromodulatie, de technische uitvoering van de PNE en permanente implantatie van het systeem worden beschreven in dit hoofdstuk. De verschillende indicaties, waarvoor neuromodulatie een therapeutische optie is, en de resultaten worden behandeld. Vervolgens worden twee behandelingsalgoritmen besproken. Het eerste beschrijft welke stappen genomen kunnen worden alvorens een patiënt wordt behandeld met neuromodulatie. Een tweede algoritme beschrijft hoe de neurostimulator postoperatief ingesteld kan worden en bespreekt problemen en mogelijke oplossingen die zich hierbij kunnen voordoen. In het intermezzo wordt uitvocrig ingegaan op de verschillende stimulatieparameters die gehanteerd worden om de sacrale wortel te stimuleren.

In Hoofdstuk 4 worden de resultaten van een studie beschreven met als doel voorspellende factoren voor sacrale neuromodulatie te vinden. Gegevens van 211 patiënten, die allen een PNE hadden ondergaan, werden geanalyseerd. Patiëntengegevens (zowel demografische als medische gegevens en resultaten van urologische onderzoeken en diagnose) werden verzameld. De PNE resultaten 
werden geëvalueerd aan de hand van mictiedagboekjes en anamnestische gegevens. Meer dan $50 \%$ verbetering van de symptomen en mictieparameters werd beschouwd als een positief resultat. Een logistische regressie analyse werd op deze gegevens uitgevoerd. De volgende factoren werden op hun voorspellende waarde getest: geslacht, leeftijd, diagnose, voorgeschiedenis, neurogeen blaaslijden, duur van de klachten en voorgaande behandelingen. De resultaten van de analyse toonden aan dat patiënten, die een operatie voor een hernia van een tussenwervelschijf hebben ondergaan en patiënten met de diagnose urge incontinentie, een hogere kans hebben op een positieve PNE. Patiënten met neurogeen blaaslijden en patiënten die relatief langer problemen hebben, vertonen een hogere kans op een negatieve PNE.

In Hoofdstuk 5 worden de resultaten van de evaluatie van sacrale neuromodulatie door middel ambulante urodynamica (ambulante cystometrie of ACM) bestudeerd. Urodynamisch onderzoek biedt de uroloog objectieve informatie betreffende het functioneren van de lage urinewegen. Bij eerder onderzoek van patiënten met een overactieve blaas (urge incontinentie en urgency frequency), werd geen correlatie gevonden tussen het klinische effect van sacrale neuromodulatie en de urodynamische (niet ambulante) metingen. Ambulante urodynamica wordt beschreven als een meer gevoelige en betrouwbaardere methode in het detecteren en kwantificeren van blaasoveractiviteit, vergeleken met standaard urodynamica. Daarnaast wordt door middel van ACM de detrusor activiteitsindex (DAI) bepaald. Deze index kwantificeert blaasoveractivitiet, waarbij 0 geen overactiviteit en 1 een zeer overactieve blaas betekent. De DAI daalde tijdens neuromodulatie significant van 0.7 naar 0.5 . Tevens werd een significante correlatie $(p=0.03)$ gevonden in de reductie van ACM parameters vooraf en tijdens sacrale neuromodulatie, vergeleken met het klinische resultaat bij deze patiënten.

In Hoofdstuk 6 worden de resultaten weergegeven van een prospectief gerandomiseerde cross-over studie, waarbij unilaterale sacrale neuromodulatie wordt vergeleken met bilaterale sacrale neuromodulatie. Het doel was om te objectiveren of bilaterale neuromodulatie superieur was aan unilaterale neuromodulatie. In totaal zijn 33 patiënten onderzocht. Alle patiënten ondergingen een bilaterale implantatie van een test elektrode (PNE). Hierna ondergingen alle patiënten zowel een unilaterale als een bilaterale testperiode gedurende tenminste 4 dagen, onderbroken door een tweedaagse rustperiode (wash-out). In totaal hadden 25 patiënten de complete stimulatieperiode afgerond. Het betrof 12 patiënten met een overactieve blaas (urge incontinentie en urgency frequency) en 13 patiënten met evacuatiestoornissen van de blaas (chronische niet-obstructieve urineretentie). Beide groepen hadden significant baat van zowel unilaterale stimulatie als bilaterale stimulatie. Echter, er werd geen significant verschil gevonden tussen de unilaterale en bilaterale teststimulatie periode onderling. Daarentegen kwamen 2 patiënten, beide met evacuatiestoornissen, alleen tot mictie gedurende de bilaterale stimulatieperiode. Derhalve is in het algemeen bilaterale sacrale neuromodulatie niet superieur aan unilaterale neuromodulatie. Indien een unilaterale teststimulatie niet succesvol is, kan een bilaterale test worden overwogen. 
In Hoofdstuk 7 wordt een andere methode voorgesteld om te verifiëren of patiënten in aanmerking komen voor sacrale neuromodulatie. Het betreft de "twee stappen" techniek. Bij deze techniek wordt de definitieve lead operatief ingebracht, waarna deze wordt aangesloten op een externe teststimulator die tijdens de PNE wordt gebruikt. Indien tijdens deze testperiode een voldoende verbetering van de mictieparameters werd geconstateerd, kon de implanteerbare neurostimulator (IPG) worden ingebracht. Deze werd aangesloten op de reeds aanwezige lead. Bij deze studie werd de "twee stappen" techniek toegepast bij 15 patiënten. Deze patiënten hadden goede resultaten tijdens de acute fase van een voorafgaande PNE, echter gedurende de subchronische fase werd onvoldoende verbetering gemeten. De lange termijn resultaten aangaande effectiviteit en veiligheid van deze "twee stappen" techniek werden onderzocht. Er werd een verbetering gevonden van vrijwel alle mictieparameters alsmede van de subjectieve resultaten. Complicaties van deze techniek zijn vergelijkbaar met die van de standaard methode. Indien deze patiënten de "twee stappen" techniek niet was aangeboden, was neuromodulatie bij hen geen therapeutische optie geweest. Deze resultaten geven aan dat de "twee stappen" techniek een betere methode is voor het verifiëren of een patiënt in aanmerking komt voor sacrale neuromodulatie. Dit komt waarschijnlijk omdat deze techniek meer lijkt op de uiteindelijke implantatie. Dit biedt de mogelijkheid om de implantatie van de sacrale elektrode via een minimaal invasieve techniek te plaatsen en te verbinden met een externe stimulator. Indien een PNE niet optimaal verloopt, biedt de implantatie in twee stappen een goed en veilig alternatief.

In Hoofdstuk 8 worden de resultaten van een multi-centre studie naar de resultaten van de gluteale implantatie van de IPG besproken. Bij de standaard operatiemethode wordt de IPG geimplanteerd in een subcutane holte in de onderste regionen van de voorste buikwand. $\mathrm{Bij}$ deze methode worden een drietal huidincisies gemaakt. Dit beslaat ongeveer 2,5 uur. Patiënten met de IPG in de buikwand klagen vaak over pijn ter hoogte van de IPG. Door middel van deze nieuwe implantatietechniek werd, onder algehele anesthesie, bij 39 patiënten de IPG in een subcutane holte in het bovenste-buitenste bil kwadrant geimplanteerd. Hierdoor is de operatietijd verkort met ongeveer 1 uur. Redenen hiervoor zijn: er is geen repositie van de patiënt noodszakelijk (van buikligging naar rug- of zijligging), er is slechts een korte subcutane tunnel nodig voor het tunnelen van de elektrode naar de IPG en er is geen extra incisie in de flank noodzakelijk om de lead aan de IPG te koppelen. Pijnklachten ter hoogte van de IPG waren minder aanwezig in vergelijking met de abdominale positie.

\section{Conclusies}

Sacrale neuromodulatie zoals is bestudeerd in dit proefschrift, is een betrouwbare behandelingsmogelijkheid voor patiënten met lage urinewegproblemen, welke met behulp van conservatieve therapie onvoldoende verholpen konden worden. De kennis die is verworven omtrent de voorspellende factoren kan helpen in het 
selecteren van geschikte patiënten voor sacrale neuromodulatie. Desondanks kan de PNE niet vermeden worden als test om te evalueren of een individuele patiënt werkelijk geschikt is. Het kan wel helpen de juiste patiënten te selecteren voor een eventuele implantatie in twee stappen. Deze techniek heeft bewezen minstens even efficiënt te zijn als een standaard implantatie van het neuromodulatie systeem. De implantatie in twee stappen kan ook effectief gebruikt worden bij patiënten die onvoldoende resultaat boeken tijdens de subchronische fase van een PNE. Bilaterale sacrale neuromodulatie is niet superieur aan unilaterale sacrale neuromodulatie. Echter, een individuele patiënt kan baat hebben bij bilaterale neuromodulatie, met name patiënten met evacuatiestoornissen. Indien een unilaterale PNE niet succesvol is, kan een bilaterale test overwogen worden. De resultaten van sacrale neuromodulatie kunnen naast mictiedagboekjes gemeten worden via ambulant urodynamisch onderzoek. Gluteale implantatie van de IPG heeft bewezen superieur te zijn aan abdominale positionering. Daarom heeft plaatsing van de IPG in de bil inmiddels de voorkeur.

\section{Toekomstverwachting}

Rondom sacrale neuromodulatie bestaan nog vele vragen. Met name naar het werkingsmechanisme van sacrale neuromodulatie op het niveau van het centrale zenuwstelsel, maar ook naar de pathofysiologie en aetiologie van lage urinewegproblematiek is nader onderzoek nodig. Onderzoek met behulp van functionele MRI-scanning en PET-scanning zou meer kennis over het (dys)functioneren van de lage urinewegen kunnen opleveren. Momenteel wordt op dat gebied inmiddels onderzoek verricht'. De laatste ontwikkeling op het gebied van sacrale neuromodulatie is de minimaal invasieve techniek. Hierbij wordt een elektrode via een minimale incisie, onder lokale anaesthesie, nabij de sacrale wortel geplaatst ${ }^{2}$. In feite is dit de "twee stappen" techniek (Hoofdstuk 7), waarbij de elektrode unilateraal wordt geplaatst onder lokale verdoving via een veel kleinere incisie. De verwachting is dat op relatief korte termijn deze techniek zich zal ontwikkelen als standaardmethode. Echter de standaard PNE bied een ideale, relatief eenvoudig uit te voeren mogelijkheid om een indruk te krijgen of een patiënt geschikt is voor implantatie. Daarnaast kan met de PNE een indruk worden verkregen of een patiënt met de stimulatie en stimulator kan omgaan. Toekomstig onderzoek aangaande neuromodulatie zal zich met name richten op het aanpassen van de instellingen van de stimulator (IPG), voorkomen van complicaties, verfijnen van de technische materialen en andere indicaties zoals fecale incontinentie, obstipatie en neurogene oorzaken voor het dysfunctioneren van de lage urinewegen. 


\section{Referenties}

1. Blok BF, Groen J, Bosch JL, Veltman DJ and Lammertsma AA: Brain activation and urodynamics during sacral neuromodulation in urge incontinence: a PET study. J Urol. suppl. Abstractbook 100th annual meeting of the AUA: abstract 1075, 2002.

2. Spinelli M, Giardiello G, Arduini A and van den Hombergh U: New percutaneous technique of sacral nerve stimulation has high initial success rate: preliminary results. Eur Urol 43: 70-74, 2003. 
104 


\section{Dankwoord en Curriculum Vitae}




\section{Dankwoord}

Allereerst wil ik u als lezer danken voor het lezen van alle voorgaande hoofdstukken. Op de voorkant, een ruime hoeveelheid bladzijden hiervoor, heeft u één naam op de kaft zien staan, echter dit boekje was er nooit geweest zonder de hulp van vrienden, collega's, bazen en familie. Allen die op een of andere manier hebben bijgedragen wil ik dan ook hartelijk danken. Dit gezegd hebbende zijn er toch personen die ik met name wil bedanken.

Professor van Kerrebroeck, mijn promotor, uw onuitputtelijke kennis en ervaring op het gebied van de neuro-urologie hebben er zeer toe bijgedragen dat het werk zoals het hier ligt tot stand is gekomen. Uw stimulerende en af en toe prikkelende aanpak zorgde ervoor dat de "dipjes", die volgens uw zeggen elke promovendus heeft, van korte duur waren. Dank voor het vertouwen, de begeleiding en de vrijheid.

Rob de Bie, mijn co-promotor. Rob, jij was altijd bereikbaar voor vragen omtrent ...eigenlijk alles. Als het ging om vragen over SPSS, controleren van de statistiek, ik kon altijd op je rekenen. Jouw uitspraak bij het verlaten van je kamer was simpel: "Zet 'm op!", maar toch altijd stimulerend. Ik kon me geen betere steun wensen!

Ernest Weil, vanaf het begin af aan waren we samen bezig met sacrale neuromodulatie. Als een van de eersten in Europa ben je met deze therapie van start gegaan, uiteindelijk heeft dat ook geresulteerd in jouw promotie. Met je enorme klinische kennis rondom de therapie heb je me flink op gang geholpen en kon ik altijd met mijn vragen bij je terecht. Ik ben blij dat middels je steun ook mijn proefschrift nu een feit is.

Erich Taubert en Michiel Dill, mijn paranymfen. Jullie hebben beiden, ieder op zijn geheel eigen wijze zowel collegiaal als amicaal bijgedragen tot het tot stand komen van dit proefschrift. Erich, jij speelde een zeer belangrijke rol in mijn beginfase als onderzoeker. Jouw enthousiasme voor de urologie was steeds een indrukwekkende motivator, en is dit nog steeds. Michiel, voor mij als beginnend student heb jij er voor gezorgd dat er door onze gezamenlijke interesses er zelden verveling was in het Maastrichtse leven. Zonder jou was het nooit zo'n leuke tijd "geworre"!

Enrico Dassen, wij deelden geruime tijd de beperkte 6 vierkante meters in ons van zonlicht onthouden "hok". Toch is er nooit een strijd om lebensraum geweest. Enrico bedankt voor je geweldige collegialiteit. Ik ben blij dat jouw onderzoek binnenkort ook leidt tot promotie!

Andrei Manu-Marin, thank you for your friendship during your stay in Maastricht. Your impressive knowledge of urology and urodynamics helped me to get started with the research. Thanks for your infinite patience, I hope you have fun with your twins in Romania!

De verpleging en de medewerkers van de polikliek en functiekamers Urologie wil ik bedanken voor hun onvoorwaardelijke steun. Het was nooit een probleem 
om patiënten tussendoor te zien of te testen. Dank voor jullie goede zorgen voor de patiënten en voor mij!

Alle dames op het secretariaat urologie wil ik bedanken voor hun continue ondersteuning ook tijdens mijn periode buiten Maastricht.

Medtronic Europe, Medtronic Intersitm en Bakken research, m.n. Ubi van den Homberg en Charles Smith wil ik bedanken voor hun onuitputtelijke voorraad mictiedagboekjes en alle ondersteuning die ik van jullie heb mogen ontvangen.

Alle stafleden en assistenten van de afdeling urologie in Maastricht, alsmede alle assistenten en stafleden van de afdeling chirurgie en urologie in het Catharinaziekenhuis in Eindhoven wil ik bedanken voor de leerzame en gezellige momenten. Het is geweldig hoe jullie me tot nu toe hebben opgeleid!

Beste heren van de Alliantie, vrienden van Loskop en Maastrichter Heeren Dispuut RHINO, ik voel me vereerd jullie eerste promovendus te zijn, maar mede dankzij jullie inspanningen en afleidingen is dit alles mogelijk gemaakt. Ik ben benieuwd wie er volgen!

Beste mannen van de derde kerstdag, jullie stonden aan de wieg van deze wetenschappelijke exercitie. Bedankt voor jullie langdurige steun!

Beste Henk en Greet van den Boom, wat heb ik toch een voorrecht gehad jullie dochter te mogen ontmoeten.

Lieve ma, dankzij jouw onvoorwaardelijke liefde en steun is dit alles mogelijk geworden, ook al heb je dat een groot deel van de tijd alleen moeten doen. Ik ben er trots op jouw zoon te mogen zijn!

Mariëlle, als laatste, ben ik jou toch wel de meeste dank verschuldigd. Bedankt voor je onuitputtelijke steun, liefde, kritiek, aanpassingsvermogen maar met name geduld die nodig waren om het voorafgaande te kunnen voltooien! Als ik er niet meer in geloofde deed jij dat gelukkig wel. 


\section{Curriculum vitae}

De auteur van dit proefschrift, Wout Scheepens, werd geboren op 28 juli 1972 te Eindhoven. In 1992 behaalde hij het VWO diploma aan de Gemeentelijke Scholengemeenschap Woensel te Eindhoven. In dat zelfde jaar startte hij met de studie Geneeskunde aan de Universiteit Maastricht dat werd afgesloten met het behalen van het artsexamen in 1999. Vanaf oktober 1999 tot en met december 2001 is hij werkzaam geweest als arts-onderzoeker op de afdeling urologie in het Academisch Ziekenhuis Maastricht (hoofd: prof. dr. Ph.E.V. van Kerrebroeck), alwaar het werk werd verzet dat aan de basis ligt van dit proefschrift. Vanaf januari 2002 is hij werkzaam in het Catharina-ziekenhuis te Eindhoven op de afdeling Chirurgie (hoofd: dr. J.J. Jakimowicz) in het kader van zijn opleiding tot uroloog. 



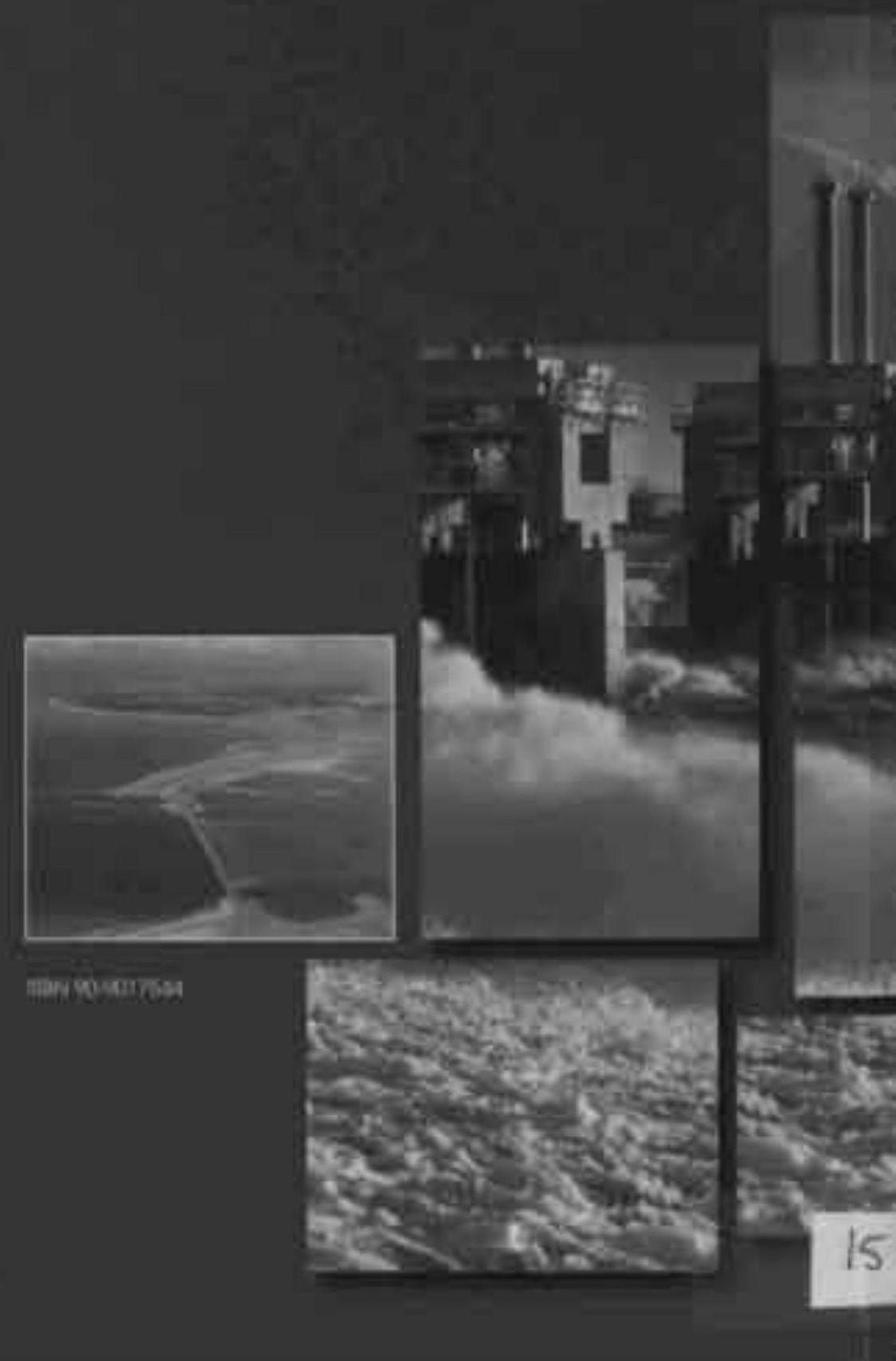

